University of Tennessee Health Science Center

UTHSC Digital Commons

\title{
Why Pharmacists Choose to Seek or Not Seek Board Certification in Pharmacy Practice: A Comparison of Motivation and Motivating Factors
}

Mark Tankersley

University of Tennessee Health Science Center

Follow this and additional works at: https://dc.uthsc.edu/dissertations

Part of the Health and Medical Administration Commons, Other Medicine and Health Sciences Commons, and the Pharmacy Administration, Policy and Regulation Commons

\section{Recommended Citation}

Tankersley, Mark, "Why Pharmacists Choose to Seek or Not Seek Board Certification in Pharmacy Practice: A Comparison of Motivation and Motivating Factors" (2008). Theses and Dissertations (ETD). Paper 258. http://dx.doi.org/10.21007/etd.cghs.2008.0315. 


\title{
Why Pharmacists Choose to Seek or Not Seek Board Certification in Pharmacy Practice: A Comparison of Motivation and Motivating Factors
}

\begin{abstract}
The stated mission of the Board of Pharmaceutical Specialties (BPS) with regard to specialization is, via board certification, to recognize specialty areas, define skill standards for those specialty areas, and evaluate the knowledge and skills of individual Pharmacy specialists. The perceived or real benefits to the pharmacist of pursuing board certification are unknown. These benefits can be evaluated by separating into values (valences) and instrumentalities, the latter of which is the perceived or known probability that a performance will lead to an outcome. The primary purpose of this study was to determine the differences in values and instrumentalities perceived by the pharmacist, and differing calculated forces of motivation, using an Expectancy Valence equation, between board certified pharmacists and those who were not.
\end{abstract}

A survey instrument, the Advanced Certification Index for Pharmacists (ACI-P), was designed to test instrumentalities, values, and calculated force of motivation. The ACI-P was deployed via electronic mail and the internet in cooperation with four major Pharmacy organizations and the Board of Pharmaceutical Specialties. Four direct comparisons between the two groups were completed. These were instrumentality, valence, valence-minus-instrumentality and valence-times-instrumentality. Additionally, the components of the valence and instrumentality products (the VI Scores) were multiplied by expectancy (anticipated chance of success of an effort leading to successful performance) resulting in a force of motivation calculation for each pharmacist's score.

The ACl-P was deployed in the summer of 2007. Of the 2,274 pharmacists who began the survey, 2,129 completed all of the survey question sets for a completion percentage of $93.7 \%$. A total of 2,057 of 2,129 completed surveys were retained for the research data representing a clean data rate of $96.6 \%$ of those completing all questions and $90.5 \%$ of those initiating the survey. This data set was comprised of 496 (24.1\%) non-board certified pharmacists and 1,561 (75.9\%) board certified pharmacists.

Validation and reliability of the ACI-P was confirmed via parallel axis analysis and Cronbach's alpha reliability coefficient. There were two factors or domains found in the data and these were Professional, Career and Personal (PCP) and Financial Support (FS). Cronbach's alpha for the PCP factor or domain was 0.94 and the FS domain had an alpha of 0.81 . The constructs were validated and the items addressed within the constructs of PCP and FS were reliable. The overall Cronbach's alpha reliability coefficient for the ACI-P was 0.94 .

In the four major comparisons, there were significant differences between non-board certified and board certified pharmacists.

The primary value used for the motivational force calculation was based on valence-timesinstrumentality-times-expectancy. The valence-times-instrumentality value was the VI score or VIS. The summed VI scores for the non-board certified pharmacists were in general lower (303.54; SD 101) than those for the board certified pharmacists (343.82; SD 83), and these were statistically different ( $t=-8.03$, $p<.0001)$.

The overall expectancy mean for non-board certified pharmacists was 4.05 and 4.4 for board certified pharmacists (5-point Likert scale), and these were significantly different $(t=-9.16, p<.0001)$.

The overall motivational force calculated using the ACI-P scoring methodology yielded a force of motivation to seek board certification of 1249 (95\% Cl 1201-1296) for non-board certified pharmacists and $1521(95 \% \mathrm{Cl} 1499-1544)$ for board certified pharmacists. The differences were statistically 
significant. $(\mathrm{t}=10.15, p=<0.001)$. A tipping point in the range of $1500-1520$ was identified that would indicate a $95 \%$ probability that a pharmacist scoring in this range would be a board certified pharmacist.

The results of this study show that there were significant differences in motivational factors between nonboard certified pharmacists and those that were board certified with the latter scoring higher on nearly every measure. The ACI-P survey instrument was shown to be a valid and reliable tool for evaluation of the force of motivation for pharmacists to seek board certification.

\section{Document Type}

Dissertation

\section{Degree Name}

Doctor of Philosophy (PhD)

\section{Program}

Health Science Administration

\section{Research Advisor}

Peter Chyka, Pharm. D.

\section{Keywords}

ACI-P, Advanced Certification Index, BPS, Board Certification, Board of Pharmaceutical Specialties, Expectancy, Motivation, Motivational theory, Pharmacists, Specialists, VIE

\section{Subject Categories}

Health and Medical Administration | Medicine and Health Sciences | Other Medicine and Health Sciences | Pharmacy Administration, Policy and Regulation 


\title{
WHY PHARMACISTS CHOOSE TO SEEK OR NOT SEEK BOARD CERTIFICATION IN PHARMACY PRACTICE: A COMPARISON OF MOTIVATION AND MOTIVATING FACTORS
}

\author{
A Dissertation \\ Presented for \\ The Graduate Studies Council \\ The University of Tennessee \\ Health Science Center
}

\author{
In Partial Fulfillment \\ Of the Requirements for the Degree \\ Doctor of Philosophy \\ From The University of Tennessee
}

By

Mark A. Tankersley

May 2008 
Copyright $(\subset$ Mark Alan Tankersley, 2008 All rights reserved 


\section{Dedication}

This dissertation is dedicated to my wife Debbie who has graced me with

companionship, love, and support for 33 years. I also dedicate this work to my daughter Jessica, my son Alan and my mother-in-law Margaret Crumley.

Their support and assistance offered along this journey have been incredible and have made this effort tolerable and worthwhile. 


\section{Acknowledgements}

I would like to thank my major professor, Dr. David Solomon, for his support, guidance and belief in this project. I would also like to thank my committee members, Dr. Dick Gourley, Dr. Cheryl Stegbauer, Dr. Peter Chyka and Dr. Vivian Loveless for their support, comments, time and assistance.

Two consultants to this project were of immense value. They were Dr. Raoul Arreola and Dr. Richard Bertin. Dr. Arreola lent considerable expertise in survey design concepts and Dr. Richard Bertin, Executive Director of the Board of Pharmaceutical Specialties, offered insight, direction and access to information.

I would also like to thank my earlier major professor, Dr. Pamala Reed, for her guidance during the development of this project.

Further, I would like to thank the Pharmaceutical Journal, the official publication of the Royal Pharmaceutical Society of Great Britain (RPSGB), for their permission to reproduce Figure 1-1.

I would also like to thank the American Pharmaceutical Association, American Society of Health-System Pharmacists, American College of Clinical Pharmacy, American Association of Colleges of Pharmacy, and the Board of Pharmaceutical Specialties for their participation, cooperation and assistance with deployment of the survey instrument employed for this research.

I would like to thank Samantha Norton for her assistance as a lay reviewer of the manuscript to assure general understandability of the narrative and concepts. 


\begin{abstract}
The stated mission of the Board of Pharmaceutical Specialties (BPS) with regard to specialization is, via board certification, to recognize specialty areas, define skill standards for those specialty areas, and evaluate the knowledge and skills of individual Pharmacy specialists. The perceived or real benefits to the pharmacist of pursuing board certification are unknown. These benefits can be evaluated by separating into values (valences) and instrumentalities, the latter of which is the perceived or known probability that a performance will lead to an outcome. The primary purpose of this study was to determine the differences in values and instrumentalities perceived by the pharmacist, and differing calculated forces of motivation, using an Expectancy Valence equation, between board certified pharmacists and those who were not.

A survey instrument, the Advanced Certification Index for Pharmacists (ACI-P), was designed to test instrumentalities, values, and calculated force of motivation. The ACI-P was deployed via electronic mail and the internet in cooperation with four major Pharmacy organizations and the Board of Pharmaceutical Specialties. Four direct comparisons between the two groups were completed. These were instrumentality, valence, valence-minus-instrumentality and valence-times-instrumentality. Additionally, the components of the valence and instrumentality products (the VI Scores) were multiplied by expectancy (anticipated chance of success of an effort leading to successful performance) resulting in a force of motivation calculation for each pharmacist's score.

The ACI-P was deployed in the summer of 2007. Of the 2,274 pharmacists who began the survey, 2,129 completed all of the survey question sets for a completion
\end{abstract}


percentage of $93.7 \%$. A total of 2,057 of 2,129 completed surveys were retained for the research data representing a clean data rate of $96.6 \%$ of those completing all questions and $90.5 \%$ of those initiating the survey. This data set was comprised of $496(24.1 \%)$ non-board certified pharmacists and 1,561 (75.9\%) board certified pharmacists.

Validation and reliability of the ACI-P was confirmed via parallel axis analysis and Cronbach's alpha reliability coefficient. There were two factors or domains found in the data and these were Professional, Career and Personal (PCP) and Financial Support (FS). Cronbach's alpha for the PCP factor or domain was 0.94 and the FS domain had an alpha of 0.81 . The constructs were validated and the items addressed within the constructs of PCP and FS were reliable. The overall Cronbach's alpha reliability coefficient for the ACI-P was 0.94 .

In the four major comparisons, there were significant differences between nonboard certified and board certified pharmacists.

The primary value used for the motivational force calculation was based on valence-times-instrumentality-times-expectancy. The valence-times-instrumentality value was the VI score or VIS. The summed VI scores for the non-board certified pharmacists were in general lower (303.54; SD 101) than those for the board certified pharmacists (343.82; SD 83), and these were statistically different $(\mathrm{t}=-8.03, p<.0001)$.

The overall expectancy mean for non-board certified pharmacists was 4.05 and 4.4 for board certified pharmacists (5-point Likert scale), and these were significantly different $(\mathrm{t}=-9.16, p<.0001)$.

The overall motivational force calculated using the ACI-P scoring methodology yielded a force of motivation to seek board certification of 1249 (95\% CI 1201-1296) for 
non-board certified pharmacists and 1521 (95\% CI 1499-1544) for board certified pharmacists. The differences were statistically significant. $(\mathrm{t}=10.15, p=<0.001) . \mathrm{A}$ tipping point in the range of $1500-1520$ was identified that would indicate a $95 \%$ probability that a pharmacist scoring in this range would be a board certified pharmacist. The results of this study show that there were significant differences in motivational factors between non-board certified pharmacists and those that were board certified with the latter scoring higher on nearly every measure. The ACI-P survey instrument was shown to be a valid and reliable tool for evaluation of the force of motivation for pharmacists to seek board certification. 


\section{Table of Contents}

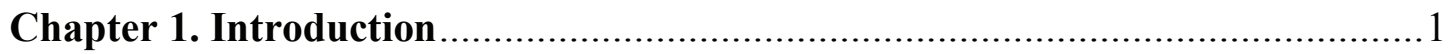

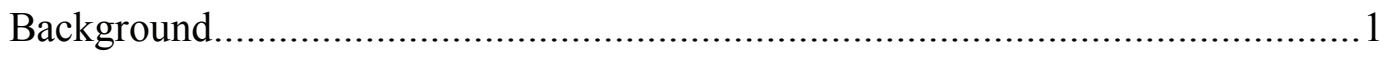

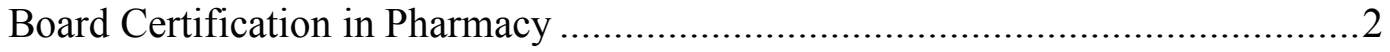

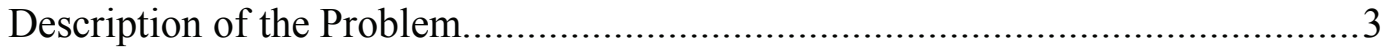

Survey Instrument Conceptual Framework.................................................... 4

Research Questions .............................................................................. 8

Purpose of the Study ........................................................................ 9

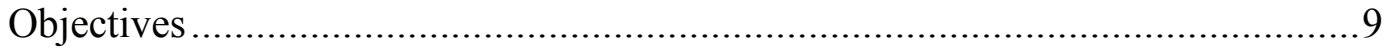

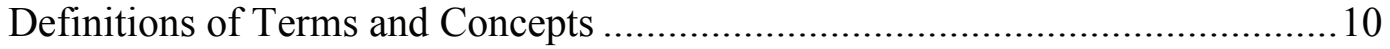

Relevance to Pharmacy, Health Outcomes and Policy Research ...................... 15

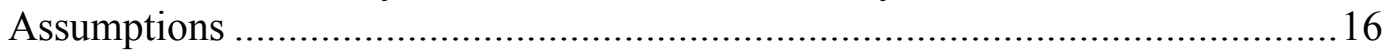

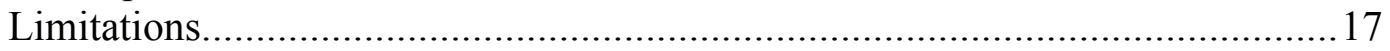

Organization of the Dissertation ......................................................... 18

Chapter 2. Literature Review................................................................... 19

History of Pharmacy Specialization........................................................ 19

Specialty Recognition and Credentialing in Pharmacy.................................. 21

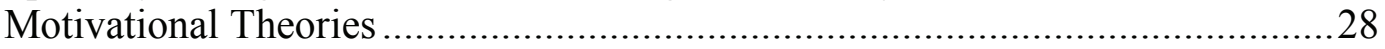

Content Theories - Maslow's Hierarchy of Needs ...................................29

Content Theories - ERG (Existence, Relatedness, Growth) Theory ..............31

Content Theories - Acquired Needs Theory ........................................ 31

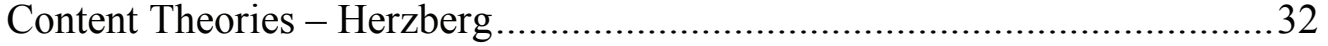

Process Theories - Equity Theory ........................................................ 34

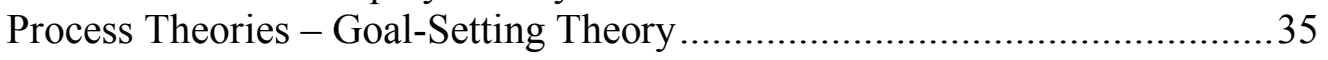

Process Theories - Expectancy Theory ............................................... 35

Process Theories - Reinforcement Theories/Operant Conditioning...............35

Expectancy Theory as a Basis for Survey Design ......................................... 37

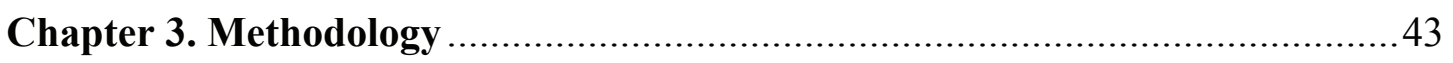

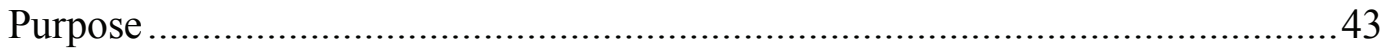

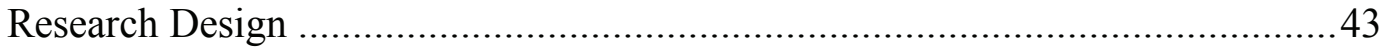

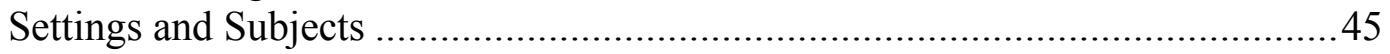

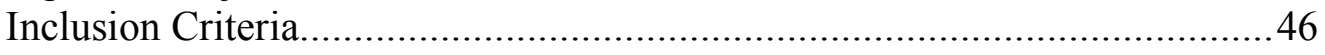

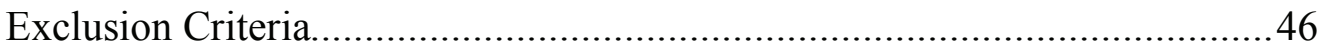

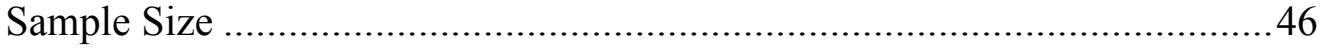

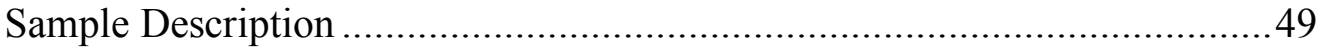

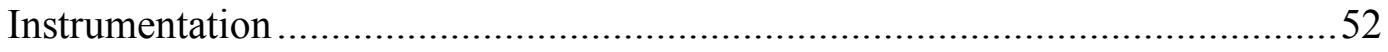

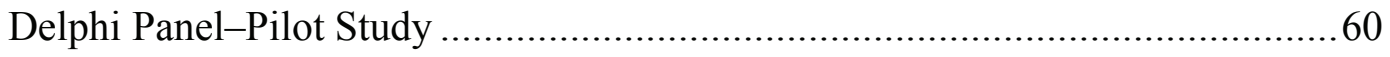

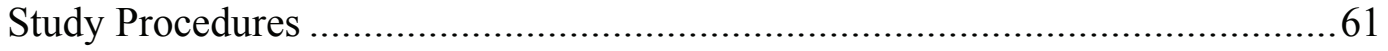

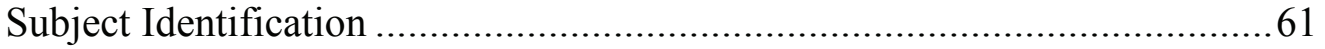

viii 


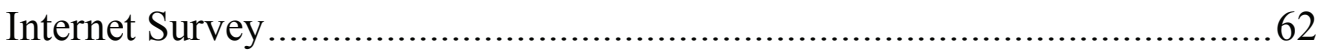

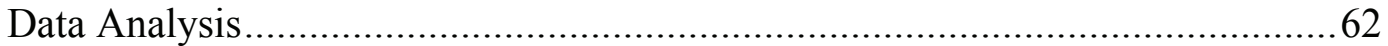

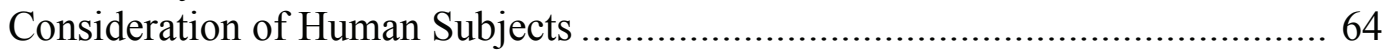

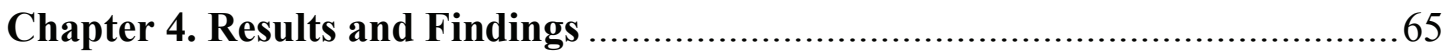

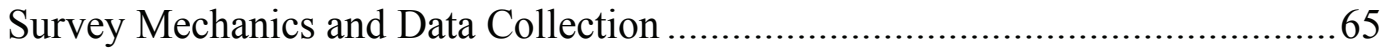

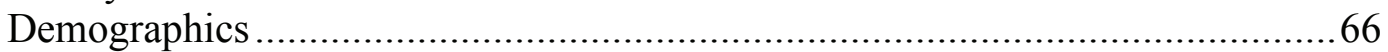

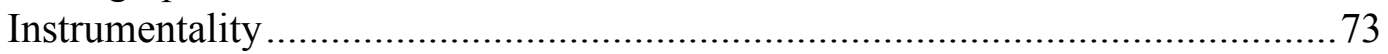

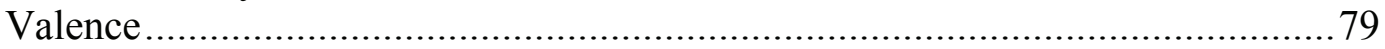

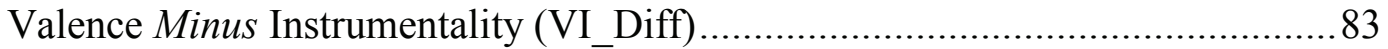

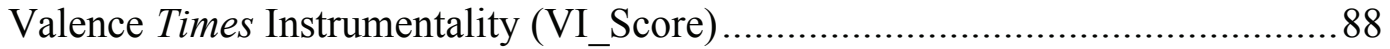

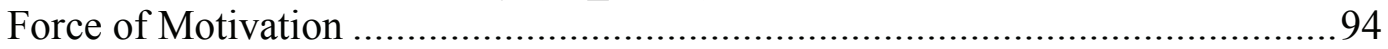

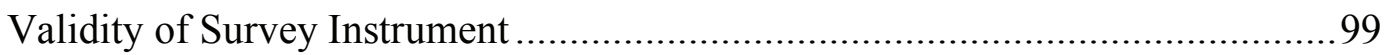

Reliability of Survey Instrument..................................................................... 105

Comparison of 2004 BPS Survey Findings and 2007 ACI-P Findings ............... 109

Comparison of Additional Comments from 2007 ACI-P Survey ........................112

Chapter 5. Study Discussion and Conclusions ................................................118

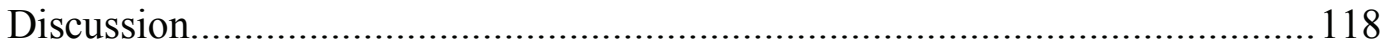

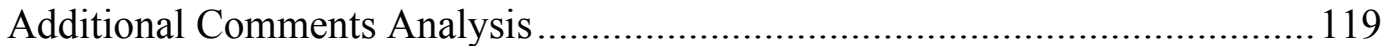

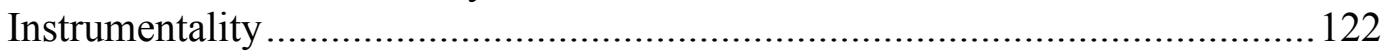

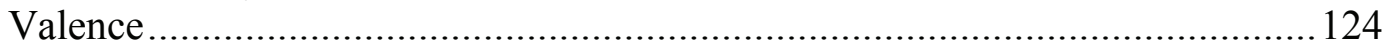

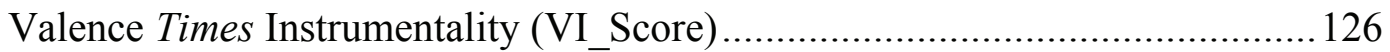

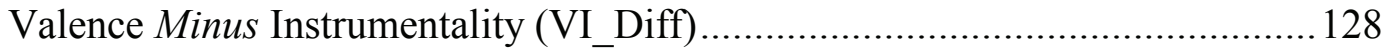

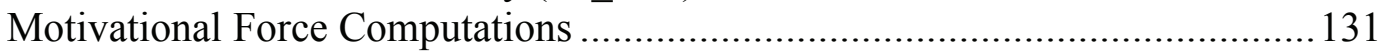

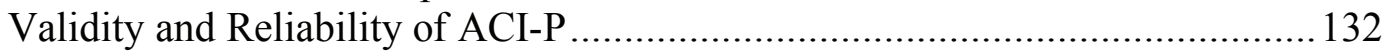

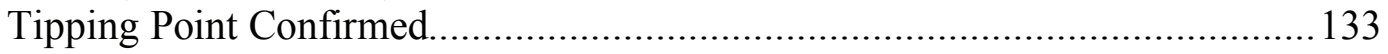

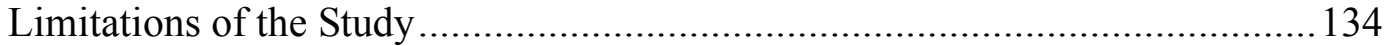

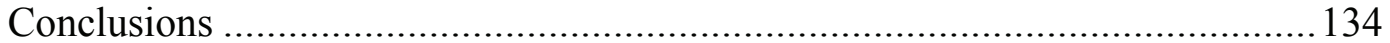

Recommendations for the Future of Board Certification in Pharmacy.......... 135

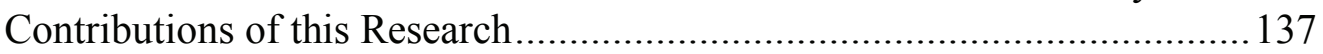

Recommendations for Future Research ....................................................139

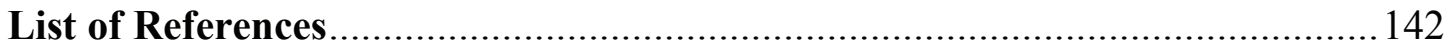

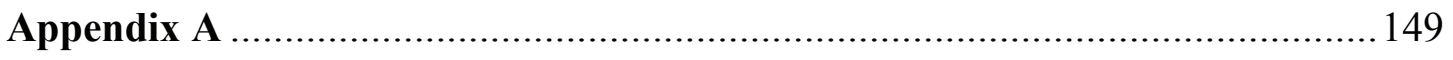

Advanced Certification Index for Pharmacists (ACI-P) ................................... 150

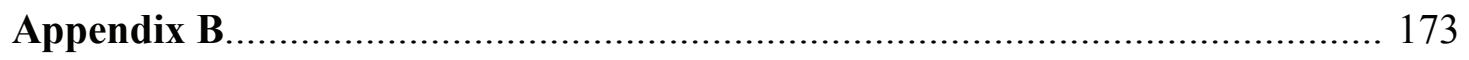

Letters to Pharmacy Organizations Seeking Assistance and Cooperation and Communications of Agreement to Participate 
Appendix C

Permission to Reprint Figure 1-1 from the Pharmaceutical Journal.................. 188

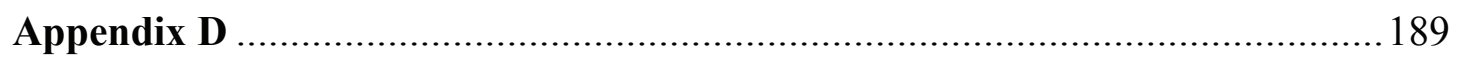

University of Tennessee IRB Approval (Exemption)............................... 190

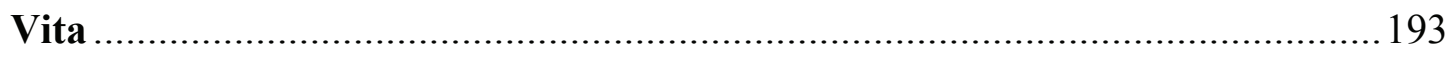




\section{List of Tables}

Table 2-1. Tangible and Intangible Benefits that BPS Certification May Bring to the Pharmacist as Reported in BPS Online Survey Results 2004

Table 3-1. $\quad$ Sample Size Projections Based on Cohen's $d$ Estimates, Effect Size is an Estimate of Discernible Effect 48

Table 3-2. Proposed Domains of ACI-P, Questions within Domains and Percentages of Total

Table 4-1. Distribution of Pharmacist Respondents to 2007 ACI-P Survey

Table 4-2. Distribution of Retained Pharmacist Respondents from 2007

ACI-P Survey

Table 4-3. Demographics of Respondent Sample in Retained Survey

Dataset from 2007 ACI-P $(N=1924$ for Age + Gender $[\mathrm{A}+\mathrm{G}])$

Table 4-4. Respondent Groups by Age, Certification Status and Gender

$(N=1,924$ for Age + Gender $[\mathrm{A}+\mathrm{G}])$.

Table 4-5. Differences in Instrumentalities, $(S D)$, between Board Certified (BCP) and Non-Board Certified Pharmacists (NONBCP)

Table 4-6. Differences in Valences, $(S D)$, between Board Certified (BCP) and Non-Board Certified Pharmacists (NONBCP).

Table 4-7. Differences in Valences Minus Instrumentality Scores (V_Diff), $(S D)$, between Board Certified (BCP) and Non-Board Certified Pharmacists (NONBCP).

Table 4-8. Differences in Valences Times Instrumentality Scores

(VI_Score), $(S D)$, between Board Certified (BCP) and Non-Board Certified Pharmacists (NONBCP)

Table 4-9. Differences in Expectancy, Sums of VIS and Motivational Force as Calculated by ACI-P, $(S D)$, between Board Certified (BCP) and Non-Board Certified Pharmacists (NONBCP).

Table 4-10. Differences in VIS for a priori Proposed Domains, $(S D)$, between Board Certified (BCP) and Non-Board Certified Pharmacists (NONBCP) 
Table 4-11. Two Factor Solution from Factor Analysis and Parallel Axis, Analysis from ACI-P Survey Findings

Table 4-12. PCP and FS Comparisons Derived with Parallel Axis Analysis from ACI-P Survey Findings, VI Scores (VIS) for Two Factor Solution (Sum of $\mathrm{V} *$ I per Domain) 106

Table 4-13. Reliability Calculated with Cronbach's Alpha for ACI-P Survey Instrument.

Table 4-14. Items and Responses from Board Certified Pharmacists from 2007 ACI-P Survey Reported and Matched to Categories from 2004 BPS Survey $(N=1561)$.

Table 4-15. Tangible and Intangible Benefits that BPS Certification May Bring to the Pharmacist as Reported in BPS Online Survey Results 2004 (Redisplay of Table 1-1)

Table 4-16. Comparison of Relative Sequence of Findings from 2004 BPS Survey and 2007 ACI-P Survey, Highest to Lowest Based on the 2004 BPS Survey....

Table 4-17. Comparison of Non-Board Certified (NONBCP) and Board Certified Pharmacists (BCP) Findings from Additional Comments and Questions (Responses $=620$, Respondents $=324$ )

Table 4-18. General Findings from Additional Comments; Responses Greater than 27 per Item in either NONBCP or BCP group $(N=591)$

Table 4-19. General Findings from Additional Comments: Responses Greater than 27 in NONBCP and BCP groups $(N=353)$

Table 5-1. Summarized Findings from Additional Comments with Combined Groups $(N=461)$ 


\section{List of Figures}

Figure 1-1. Expectancy Theoretical Model Demonstrated as a Model of Motivation (Reproduced with Permission of the Pharmaceutical Journal).

Figure 1-2. Conceptual Framework of Practitioner Valence, Instrumentality and Expectancy Perceptions of Board Certification (Original Work adapted from Theoretical VIE Model of Motivation)................7

Figure 4-1. VIS Score Relative Values for Non-Board Certified and Board Certified Pharmacists from 2007 ACI-P Survey. .95 


\section{Chapter 1. Introduction}

\section{Background}

Drug therapy is an integral component of the modern health care delivery system accounting for $10 \%$ of health care spending and $16 \%$ of incremental spending. ${ }^{1}$ Market introduction of drugs and the rate of drug approval has doubled in the last three decades while expenditures for research and development have increased more than twelve times. ${ }^{2}$ These new drugs and new drug delivery systems offer options for the treatment of conditions that were deemed untreatable just a few years ago. In addition to an increasing number of drugs, the types of drugs have increased in complexity. Currently there are more than 400 biotechnology medicines in the drug pipeline. "These include 210 medicines for cancer, 50 for infectious disease, 44 for autoimmune diseases and 22 for AID/HIV and related conditions". 3 Newer genetically engineered and biotechnology drugs have set the stage for a paradigm shift in healthcare, particularly in the practice of Pharmacy. New practice models and practitioner competencies are required to assure that the needs of the public and health care system are met. Specialization in healthcare has become more of a need as these rapid advancements in drug therapy and technology have created an environment requiring extensive knowledge of the many facets of healthcare and how drug therapy can best be incorporated to provide optimal patient care. ${ }^{2,4-6}$ Specialization is an evolution within a profession to accommodate new knowledge, techniques and/or technology into the improvement of health care. "Specialization in the healing arts is unique because it places the needs of the person receiving care at 
the center of concern." 5,7 Accommodating these changes calls for specialization and specialized practitioners in Pharmacy. Does a pharmacist stand to gain from achieving specialization? Why do qualified pharmacists seek specialty board certification? Why do qualified pharmacists not seek board certification? Is specialization attainable without formal recognition of an "approval body"? The purpose of this research was to examine and compare pharmacist groups seeking or not seeking board certification.

\section{Board Certification in Pharmacy}

Becoming board certified in Pharmacy is a rigorous and involved process. ${ }^{8,9}$ It is also voluntary and may not lead to a tangible reward. In the practice of Medicine, and in some other health care disciplines, board certification may not be required but is highly desired for practice. It is required for advanced practice licensure in most states for nursing. Reimbursement and/or accreditation processes may also be tied to the number of board certified practitioners, especially physicians, in a practice or area. ${ }^{9} \quad$ Although not required, there are a number of factors which motivate pharmacists to pursue board certification, as well as a perceived value of those motivating factors. It is reasonable to expect that the number of pharmacists seeking board certification is related to these factors and their perceived values. Studies assessing expectations and related perceived values of a pharmacist pursuing board certification were not found in the literature. 


\section{Description of the Problem}

There are potential benefits to employers, and other health care providers, of pharmacist specialization. It has also been postulated, and is indeed the point of board certification, that such pursuit and accomplishment produces a better provider of care. However, in the medical profession, this has yet to be definitively proven. ${ }^{9}$

The practice setting may affect the perceived or actual benefits to a pharmacist. In areas where financial reward is greater, that particular benefit may take prominence. In practice areas that have a preference for specialty certification, work related benefits may move to the forefront.

Board Certification in any Pharmacy practice area has specifics that make it unique, hence the specialization designation. Contributing factors may be a perceived difference due to the fact that the pharmacist's practice area is quite different from standard clinical practice and they seek some level of differentiation. There may also be more reward or benefit within a particular specialty than the others. The tangibility of these rewards may be questionable as there are a number of former board certified pharmacists that have elected to not maintain their certification. To evaluate the issues of possible benefits or rewards specific to being a board certified pharmacist, a conceptual model and survey instrument based on Expectancy theory was developed. Principal to this model and instrument design were the values (valence), probability of performance leading to the outcome (instrumentality) and the attributed expectation (expectancy).

Four domains of valence and instrumentality were proposed. They were:

1. Personal 
2. Financial

3. Career

4. Professional

The purpose of the use of this theory was to fashion a survey instrument based on its components and not to prove the validity of the theory or its application to this research. Some discussion focuses on potential uses and applications of the instrument derived from this study.

\section{Survey Instrument Conceptual Framework}

Valence-instrumentality-expectancy (VIE) theory is a major theory of motivation and work behavior. It may also be called Expectancy theory, ExpectancyValence (EV), instrumentality theory, and path-goal theory. The three major variables are expectancy, instrumentality and valence (value). ${ }^{10-12}$ For the purpose of this study, VIE is an explanatory acronym that is used as a synonym for Expectancy theory and these two terms or names may be considered interchangeable. It is a process theory in that it seeks to identify the relationship between the variables in a dynamic state as they affect individual behavior. Vroom, the initiator and synthesizer of Expectancy/VIE theory, postulated that one's perception of a link between effort and reward, plus values attributed to aspects of the task or rewards at hand, lead to motivation at work. In this theory, the relationships between the inputs are more the focal point than the inputs themselves. ${ }^{12}$

Figure 1-1 is a graphical depiction of Expectancy theory listed as the components of VIE Theory. ${ }^{10}$ In this figure, expectancy is a perceived probability 


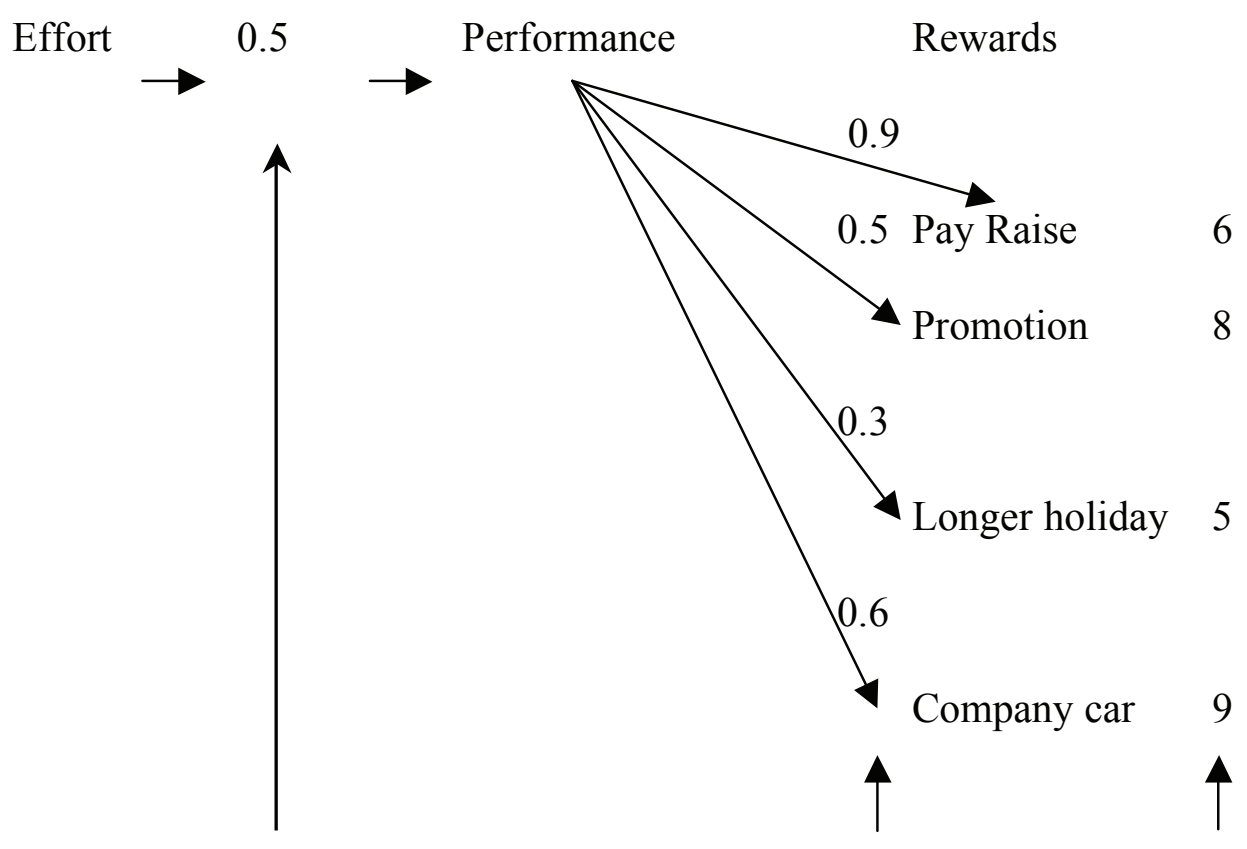

Expectancy Instrumentalities $\quad$ Valences

Figure 1-1. Expectancy Theoretical Model Demonstrated as a Model of Motivation (Reproduced with Permission of the Pharmaceutical Journal) ${ }^{10}$ 
that an effort will lead to a successful performance. In this example the individual in question believes that there is a $50 \%$ chance that a particular effort will lead to a successful performance therefore the expectancy is listed as the decimal equivalent or 0.5 .

Instrumentalities, also called "cognized instrumentalities" are perceived probabilities that performance will lead to a particular reward. These also are presented as the decimal equivalent of the probability so $90 \%$ performance-to-reward expectation (instrumentality) is presented as 0.9 . In this example, $90 \%$ perceived probability that a particular performance will lead to a pay raise is 0.9 . Valences are the level of value to the individual. Valences are independent of 1) Effort to Performance $(E \rightarrow P)$ and 2) Performance to reward (referred to in VIE theory as Outcomes) expectancies $(P \rightarrow O)$. These are generally listed on a 5 or 10 point scale in whole numbers since they are values not probabilities. (Reproduced with permission of the Pharmaceutical Journal). ${ }^{10}$ These mathematical associations are covered in more detail in Chapter 2.

A conceptual framework examining the design considerations for the survey instrument is listed in Fig. 1-2. The conceptual framework presented demonstrates one way of relating these different potential areas of influence. The purpose of this research was not to validate these suggested domains but to evaluate the components that fall within each as designed within the survey instrument. There were questions framed and designed to fit within the four domains of career, professional, personal and financial. 


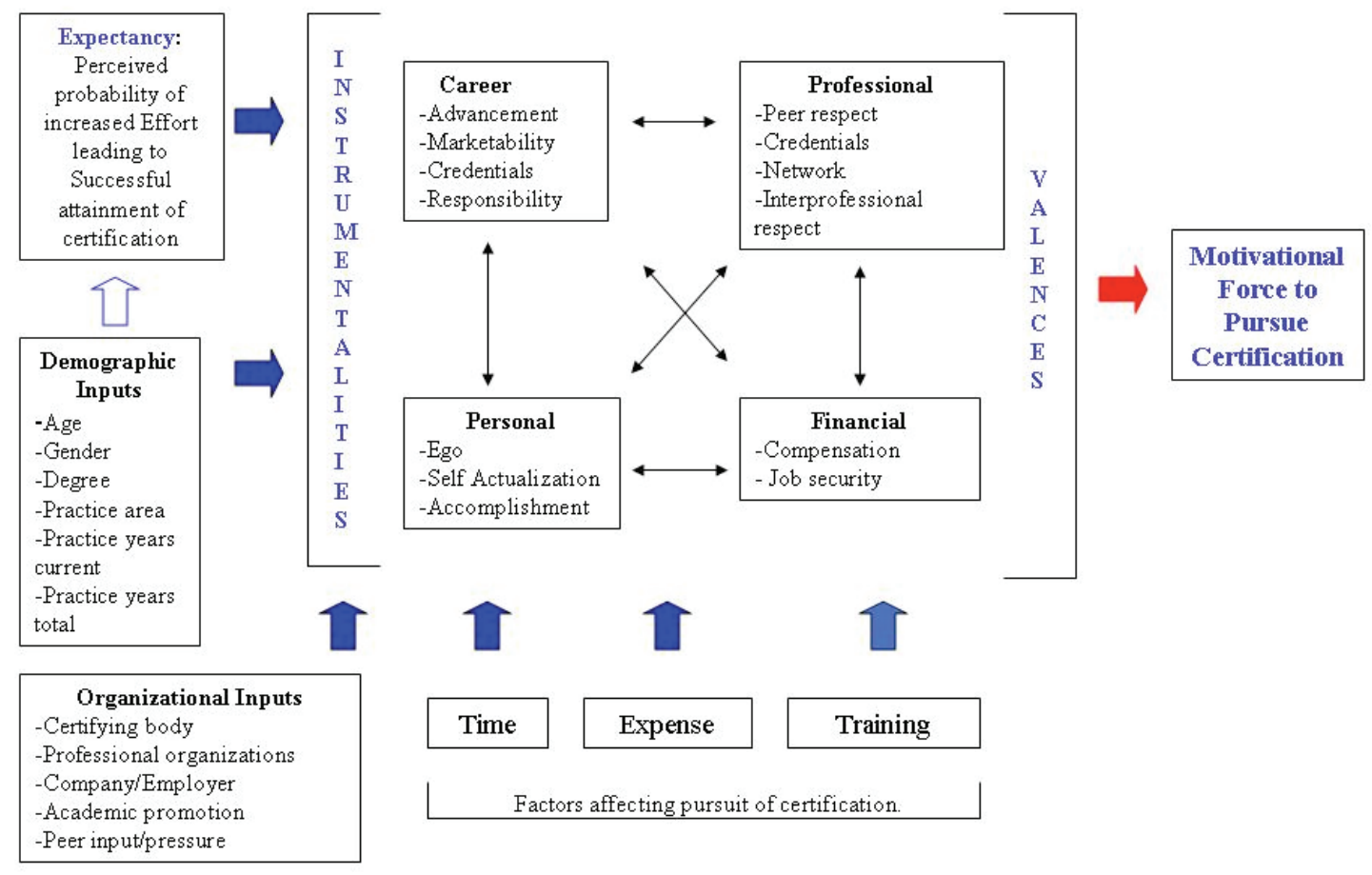

Figure 1-2. Conceptual Framework of Practitioner Valence, Instrumentality and Expectancy Perceptions of Board Certification (Original work adapted from theoretical VIE Model of Motivation) 


\section{$\underline{\text { Research Questions }}$}

The principal question asked in this research was; what are the differences in instrumentalities, values placed on those outcomes and force of motivation between board certified pharmacists and those that are not board certified? Instrumentalities are perceived probabilities that performance will lead to particular benefits, rewards or outcomes.

The following specific questions, based on the perception of the pharmacist, were addressed:

1. What were the differences in instrumentalities (probabilities) between board certified and non-board certified pharmacists?

2. What were the differences in valences (values) between board certified and non-board certified pharmacists?

3. What were the differences in the product of instrumentalities and valences between board certified and non-board certified pharmacists?

4. What were the differences between the value-minus-instrumentality calculation between board certified and non-board certified pharmacists?

5. What were the differences in calculated force of motivation, as defined by the Expectancy Value (VIE) model, between board certified and nonboard certified pharmacists?

6. Was there a tipping point where a certain combination of factors would indicate a pharmacist would be board certified, i.e. would a certain calculated overall force of motivation be definitely different in board certified pharmacists than in those that were not board certified? 
7. Were there certain instrumentalities, valences or combinations of instrumentalities and valences, as well as expectations, as defined by the Expectancy Value (VIE) model, that were the most valued by pharmacists that are board certified?

\section{Purpose of the Study}

The primary purpose of this study was to compare the values, instrumentalities, expectations, and calculated force of motivation between pharmacists that choose to seek or not seek board certification in a Pharmacy specialty.

\section{Objectives}

The objectives of this study were to:

1. Create a survey instrument and utilize to determine the differences in motivating factors (forces) between board certified and non-board certified pharmacists.

2. Determine the overall scores of those factors or forces.

3. Evaluate the relationships among and between the factors or forces.

4. Compare motivating factors between board certified pharmacists and those that were not board certified in specialty Pharmacy practice.

5. Compare calculated motivational force between board certified pharmacists and those that were not board certified in specialty Pharmacy practice. 


\section{Definitions of Terms and Concepts}

- Expectancy: Expectancy refers to the expectation, or anticipated chance of success of an effort leading to successful performance. In this case that would be exertion of effort leading to achievement of the designation of board certification in a specialty by BPS. ${ }^{10-12}$

- Valence: Valence refers to the perceived value that correlates to the instrumentality of the particular outcome. This may also be interpreted as value to the individual..$^{10-12}$

- Instrumentality: Instrumentality is a perceived or known probability that a performance will lead to an outcome. It is also called a performance-tooutcome expectancy $(P \rightarrow O)$. This may also be called cognized instrumentality. ${ }^{10-12}$

- VIE (Valence-Instrumentality-Expectancy) Theory: VIE, also called expectancy theory, it is a major theory of motivation and work behavior. It is a process theory in that it seeks to identify the relationship between the variables in a dynamic state as they affect individual behavior. Other synonyms include instrumentality theory and path-goal theory. ${ }^{10-12}$

- Expectancy Theory: Also called VIE theory, it is a major theory of motivation and work behavior. It is a process theory in that it seeks to identify the relationship between the variables in a dynamic state as they affect individual behavior. Other synonyms are instrumentality theory and path-goal theory. ${ }^{10-12}$ 
- Demographic Variances and Inputs: Pharmacists may be influenced by demographic inputs and these may be categorized. Some of these characteristic demographic categories may or may not have a bearing on the outcome of the study. Categories of characteristics, or demographic variances (inputs), captured during the survey process in this study were:

1. Current professional Pharmacy organizations memberships

2. Age

3. Gender

4. Current board certification status

5. City of primary practice setting

6. State, territory or location of primary practice setting

7. Practice position/title/role at primary practice site (could be multiple)

8. Type of practice setting

9. Average number of hours worked per week in the practice of Pharmacy

10. Entry level Pharmacy degree

11. Highest level Pharmacy related degree

12. Type of Pharm.D. Degree (if earned)

13. Residency completion status and type

14. Number of years worked in full or part-time status as a licensed pharmacist

15. Number of years worked in current specialty or practice focus

16. Primary reason for seeking board certification

17. Secondary reason for seeking board certification 
- Organizational Inputs: This refers to the various groups and associations that may be considered influential in the pharmacist's decision to become a board certified pharmacist. For the purposes of this study, those considered were as follows:

1. Board of Pharmaceutical Specialties (BPS)

2. Professional organizations were the American Society of Health-System Pharmacists (ASHP), American Pharmacists Association (APhA), American College of Clinical Pharmacy (ACCP), American Association of Colleges of Pharmacy (AACP)

3. Company (employer)

- AMA: The American Medical Association is the nation's largest physician's professional association and by their own credo advocate on the part of the nation's health. ${ }^{13}$

- ABMS: "The American Board of Medical Specialties (ABMS), a not-forprofit organization comprising 24 medical specialty boards, is the pre-eminent entity overseeing physician certification in the United States.",14

- AMA Council on Medical Education: Also known as the American Medical Association Council on Medical Education. "The Council on Medical Education (CME) formulates policy on medical education by recommending educational policies to the American Medical Association (AMA) House of Delegates, through the AMA Board of Trustees. The Council is also responsible for recommending the appointment of representatives to accrediting bodies and to other national organizations." $" 13$ 
- Board of Pharmaceutical Specialties (BPS): The Board of Pharmaceutical Specialties (BPS) was established by the American Pharmaceutical Association (now the American Pharmacists Association, APhA) in 1976. The stated mission of BPS with regard to specialization is, via board certification, to recognize specialty areas, define skill standards for those specialty areas, and to evaluate the knowledge and skills of individual Pharmacy specialists. The purpose of board certification was to respond to the rapidly evolving requirements of patients and other health care professionals for pharmacists. ${ }^{4,15-17}$

- Pharmaceutical Care: Pharmaceutical care is a manner of Pharmacy practice that strives to promote health, prevent disease, and assess, monitor, and modify medication use to assure that drug therapy regimens are appropriate, safe and effective. ${ }^{18}$

- APhA: "The American Pharmacists Association (APhA), a national professional association of pharmacists, founded in 1852 as the American Pharmaceutical Association, is the first-established and largest professional association of pharmacists in the United States."19

- ASHP: ASHP is the American Society of Health-System Pharmacists. It was known as the American Society of Hospital Pharmacists until the scope and name change in 1995. It is a "national professional association that represents pharmacists who practice in hospitals, health maintenance organizations, longterm care facilities, home care, and other components of the health care system." 
- ACCP: "The American College of Clinical Pharmacy (ACCP) is a professional and scientific society that provides leadership, education, advocacy, and resources enabling clinical pharmacists to achieve excellence in practice and research. ACCP's membership is composed of practitioners, scientists, educators, administrators, students, fellows, and others committed to excellence in clinical Pharmacy and patient pharmacotherapy."21

- AACP: "Founded in 1900, the American Association of Colleges of Pharmacy (AACP) is the national organization representing the interests of Pharmacy education and educators. [It is comprised of] all 105 U.S. colleges and schools of Pharmacy including more than 4,300 faculty, 48,500 students enrolled in professional programs and 3,600 individuals pursuing graduate study. AACP is committed to excellence in Pharmacy education.",22

- Clinical Pharmacy: "Clinical Pharmacy is a health science discipline in which pharmacists provide patient care that optimizes medication therapy and promotes health, wellness, and disease prevention. The practice of clinical Pharmacy embraces the philosophy of pharmaceutical care; it blends a caring orientation with specialized therapeutic knowledge, experience, and judgment for the purpose of ensuring optimal patient outcomes. As a discipline, clinical Pharmacy also has an obligation to contribute to the generation of new knowledge that advances health and quality of life."21

- Accreditation Council for Pharmacy Education (ACPE): “Accreditation Council for Pharmacy Education (ACPE) is the national agency for the accreditation of professional degree programs in Pharmacy and providers of 
continuing Pharmacy education. ACPE was established in 1932 for the accreditation of Pharmacy education, and in 1975 its scope of activity was broadened to include accreditation of providers of continuing Pharmacy education. The Council is an autonomous and independent agency whose 10 member Board of Directors is comprised of representatives of the American Association of Colleges of Pharmacy (AACP), the American Pharmacists Association (APhA), the National Association of Boards of Pharmacy (NABP) (three appointments each), and the American Council on Education (ACE) (one appointment). ${ }^{, 23}$

- SAS: SAS is an acronym for statistical analytical software. This research employed SAS Version 9.1 TS Level M3, Copyright ( C 2002-2003 by SAS Institute Inc., Cary, NC, USA. All Rights Reserved. ${ }^{24}$

\section{Relevance to Pharmacy, Health Outcomes and Policv Research}

Board certification in many health specialties is preferred or expected and, in some cases, driven by financial reimbursement or rights to practice in certain settings. In Pharmacy, however, becoming board certified in specialty areas is still a voluntary effort. This is true in all specialty areas of Pharmacy practice. ${ }^{8,9}$ Therefore, determining the motivational factors and values ascribed to those factors is essential for determining measures that could be taken to increase the numbers of pharmacists seeking certification. The scope of Pharmacy is expanding. Board certification could become more important as pharmacists take on new challenges. Indeed, the interest of pharmacists in seeking board certification could be instrumental in acceptance of 
new practice models for pharmacists, as well as helping to form a structure for reimbursement of cognitive clinical activities. ${ }^{16,17,25}$

This research was expected to offer information on differences in factors or influences between board certified and non-board certified pharmacists. This information has the opportunity of determining a level of motivation that may be able to predict whether a pharmacist might pursue board certification. This could have an impact on the overall pursuit of board certification by pharmacists. An effective tool that could identify those individuals would be of enormous value. This information may add to the knowledge needed for continued review and possible modification of the certification process. If value to a pharmacist is not present or perceived then a road map of where value needs to be improved would be helpful.

\section{$\underline{\text { Assumptions }}$}

1. Pharmacists involved in completing the study's survey would respond to survey items as honestly and accurately as possible.

2. Pharmacists taking the survey would only complete one survey.

3. Sufficient numbers of pharmacists would have internet access to assure an adequate number of respondents.

4. Pharmacists that respond to the internet based survey would represent the targeted pharmacist population.

5. There is sufficient evidence of the effectiveness and value of the pharmacist clinician. 


\section{$\underline{\text { Limitations }}$}

The following limitations were identified prior to initiation of research:

1. The study references surveys completed by the Board of Pharmaceutical Specialties and others utilized and referenced by BPS in 1989, 1996, 2002 and 2004. ${ }^{26}$ There are economic, socioeconomic, and health care system factors that may have changed in the years between surveys that were not measured in the surveys.

2. Limited data are available on the number of pharmacists licensed to practice in the United States, as well as overlap of practice areas, e.g. pharmacotherapy and nutritional support.

3. Although BPS records the number of pharmacists who seek board certification, limited data are available on the percentage of licensed pharmacists seeking board certification in a specialty area because practice area focus and total numbers of pharmacists in practice are difficult to obtain and confirm.

4. Prior studies assessing values associated with expectations, instrumentalities, and values related to Pharmacy specialization were not found in the literature.

5. The time and expenses involved in pursuing board certification vary among candidates and this variance could have biased the results.

6. Poor survey return rate could have impaired interpretation of the results.

7. Duplicate entries into the survey instrument could not be prevented.

8. Non-pharmacist entries into the survey instrument could not be prevented. 


\section{Organization of the Dissertation}

The remainder of this dissertation is organized into the following four chapters. Chapter 2 reviews the literature relative to the history and process of becoming board certified in a Pharmacy specialty. The literature related to motivational theories and expectancy theory is also reviewed as it pertains to the reason for the selection of the expectancy theory mathematical model for the survey instrument design.

Chapter 3 provides a description of the methods used, including the research design, inclusion and exclusion criteria, data collection, and statistical methodology. Chapter 4 describes the results and findings of the research and offers some discussion regarding the mathematical aspects of expectancy theory. This is followed in Chapter 5 by a review of the study conclusions and discussion. 


\section{Chapter 2. Literature Review}

\section{History of Pharmacy Specialization}

The practice of Medicine has long utilized specialization to differentiate practitioners. For over 100 years the medical profession has formally recognized specialty practice. As far back as the recognition of a priest, shaman, or medicine man as having special knowledge, insight, or power to heal, specialization in the healing arts has been in place. That difference set them apart from the rest of the village, community, clan, or town. ${ }^{9,27}$ Medicine, nursing, optometry, and dentistry exhibit a history of advanced level credentialing. ${ }^{9,28}$ The history of specialization in Medicine began in the 1920's and 1930's and was a result of the developments in medical science and was perhaps causal in the resulting improvements in the delivery of medical care. Specifically, specialization in the United States in Medicine can be seen as a result of the need to master all the special tools and skills needed for the delivery of appropriate and targeted health care. In addition to the development of these skills, social, political and economic forces shaped the framework of the medical specialties. In the practice of Medicine, specialty areas developed around organ systems or functions. The current specialty titles are clear indicators of these. Some examples of medical specialties are cardiology, obstetrics, gynecology, dermatology, thoracic surgery, ophthalmology, otolaryngology, gastroenterology, and neurosurgery. Clearly, the area or particular anatomical need or function played a significant part in medical practice's path toward specialization. Early on, individual physicians were the only persons to assess their specialization qualifications. Lacking 
was a formal process and a set of guidelines, requirements and rules to determine who was indeed qualified to be known and practice as a specialist. Medical educational institutions and specialty societies collaborated to create boards to define specialty qualifications. These boards would function both to identify requirements of a specialist and to assure the public of the specialist's qualifications. ${ }^{9,28}$

The first specialty board formed in the United States was the American Board of Ophthalmology established in 1917. Candidates wishing to practice ophthalmology had established guidelines for their education, training, and importantly, evaluation of their skills. The American Board of Otolaryngology followed in 1924. In 1930 the American Board of Obstetrics and Gynecology was formed. They were joined shortly with the formation of the American Board of Dermatology and Syphilology in 1932. Several other specialty groups followed with the formation of the American Board of Internal Medicine in 1936 and the American Board of Surgery in 1937., 28, 29

Board certification for physicians was based on the concept that physician specialists who met certain qualifications and standards, and having attained the necessary level of knowledge, skill, and experience in their respective area of practice offered a higher level of care than practitioners who did not. While it may seem intuitively logical that such specialists would produce better health care outcomes, with lower morbidity and greater efficiency, this has not been validated by any studies. ${ }^{9}$ Some have argued that the highly skilled and trained specialist dominated care model actually does not improve outcomes over simpler and less expensive 
models of health care. ${ }^{30}$ However, this has not deterred or altered the progression and acceptance of the model of board certification as a means to improve healthcare.

Since 1934 specialty boards in Medicine have been officially recognized by the American Board of Medical Specialties (ABMS) and the American Medical Association (AMA) Council on Medical Education (CME). The American Board of Medical Specialties approves 24 medical specialties and has become the standard by which the profession and the public recognize physician specialists in the United States. Additionally, 180 other non-ABMS boards issue specialty certifications. ${ }^{9,29}$

Board certification is not currently required for a physician to practice Medicine in most areas. But there is value to a specialty certification. Managed care organizations require a certain percentage of the members of a medical staff to be board certified for many contractual arrangements and the Joint Commission on Accreditation of Health Care Systems (JCAHO) and the National Committee of Quality Assurance (NCQA) incorporate medical specialty board certification in their accreditation standards. These measures of acceptance provide a basis for the public view of medical specialty board certification as a measure of expertise and achievement and seem to be the entrenched pattern of acceptance. ${ }^{9,31}$

\section{Specialty Recognition and Credentialing in Pharmacy}

Throughout most of its history Pharmacy has remained undifferentiated. Hospital Pharmacy first began movement toward differentiation in the late 1960's and through the mid-1970's. This environment of thought began to require a new model of practice. Pharmacists practicing in these areas took on new roles. Activities and 
communications in the late 1960's and through the mid 1970's addressed this new practice model and the need for the development of a "new practitioner" who had unique roles distinctive from those of the traditional dispensing pharmacist. ${ }^{9,} 32$

Early pioneering pharmacists participated with physicians in a variety of tasks including therapeutic decision making. These tasks offered new opportunities. ${ }^{9}$ Recommendations were made to organize hospital Pharmacy departments in novel ways to recognize and utilize what were then the new Pharmacy specialists. It was suggested that the medical model of specialization be applied to Pharmacy. ${ }^{9,} 32$ Between the years 1973 and 1976 many activities, resulting from the movements dating back to the late 1960's and through the early 1970 's, took place that moved the profession of Pharmacy into the realm of specialization. ${ }^{4,6,17,33}$ There are a variety of ways that pharmacists may be additionally trained and credentialed to meet the needs of their expanding and more specialized roles. These include residencies, fellowships, certificates and board certification., 6, 9, 15-17, 34

The American Pharmaceutical Association (now the American Pharmacists Association, APhA) established the Board of Pharmaceutical Specialties (BPS) in 1976. ${ }^{5}$ The stated mission of BPS with regard to specialization is, via board certification, to recognize specialty areas, define skill standards for those specialty areas, and to evaluate the knowledge and skills of individual Pharmacy specialists. The purpose of board certification was to respond to the rapidly evolving requirements of patients and other health care professionals for pharmacists. The first Pharmacy specialty recognized by BPS was Nuclear Pharmacy, which occurred in 
1978. The others were Nutrition Support Pharmacy (1988), Pharmacotherapy (1988), Psychiatric Pharmacy (1992), and Oncology Pharmacy (1996)..$^{4-6,8,9,15,17}$

Since the inception of Pharmacy board certification in these areas, research and emphasis has been focused on the value that this specialization brings to the patient, other members of the health care team and the health care system as a whole. Areas of research have been in demonstrating higher levels of practice, better patient outcomes, and cost reduction, where possible. Studies evaluating the effectiveness of the pharmacist in pharmaceutical care have demonstrated successful activities in lower drug costs and reduced overall health care expenditures, lower mortality rates and prevention of errors. Meta-analyses and individual articles have outlined pharmaceutical outcomes research as well as scientific applications of pharmaceutical care. These reveal that indeed pharmacists do make an impact. ${ }^{35-56}$

Pharmaceutical care is designed to promote health, prevent disease, and assess, monitor, and modify medication use to assure that drug regimens are safe and effective. $^{25,34-43,48,51}$ In general, it appears that pharmacists' activities in the hospital, nursing home, retail/ambulatory practice and clinic settings have been well received and have demonstrated the effectiveness of pharmaceutical care. For the purposes of this study, it will be assumed that at this point in the development of the model of pharmaceutical care that there is sufficient research evidence of the effectiveness and value of the pharmacist clinician..$^{35-56}$ These findings, along with the development of increased and improved automated systems, and the move to the entry-level Doctor of Pharmacy (Pharm.D.) degree, have prompted some medical organizations and governmental bodies to strongly support the expanded role of pharmacists. ${ }^{25}$ Official 
recognition via increased pay, and/or ability to receive reimbursement for services, has been offered by others. $25,57,58$

Becoming board certified in Pharmacy is a rigorous and involved process. ${ }^{8}$ It is also voluntary and perhaps lacks a tangible reward. In the practice of Medicine, and in some other health care disciplines like nursing, board certification may not be required but is highly desired for practice. Reimbursement and/or accreditation processes may also be tied to the number of board certified practitioners, especially physicians, in a practice or area. Although not required, there are a number of factors, as well as a perceived value of those motivating influences or factors, which may motivate pharmacists to pursue board certification. It is reasonable to expect that the number of pharmacists seeking board certification is related to these factors and their perceived values. Studies assessing associated expectations and values of pharmacists pursuing board certification were not found in the literature.

Although some professional groups and societies have suggested board certification by pharmacists as a necessary credential for acceptance as a peer practitioner, ${ }^{25}$ the number of pharmacists seeking board certification in the various specialties is relatively small. From 1995 to 2006 the numbers of board-certified Pharmacy specialists has grown from 1649 to 4940 , a three-fold increase. ${ }^{59}$

This type of percentage increase would seem to be impactful. But during this same period it was estimated that fewer than $5 \%$ of practicing pharmacists had sought any advanced practice certification. ${ }^{9,33}$ Of the currently licensed pharmacists, precise percentages of those seeking certification is difficult to determine due to the lack of records of numbers of all practitioners and/or possible overlapping practice areas, e.g. 
pharmacotherapy and nutrition support. As in any health care discipline, becoming board-certified represents an additional amount of effort on the part of the candidate beyond licensure.

The requirements for becoming certified in a Pharmacy specialty area are multi-faceted. Typically it requires many hours of training and experience (which might be gained in several ways including supervised work experience, postgraduate academic programs, certificate training programs, residency, etc.) and successful completion of a rigorous written exam. ${ }^{8,9,60}$ Once a pharmacist has obtained certification, recertification by written exam is required every seven years. ${ }^{8,60}$ One question this study sought to answer was what would motivate a pharmacist to exert the time, energy, and money to obtain this certification, given the fact that it was not required for him or her to obtain or maintain employment?

In the case of the physician or the nurse-practitioner, the motivating factors are more obvious. They may seek certification as a condition of practice, and they can therefore expect to practice under the umbrella of their sanctioning organization. They can also expect to reap the benefits, e.g. enhanced professional stature or abilities to provide services for certain health insurance or third-party payment providers that require such certification, such a level of achievement affords. However, they are also proceeding with the knowledge of what they would not be able to do without that certification. This latter limitation may be imposed by the sites where they practice or by regulations in their area of practice.

Since board-certification in Pharmacy is not currently required, the pharmacist must recognize or perceive that there are benefits of board certification. One survey in 
1996 of 733 BPS certified specialists sought to measure the tangible and intangible benefits that BPS certification might bring to the pharmacist. Of the respondents, 90\% practiced Pharmacy within their specialty. Cited as their reason for pursuing board certification were 1) to test their competence $(65.5 \%) ; 2)$ increase marketability (49.6\%); and 3) to increase their acceptance by other health care professionals $(34.3 \%){ }^{61}$ A small number noted financial or career boosts that resulted from the certification. A prior survey in 1989 of board certified pharmacists found $72 \%$ of respondents listed self-recognition and acceptance as their principal satisfactions. ${ }^{61}$ This same group reported the least satisfaction related to employers. It is not immediately obvious as to whether their employers attached any value to their status because respondents were able to answer with multiple responses. Other studies have found that some financial reward, e.g. slightly higher compensation, may exist for certain specialists like those certified in pharmacotherapy. BPS surveyed 1141 boardcertified pharmacists in 2002. Less than 5\% reported that certification was required for their job, although $31 \%$ listed it as preferred by their employers. This study found that there was some employer recognition. However, only reports of public recognition (21\%), financial reimbursement for certification (33\%), and financial reimbursement for recertification (24\%) managed to exceed the $20 \%$ mark. $^{61}$

In the 2004 on-line survey of BPS-Certified Specialists, represented in Table $2-1$, some changes were noted. Specifically $31 \%$ of total respondents reported no formal employer recognition which could mean that $69 \%$ did. This demonstrates a slight decrease from 2002 where 333 out of 1135 respondents (29\%) reported no recognition, so $71 \%$ were apparently recognized in some way. Other attestations of 
Table 2-1. Tangible and Intangible Benefits that BPS Certification May Bring to the Pharmacist as Reported in BPS Online Survey Results $2004^{63,64}$

\begin{tabular}{lcc}
\hline Survey Item & $\begin{array}{c}\text { Number of BPS responses } \\
\text { (Multiple Allowed) }\end{array}$ & $\begin{array}{c}\text { Percentage of BPS } \\
\text { Respondents (N=1995) }\end{array}$ \\
\hline Pay Certification Costs & 686 & $34 \%$ \\
No Recognition & 618 & $31 \%$ \\
Pay Recertification Costs & 433 & $22 \%$ \\
Public Notice & 325 & $16 \%$ \\
Hiring Priority & 324 & $16 \%$ \\
Salary Increase & 302 & $15 \%$ \\
Pay BPS Annual Fee & 296 & $15 \%$ \\
Increased Responsibility & 224 & $11 \%$ \\
Promotion Priority & 137 & $7 \%$ \\
One-time Pay Bonus & 98 & $5 \%$ \\
\hline
\end{tabular}


their accomplishments were spread among a variety of types of recognition and respondents could answer with multiple responses. It should be noted that in the surveys done in 1996, 2002, and 2004, respondents could choose as many recognition types (responses) as they wanted, therefore the number of recognition responses greatly exceeded the number of survey respondents. ${ }^{62}$

In this survey, $34 \%$ reported that their employer paid their certification costs and $22 \%$ had their employer pay their recertification costs. Tangible or intangible rewards for either hiring priority or public notice were tied at $16 \%$. And $15 \%$ reported a salary increase which was the same as those saying their employer paid their annual BPS fee. Only $5 \%$ reported a one-time pay bonus. There may be some increase occurring in willingness by employers to recognize and value the BPS certification, but it appears to be minor compared to previous periods. ${ }^{63}$

What, then, would motivate a pharmacist to exert the time, effort and money to obtain this certification, given the fact that it is not required for him or her to obtain or maintain employment and that there may be few work-related rewards after completion? A discussion of motivational theories may offer some direction in answering that question.

\section{Motivational Theories}

Motivational theories are classically divided into two major categories. These are content and process. ${ }^{10}$ Content theories are based on the assumption that all individuals possess a given set of needs. Process theories stress the differences in the individual's needs and are more related to the human cognitive processes that create 
differences. The four primary content theories are Maslow's theory, The Existence, Relatedness and Growth (ERG) theory, Acquired Needs theory, and Herzberg's twofactor theory. ${ }^{11}$ The three primary process theories are Equity theory, valenceinstrumentality-expectancy (VIE) theory, more commonly called Expectancy theory, and Goal-Setting theory. ${ }^{10}$ Additionally, Reinforcement theory, also commonly classified into process theories, seeks to explain the role of rewards and how those rewards may lead to changes in behavior. These basic types of theories vary in their scope. Some of these theories seek to explain human behavior while others are focused entirely on workplace motivation. Simply put, content theories seek to explain what motivates us, process theories seek to explain why and how we are motivated, and reinforcement theory, a subset of process theories, seeks to explain how outcomes influence behaviors. For the purposes of this discussion psychological theories related to organizational motivation and job satisfaction alone are omitted in favor of focusing on those theories that may have application to personal motivation. To better understand what factors may be affecting pharmacists in their decision to pursue or not to pursue board certification a review of each of the theories mentioned above follows.

\section{Content Theories - Maslow's Hierarchy of Needs}

Some theories of motivation propose a hierarchical approach to explaining or describing a transitional approach to motivation. Abraham Maslow was a pioneer in this type of approach and indeed one of the early promoters of the field of selfactualization $^{65}$. His initial work in 1943 synthesized many fragments and smaller 
theories into a more cohesive framework. This was later updated by Maslow and Lowery in 1998 to explain "growth levels" and again in 1971 to identify some more differentiation at the higher levels formerly titled "self-actualization". ${ }^{65,66}$ The final components of Maslow's work from 1943-1971 demonstrate a pyramid of effects that posit that humans go through a progression of states to reach the higher levels. The stages, listed from the lower to the higher are: ${ }^{11,65}$

1. Physiological Needs (hunger, thirst, sexual, comforts, etc.)

2. Safety Needs (security, out of harm's way, no fear, etc.)

3. Belongingness and Love Needs (being accepted, approval of peers)

4. Esteem Needs (achievement, accomplishment, etc.)

5a. Cognitive Needs (to know, to understand, to explore, etc...)

5b. Aesthetic (symmetry, order, beauty, etc.)

6a. Self-actualization (self-fulfillment, realization of potential, etc.)

6b. Self-transcendence (connection to a greater good, assisting others with self-fulfillment, self-actualization or self-transcendence)

These values are traditionally arranged in a pyramid, with the higher numbers at the top of the pyramid and the lower numbers at the bottom, and is often called Maslow's "pyramid of needs". This theory has been widely reviewed and accepted by many despite a lack of empirical evidence that any of the segments are in fact distinct, or that the progressions must occur linearly. Some suggest that Maslow's concepts of self-actualization and transcendence are perhaps the most important contributions to the study of human behavior and particularly motivation. ${ }^{65}$ Others 
have attempted to modify and improve upon Maslow's work and these are discussed below.

\section{Content Theories - ERG (Existence, Relatedness, Growth) Theory}

Clayton Alderfer took the results of studies done on Maslow's work and developed a similar and comparable structure, albeit more simplified. He called this the existence, relatedness and growth (ERG) theory. ${ }^{11,67,68}$ Contrary to hierarchical, i.e. progressive nature of the component sections of Maslow's pyramid, Alderfer posited that existence, relatedness and growth needs existed simultaneously and may vary for each person. ${ }^{11,67-69}$ An important contribution from the ERG theory is that it was recognized that a frustration-regression principle could occur, i.e. if a person did not achieve a higher level and remained unfulfilled then that individual might regress to an easier and more comfortable level. This is an important concept as it speaks to positive and negative work place motivation. ${ }^{11,69}$

\section{Content Theories - Acquired Needs Theory}

David McClelland proposed that a person's needs are acquired over time.

These needs are specific to the individual and are shaped by experiences in life. The needs fall into three categories which are the need for achievement (nAch), the need for power (nPower) and the need for affiliation (nAff). ${ }^{11,68,70}$ The need for achievement should increase the desire to do things better, work more efficiently, solve problems, master complex tasks or other measures of measurable achievement. Persons high in $n A c h$ prefer to work alone or with other high achievers and take 
personal ownership of results. They prefer achievable goals and will seek things that are challenging as long as they are perceived as doable. Regular feedback is important to this group. ${ }^{11,68,70}$

There are two types of power addressed with the nPower category. These are social or institutional power and personal power. Persons with high personal nPower are likely to be controlling of other persons by influencing their behavior and perhaps will become responsible for the work of others. This trait is generally perceived as undesirable. Those with high social nPower use organization as a means to further their goals, which are generally the goals of the social group. This trait is generally perceived as desirable and is in fact a sought after trait for managers within organizations. ${ }^{11,68,70}$ The third category of needs is $n$ Aff. This speaks to the need for affiliation. Individuals with high $n$ Aff tend to work toward creation of harmonious relationships and seek to establish and maintain relationships. People with high $n A f f$ will generally conform to the needs of their work or social group.

McClelland developed a test called the Thematic Apperception Test (TAT). The TAT is a test of imagination and is based on ambiguous pictures and the subject's ability to spontaneously develop a story about each picture. Scoring with this instrument has been refined to test individuals to determine types of jobs for which an individual may be best suited. ${ }^{70}$

\section{Content Theories - Herzberg}

Frederick Herzberg studied employees in the workplace to determine factors leading to satisfaction and dissatisfaction. He published his findings in 1959 in The 
Motivation to Work. ${ }^{71}$ Herzberg found that job dissatisfaction and job satisfaction were not just different ends of a scale but were in fact a set of independent factors. He labeled those factors having to do with job dissatisfaction as hygiene factors and those related to job satisfaction as motivators or motivational factors. ${ }^{11,68,71,72}$ These two groupings of factors are known as the two-factor theory although it really is two primary factors, hygiene and motivational factors, that are comprised of many subfactors.

The top six hygiene factors are: ${ }^{68,71,73}$

1. Policies and rules,

2. Supervision,

3. Relationship with supervisor,

4. Relationship with peers,

5. Base salary or wages,

6. Working conditions.

The top six motivators or motivational factors are: $68,71,73$

1. Achievement,

2. Recognition,

3. Work itself,

4. Responsibility,

5. Advancement,

6. Personal growth.

Herzberg's theory has critics. Job satisfaction does not necessarily indicate or imply a high level of motivation. ${ }^{73}$ His assertion that true motivation comes from 
within the individual however does seem to be an overarching take-away from his perhaps difficult to confirm factor interactions.

\section{Process Theories - Equity Theory}

Equity theory, also known as Adam's Equity Theory, developed by John Stacy Adams in 1963, is based on a perceived sense of equity, i.e. people are happiest in relationships where the inputs they bring to a job and the outcomes that they receive from those inputs are the same as that of others.$^{11,68,74,75}$ Equity theory also has application to personal relationships where the give and take aspects of the relationship must be perceived to be equitable or dissatisfaction or distress will occur. Whether focused on personal relationships or job satisfaction, equity theory proposes that motivation that comes from the outcomes or outputs from the company, project, or task must have tangible and intangible aspects that are in balance with the inputs. ${ }^{11,68,75}$ In essence, the referents for comparison are our friends, colleagues, family, competitors, workplace superiors and inferiors, and it is by these that equity is evaluated.

Critics of Equity theory argue that the model is too simple to explain many real world interactions of complex factors. ${ }^{75}$ A reasonable summary of Equity theory, as it could have application to this study, is that individuals could equate value of rewards to effort and compare those values to other people, in effect making motivation perhaps based on competition. ${ }^{11}$ 


\section{Process Theories - Goal-Setting Theory}

Goal-Setting Theory was developed by Edwin Locke. It is based on a simple premise. Properly set and managed goals can be motivating. Goal-setting theory has four major components which are difficulty, specificity, acceptance and commitment. ${ }^{4,11,76,77}$ This theory focuses on specific motivations that are task based. Feedback and reward are principal aspects of this theory. Feedback is important to reinforce progress made toward goals. Reward is anticipated and interim rewards often are defined as goals building toward a larger goal. The realm of sports is an area where goal setting theory has application. It is also the underpinning for the modern management by objectives (MBO) tool common in the business world. ${ }^{11,68,78}$

Goal setting theory as an abstract concept could have an explanatory value for individual motivation to achieve things. No sound mathematical model to evaluate different interactions and relative weights to the different types of goal and rewards based on this theory was found in the literature.

\section{Process Theories - Expectancy Theory}

Expectancy theory is covered in detail later as it is the basis for the survey instrument design and metrics for this study. It is classified as a process theory but it also brings together many aspects and elements of both content and process theories.

\section{Process Theories -Reinforcement Theories/Operant Conditioning}

B.F. Skinner proposed the concept of operant conditioning which is now commonly referred to as Reinforcement theory. This theory explains the role of 
rewards, or reinforcements, as they cause behavior to change or remain the same over time. Since rewards can be both positive and negative within this theory consequences and rewards are sometimes used interchangeably. ${ }^{11,68}$

There are four operant conditioning strategies according to this theory. They are positive reinforcement, negative reinforcement, punishment and extinction.

Two are intended to strengthen a behavior. Positive reinforcement is the process of the getting something for doing something paradigm. Frequency or quality of a behavior then is increased as consequences of that behavior are rewarded. Negative reinforcement is the process of strengthening a behavior by the removal of some undesired consequence. Frequency or quality of a behavior is increased as negative consequences, also called stressors, diminish.

The other two operant conditioning strategies are intended to weaken a behavior. Extinction is the process of getting nothing for doing something. Extra effort means no additional rewards or basically no reward period. Extinction decreases the frequency or quality of a behavior. Punishment is the process of being punished for a behavior. If you do an undesired behavior there will be a commensurate punishment or removal of a pleasant consequence. ${ }^{68}$

In addition to the operant conditioning strategies there are two types of reinforcement schedules. The first of these is the continuous reinforcement schedule where each time a desired behavior is performed there is reinforcement or reward. The second is the intermittent reinforcement schedule. This schedule has fixed and variable categories. These categories are the fixed-interval schedule, fixed-ratio schedule, variable-interval schedule and the variable-ratio schedule. The fixed 
interval schedule provides reinforcement after some predefined time period has elapsed. The fixed-ratio schedule provides reinforcement after a predefined number of desired actions or responses. The variable-interval schedule provides reinforcement after varying amounts of time have elapsed and the variable-ratio schedule provides a reward after varying amounts of correct responses or actions have occurred. ${ }^{11,68}$

Reinforcement theory has some place in understanding individual motivation from an abstract aspect. It does explain the concept of reward for behavior or lack of reward for no desired activity. It is probably better suited for an organizational approach to motivation than one to describe individual motivation.

For the purposes of this study it was desired that pharmacists' perceptions at some point in time be measured and operant conditioning theory works better to describe overall behavior over some time period.

\section{Expectancy Theory as a Basis for Survey Design}

Valence-instrumentality-expectancy (VIE) theory, as noted above, is a major theory of motivation and work behavior. It may also be called Expectancy-Valence (EV), instrumentality theory, and path-goal theory. The three major variables are

expectancy, instrumentality and valence (value) ${ }^{10}$ so VIE is commonly used as a title for this theory. It is a process theory in that it seeks to identify the relationship between the variables in a dynamic state as they affect individual behavior. Vroom, the initiator of VIE theory postulated that what was crucial to motivation at work was 
the perception of a link between effort and reward. In this theory, the relationships between the inputs are more the focal point than the inputs themselves. ${ }^{12}$

Expectancy theory has applicability to the evaluation of motivation for pharmacists choosing to pursue board certification. The purpose of this theory is to evaluate possible connections between expectations of effort to performance, instrumentality of the performance to outcomes, and the valences (or values) that individuals ascribe to those actions. It also addresses instrumentality as the perceived probability of a performance leading to a desired outcome. Instrumentality is therefore sometimes also called cognized instrumentality. ${ }^{12}$

It may seem intuitive that financial inducements would increase interest in the pursuit of Pharmacy practice specialization, but at what point does this occur? While this may seem reasonable, there is no definitive evidence that financial rewards are the critical or most significant motivating factor. Other factors related to career, personal concerns, and professional standing may have an equal or greater impact on decisions. More likely, combinations of factors within these four proposed domains, and potentially the interactions among the domains, may be involved with the motivation to pursue or not pursue board certification for pharmacists.

There are two key concepts at the base of Expectancy theory. The first is that "...the valence of an outcome to a person is a monotonically increasing function of the algebraic sum of the products of the valences of all other outcomes and his conceptions of its instrumentality for the attainment of these other outcomes.",

This can be expressed mathematically as: ${ }^{12}$ 


$$
\mathrm{V}_{j}=f_{j}\left[\sum_{k=1}^{n}\left(\mathrm{~V}_{k} \mathrm{I}_{j k}\right)\right](j=1 \ldots \mathrm{n})
$$

$f^{\prime}>\mathrm{O}: i \mathrm{I}_{j j}=\mathrm{O}$

Where $\mathrm{V}_{j}=$ the valence of the Outcome $j$

$\mathrm{I}_{j k}=$ the cognized instrumentality $\left(-1 \leq 1_{j k} \leq 1\right)$ of outcome $j$ for the attainment of outcome $k$.

With the assumption that choices made by people are inherently and subjectively rational, the second major assumption is that “...the force on a person to perform an act is a monotonically increasing function of the algebraic sum of the products of the valences of all outcomes and the strength of his expectancies that the act will be followed by the attainment of these outcomes." ${ }^{, 12}$ This can be expressed in the following equation: ${ }^{12}$

$$
\mathrm{F}_{i}=f_{i}\left[\sum_{f=1}^{n}\left(\mathrm{E}_{i j} \mathrm{~V}_{j}\right)\right](i=\mathrm{n}+1 \ldots \mathrm{m})
$$

$\mathrm{fi}^{\prime}>\mathrm{O}: i \cap j=\Phi, \Phi$ is the null set

Where $\mathrm{F}_{i}=$ the force to perform act $i$

$\mathrm{E}_{i j}=$ the strength of the expectancy $\left(\mathrm{O} \leq \mathrm{E}_{i j} \leq 1\right)$ that act $i$ will be followed by outcome $j$

$\mathrm{V}_{j}=$ the valence of outcome $j$

$\cap=$ Intersection 
This equation can also be written more simply as:

$$
\mathrm{F}=\sum_{t=1}^{n}\left(\mathrm{E}_{i} \mathrm{~V}_{i}\right)
$$

The value $\mathrm{E}_{i}$ has two components. One is the effort-to-performance expectancy $(E \rightarrow$ $P)$. The second is the performance-to-outcome expectancy $(P \rightarrow O)$ which is also known as instrumentality. ${ }^{72,79}$ This can be mathematically expressed, in VIE terms, as: ${ }^{12}$

$$
\mathrm{F}=\sum\left[(E \rightarrow P) \times \sum[(P \rightarrow O)(V)]\right]
$$

Where, $(\mathrm{E} \rightarrow \mathrm{P})=$ Expectancy, $(\mathrm{P} \rightarrow \mathrm{O})=$ Instrumentality, and $\mathrm{V}=$ Valence (Value).

From the example shown in Figure 1-1, and utilizing the derived formula in Equation 2-4, the value of the motivational force to pursue a position, certification or additional qualification (or effort that is willing to be expended) can be calculated by adding the values of the valence and the instrumentality calculations (products) and multiplying the total by the expectancy value.

If we review the data from Figure 1-1 we find that the values discussed and represented as decimal equivalents were:

- $\quad$ Expectancy $=0.5$

The performance-to-expected reward instrumentalities were:

- $\quad$ Performance to pay raise $=0.9$

- $\quad$ Performance to promotion $=0.5$

- $\quad$ Performance to longer holiday $=0.3$ 
- Performance to company car $=0.6$

Valences or values were:

- $\quad$ Pay raise $=6$

- Promotion $=8$

- $\quad$ Longer holiday $=5$

- Company car $=9$

The instrumentality and valence products summed are:

$(0.9 \times 6)+(0.5 \times 8)+(0.3 \times 5)+(0.6 \times 9)=16.3$. With the result multiplied by the expectancy of 0.5 this yields 8.15 based on $16.3 \times 0.5 .^{10}$ The decimal equivalents are typically seen but the whole number equivalent can be used as well. The only change to the result is the order of magnitude. For example, using the numbers just listed but substituting whole numbers we see $(9 \times 6)+(5 \times 8)+(3 \times 5)+(6 \times 9)=163$, and $163 \times 5=815$. So the formula is reduced to the sums of instrumentality multiplied by the value sums and then multiplied by the expectancy, or Motivation $=$ Expectancy $\mathrm{x}$ Instrumentality x Value (M = E x I x V).

In the classical use of the expectancy theory formula, zero values are allowed but the expectancy (expectancy-to-performance, $\mathrm{E} \rightarrow \mathrm{P})$, instrumentality $(\mathrm{P} \rightarrow \mathrm{O}$, performance-to-outcome, valence (value) must all have at least one value greater than zero or the resultant calculation leads to zero.

This is the numerical representation of the force of motivation. With a numerical result calculable, the potential to mathematically compare various persons or groups exists. Rather than relying on complex statistical comparisons a rapid mathematical comparison of motivational force and categorization can be performed. 
The result of the VIE calculation has no independent value. However, results of multiple VIE calculations, which are measures of motivational force, have comparative value. It was for this reason that a survey instrument was developed based on this mathematically based theory and that the methodology described in the next chapter utilizes it as underpinning for the study. 


\section{Chapter 3. Methodology}

\section{$\underline{\text { Purpose }}$}

The primary purposes of this study were to: (1) compare the benefits and rewards (instrumentalities) that are perceived as most important by pharmacists with regard to board certification by BPS, (2) compare the most valued aspects or factors perceived by pharmacists with regard to board certification, (3) evaluate the relationship between instrumentalities and values, (4) determine if a certain set of factors was more prevalent in board certified pharmacists than those that were not, (5) compare the calculated force of motivation between board certified and non-board certified pharmacists and, (6) evaluate if there was a tipping point where a certain combination of factors would be present in board certified pharmacists that were greater than non-board certified pharmacists. This latter point was defined as a marked difference in overall score on the VIE scale, or calculated force of motivation (MF), on the survey instrument.

\section{$\underline{\text { Research Design }}$}

This research was designed as a prospective internet survey employing an exploratory descriptive design. Participants that agreed to participate in the study were asked to respond to a series of survey items related to probability of occurrence of an event stated and the importance or value to them of that event or action. Additionally, the respondents were asked a question regarding their anticipated 
success rate given that the effort was put forth. The survey instrument was unique in design in that multiple levels of answers to the same statement were required.

Summary and descriptive statistical measures were used to evaluate means, variance and other related aspects of the study population. The primary statistical marker was the Student's t-test ${ }^{80}$ as a comparative measure for all variables between pharmacists that were board certified and those that were not. For the purposes of this study a significance level of $p<0.05$ was established. Included in this evaluation was a determination of a threshold level, i.e. the level that motivational force, measured as an overall score based on the collective individual scores, caused individuals to take action.

A survey instrument titled "Advanced Certification Index for Pharmacists" (ACI-P) was developed for this study. There were three levels of items to be addressed via the survey instrument. These were instrumentality, valence and expectancy. Instrumentality is an individual's anticipated probability of an event occurring. Valence, also known as value, is a measure of the value or importance to the respondent of that particular item, question or statement. Expectancy is a measure of the respondent's belief that an action or series of actions will lead to a successful outcome. In this case the outcome was attainment of specialty certification in one or more of the five identified Pharmacy practice specialties.

The survey instrument design used an a priori determination of domains as a means to fashion the item sets. The intent of this research was not to prove or substantiate those domains but rather to evaluate the item sets and compare the generated responses. 


\section{Settings and Subjects}

The study was completed via the internet. Respondents hailed from various practice settings including private pharmacies, hospitals, academia, specialty pharmacies, government, and large chain/company owned pharmacies. Due to the fact that specialty certification may not have been a job requirement in a majority of settings, but may have been in others, the practice setting of the individual may have contributed to the individual's opinions. Access to computers and assurance of anonymity of the respondent was important. The study setting allowed for remote access, i.e. home, library, or other portal into the data collection mechanism. The internet protocol (IP) address for the computer used by the respondent was not captured. This can be captured automatically by survey tools but was deliberately omitted for the purposes of this study to assure anonymity of respondents.

The study group included currently BPS board certified members from the five specialties, those that were not currently board certified, and those that had never been board certified that were members of one or more of the American Society of Health-System Pharmacists (ASHP), American Pharmacists Association (APhA), the American College of Clinical Pharmacy (ACCP), the American Association of Colleges of Pharmacy (AACP) and the Board of Pharmaceutical Specialties (BPS). Former board certified pharmacists that had not renewed their certification were considered for the comparison and their responses were included with the ones that were not board certified. Information that was gleaned from this research will be shared with the Board of Pharmaceutical Specialties and other professional organizations as summary information only. 


\section{Inclusion Criteria}

All pharmacists practicing in any practice setting were eligible to participate. The focus was directed toward members of APhA, ASHP, ACCP, AACP and BPS. However, since dissemination of the survey link was also to non-members of any of these organizations, via word of mouth or secondary electronic transmission to colleagues, any practicing pharmacist was eligible to participate whether a member of an organization or not.

\section{Exclusion Criteria}

Non-pharmacists were not to complete the survey and if they did their data was excluded.

\section{Sample Size}

To determine a sample size needed for the study a technique was established as the primary statistical method for evaluation. This was the Student's t-test. Using a methodology developed by Cohen known as the Cohen's “ $d$ ”, sample size estimates were made. ${ }^{81}$ The Cohen's $d$ procedure for sample size determination is adequate even when the standard deviation (sigma) of a population is unknown. These estimates or projections were made based on an unknown sigma on two independent means. Effect size, as defined by Cohen, is the difference in means between two groups divided by the standard deviation. ${ }^{81}$ Interpretation of the Cohen's $d$ allows a differential when comparing statistical significance versus practical significance. One way of looking at the comparison of effect size is to consider $d=0.0$ to 0.2 as a trivial 
effect size, $d=0.2$ to 0.5 as a small effect size, $d=0.5$ to 0.8 a moderate effect size and $d>0.8$ to be a strong effect size. Or, more commonly, $0.2=$ small effect, $0.5=$ moderate effect and $0.8=$ strong effect. ${ }^{81}$ In other words, if one expects a more easily discernible effect (a strong effect) a 0.8 would be the choice and if one were to expect the effect to be small then the 0.2 would be the choice for the Cohen $d$ classification.

Using tables based on Cohen's $d$, three sample size potentials were found and are listed in Table 3-1.

Since there were no assumptions about the effect size that could be expected, a sufficient sample size was projected to determine the smallest possible effect size so 790 was the projected sample size with at least 395 occurring within the board certified group and at least 395 occurring in the non-board certified group. To account for incomplete or missing data, actual projections were escalated by $20 \%$ higher than these numbers, therefore it was estimated that $474(1.2 \times 395)$ would be needed for each group. To attain the large numbers needed for this study four of the large Pharmacy organizations and the Board of Pharmaceutical Specialties were requested to contact their membership electronically and solicit participation.

Exploratory factor analysis and parallel axis analysis were used to evaluate like factors and determine the underlying constructs, or commonly associated items, within the data. It must be pointed out that although confirmation of stated or particular factors can be useful for many survey instruments, the purpose of this research was not to prove or disprove the a priori proposed domains, and therefore confirmatory factor analysis was not attempted. These a priori domains were helpful in creation and stratification of the questions for the survey instrument. 
Table 3-1. Sample Size Projections Based on Cohen's $d$ Estimates, Effect Size is an Estimate of Discernible Effect

\begin{tabular}{cccc}
\hline Effect Size & $\begin{array}{c}\text { Group One } \\
\text { Subjects }\end{array}$ & $\begin{array}{c}\text { Group Two } \\
\text { Subjects }\end{array}$ & $\begin{array}{c}\text { Total } \\
\text { Subjects }\end{array}$ \\
\hline 0.2 & 395 & 395 & 790 \\
0.5 & 65 & 65 & 130 \\
0.8 & 27 & 27 & 54 \\
\hline
\end{tabular}

Note: An effect size of 0.2 means a difficult to discern effect, 0.5 and 0.8 mean medium and easy to discern effects, respectively. 
To calculate a sample size for exploratory factor analysis or parallel analysis, in order to evaluate relationships among the questions on the survey, ten responses per question were necessary. Much debate in the literature has focused on an appropriate subject-to-item ratio with the lower level seen at 2:1 and the upper end at 100:1. However, $63 \%$ of studies evaluated have used $10: 1$ or less with the $10: 1$ ratio still considered a prevalent rule of thumb for a priori evaluations of sample size. ${ }^{82-84}$ With a survey totaling 51 items, not including demographics, that translates to a sample size of 510 subjects. However, since there are 25 question sets each of the subsets could be considered an independent set for the same issue which means only 260 responses would be necessary. This included the additional question regarding expectancy $(25+1 \times 10=260)$.

Some assumptions of data lost similar to those mentioned under the Cohen's $d$ projection were factored in to increase the projected need of 260 by $20 \%$ to 312 total respondents needed. However, utilizing the small effect calculation via Cohen's $d$, a sufficient sample size would have been attained for factor and parallel axis analysis.

\section{Sample Description}

The investigator obtained demographic information that was completed by the respondents. The demographic information included age, gender and an additional 13 items summarized from the five separate board certification tests currently in use by the Board of Pharmaceutical Specialties for their Pharmacy Examination Demographic Survey, which accompanies the component of the Certification Examination for Board Certification in any specialty area in Pharmacy. ${ }^{85}$ The 
demographic responses were not required of the respondent although this information was requested to compare findings of this survey with those done previously by BPS. The demographic findings and relationships were pertinent but were not a focal point of the study.

The included items in the demographic and BPS survey alignment for this project, minus the responses, are listed below. These retain original wording where possible from the BPS surveys. The demographic and BPS survey alignment section followed the primary questions on the survey.

1. Age.

2. Gender.

3. What is your current board certification status? List all that apply.

4. What is the CITY of your PRIMARY practice setting?

5. What is the STATE, TERRITORY or LOCATION (e.g. international work location) of your PRIMARY practice setting?

6. Which of the following most closely classifies your position at your primary practice setting? Multiple answers are allowed but please limit to two.

7. What is the average number of hours you typically work each week in the practice of Pharmacy?

8. What was your ENTRY LEVEL Pharmacy-related degree?

9. What is the HIGHEST Pharmacy-related degree you have earned?

10. If you earned a Pharm.D. degree, please indicate the TYPE of Pharm.D. program. 
11. Have you completed a residency training program?

12. In total, how many years have you worked full- and/or part-time as a licensed pharmacist?

13. In total, how many years have you worked full- and/or part-time in your current area of specialty or practice focus?

14. Indicate your PRIMARY reason for seeking board certification.

15. Indicate a SECONDARY reason for seeking board certification.

16. List Pharmacy organizations to which you belong.

Additionally the respondents were asked to respond to twenty-five different sets of two questions or statements. These two set questions were divided into PVI groups (PVIGs). For each instrumentality response statement, the part "a" of the statements/questions (items) addressed the instrumentality related to that factor or aspect. This was the probability of that factor or aspect occurring as perceived by the respondent. Part "b" of the item set was related to the value (valence) an individual held for that particular aspect. The item sets were numbered and had a part "a" and "b" to reduce confusion. They were organized in such a way that, except for question 26 and higher, each was a set involving an instrumentality question (probability of occurrence) and valence (value) component, in that order.

High instrumentality does not indicate high valence and low instrumentality does not indicate low valence. The opposite may well be true. 


\section{Instrumentation}

The survey instrument titled "Advanced Certification Index for Pharmacists" (ACI-P) which was developed for this study records three primary response types within the context of the design. All responses were answered using a Likert type five-point scale with the lower end identified as "Will definitely not occur" and the upper end identified as "Will definitely occur" on the instrumentality (perceived probability) questions. The value (valence) questions had a scale with the lower end identified as "No value" and the upper end as "Highly valuable". Each lower end was treated statistically as a " 1 " and each upper end was treated as a " 5 ". Both scales had an identified neutral point. The utilization of these scales shaped the VIE theorybased instrument into a non-zero environment, which means that zeros, which can cause problems with the calculations, were eliminated. Also, since it was posited that the absolute value of the VIE calculation had no true definition or baseline, relative metrics were more important. By using a non-zero scale and using the whole numbers of the 5-point scale a useful scoring methodology was employed.

With all demographics and ACI-P specific questions the total number of items was sixty-seven $(16+51=67)$. This was a lengthy survey but could be completed in about 15 minutes utilizing the on-line/internet format. Demographic questions were included at the end of the survey to prevent possible survey fatigue from interfering with the most needed responses from the instrumentality and valence sections.

The ACI-P was modified to fit an internet-only approach. This is discussed in more detail below under Internet Survey. 


\section{The instructions for the ACI-P Survey Tool were listed on page one of the}

\section{web survey tool. They read:}

This survey seeks your opinions on the factors that may influence a pharmacist's decision to seek board certification in a Pharmacy specialty. The survey should take no more than 15 minutes.

Your input is important whether you have no intention of pursuing board certification in Pharmacy practice, intend to pursue in the future, have already completed the certification or were previously board certified.

This survey is based on two components of each factor that may be related to pursuit of specialty certification in Pharmacy practice. These components are: 1) the probability of occurrence as you perceive it, and 2) the value of that particular factor.

Definitions:

For the probability of occurrence (the first part of each question) the scale is a measure of perceived probability with the lower end "Will not occur" being the lowest probability of occurrence and "Will definitely occur" being the highest.

For the value assessment, the lower end value of "No value" means the lowest value to you as a pharmacist and "Highly valuable" means the highest value to you. Please check the corresponding bubble for each selection.

All questions are related to pursuit and achievement of board certification in Pharmacy by the Board of Pharmaceutical Specialties. An asterisk (*) next to a question means a response is required and only applies to the first 26 questions."

Additional Information:

There are 16 demographic questions at the end of the survey that will be used in comparing this information with what has been collected by the Board of Pharmaceutical Specialties in previous surveys.

This study has been approved by the University of Tennessee Institutional Review Board. There is no consequence for refusing to take the survey or any direct benefit to you other than professional value to Pharmacy in general. Your identity will not be disclosed and no relational information regarding your demographics information will be attempted. The scope of this study is to characterize aggregate trends and not those of an individual. Summary data only will be made available to Pharmacy organizations. The results of this survey may be presented at a professional meeting, become published or become part of a Ph.D. dissertation.

Consent for Participation:

This survey is voluntary. By proceeding with this survey I consent to participate.

The questions on the survey were arranged so that each value (valence)

question was listed at the same time on the computer screen with the instrumentality

(perceived probability of occurrence). These were the Perceived Valence 
Instrumentality groups (PVIGs) described above and were important considerations for data evaluation. Some value questions were so basic to the human condition that it was expected that most of the responses would be on the high end. However others were expected to have considerable variance. Not aligning the benefits to the pharmacist with highly regarded values could be problematic and where they do not align was an important finding of the study. For this reason one variable within the PVIG analysis was the result of subtracting the instrumentality from the value.

The questions were designed based on a priori proposed domains. These four proposed domains were professional, personal, career and financial with the understanding that the lines of distinction between these were not clearly defined and that these domains may not have existed as separate constructs. Item to domain relationships were proposed and are listed in Table 3-2. The domains were not equally represented by numbers of items and career and financial aspects were the two most highly represented of the domains. It was thought that these may be more influential and more items were added in these sections to more fully characterize these elements.

Item sets were arranged with specific Perceived Value Instrumentality groups. The PVI groups and survey questions are listed below. The Perceived Valence Instrumentality groups are helpful to understand some discussions in Chapter 4. The PVI group headings are listed with the designated item group as follows: 
Table 3-2. Proposed Domains of ACI-P, Questions within Domains and Percentages of Total

\begin{tabular}{lcc}
\hline Domain & Item Sets & Percentage of Total \\
\hline Professional & $4,5,11,16,24$ & $5 / 25=20 \%$ \\
Personal & $1,10,17,18,23$ & $5 / 25=20 \%$ \\
Career & $2,6,7,8,13,19,22,25$ & $8 / 25=32 \%$ \\
Financial & $3,9,12,14,15,20,21$ & $7 / 25=28 \%$ \\
Expectancy & 26 & N/A \\
\hline
\end{tabular}


1. Self image

a. My self image will be improved by becoming board certified.

b. I value my self image.

2. Employable

a. I would become more employable if I were board certified.

b. I value becoming more employable.

3. Higher salary

a. I will receive a higher annual salary if I am board certified.

b. I value a higher annual salary

4. Professional opportunities

a. My professional opportunities will improve with board certification.

b. I value professional opportunities.

5. Peer respect

a. I will have increased peer respect by becoming board certified.

b. I value peer respect.

6. Career advancement

a. My career will be positively advanced by becoming board certified.

b. I value career advancement.

7. Academic opportunities

a. My academic opportunities will improve if I am board certified.

b. I value academic opportunities.

8. Downsizing protection 
a. In a workplace that is downsizing, board certification will protect my job

b. I value a protective effect from downsizing.

9. Initial costs

a. My initial certification costs will be paid by my employer.

b. I value my initial certification costs being paid by my employer.

10. Credibility

a. Board certification credentials will add credibility to my opinions.

b. I value credentials to improve my credibility.

11. Professional respect (Colleagues)

a. Other practitioners within my profession will respect my board certification status.

b. I value professional respect from my colleagues.

12. Annual salary increases

a. If I am board certified I will receive higher annual salary increases.

b. I value higher annual salary increases.

13. Hiring influence

a. I would hire a board certified practitioner over another non-board certified practitioner with otherwise equal qualifications.

b. I value board certification enough to positively influence a hiring decision between candidates with otherwise equal qualifications.

14. Financial incentive to SEEK board certification 
a. Increased financial incentive from my employer would cause me to SEEK board certification status.

b. I value a financial incentive from my employer based on SEEKING board certification.

15. Financial incentive to MAINTAIN board certification

a. Increased financial incentive from my employer would cause me to MAINTAIN board certification.

b. I value a financial incentive from my employer to MAINTAIN board certification status.

16. Non-professional co-workers' respect

a. Non-professional co-workers will respect board certification status.

b. I value non-professional co-workers respect of board certification status.

17. Practice skills confidence

a. I will have increased confidence in my practice skills as a result of being board certified.

b. I value increased confidence in my practice skills.

18. Personal accomplishment

a. I will feel a sense of personal accomplishment by becoming board certified.

b. I value personal accomplishment demonstrated by a board certification credential.

19. Increased responsibility 
a. I will have increased responsibility in my job role after becoming board certified.

b. I value increased responsibility in my job role.

20. One time bonus

a. I will receive a one time pay bonus upon completion of board certification.

b. I value a one time pay bonus for completion of board certification.

21. Paid certification costs

a. My recertification costs will be paid by my employer.

b. I value that my employer would pay my recertification costs.

22. Promotion potential

a. I will be more likely to be promoted by my employer by employer if I am board certified.

b. I value promotions based on board certification.

23. Public notification

a. There would be a public notification of my achievement and status if I become board certified.

b. I value a public notification of my achievement and status.

24. Improved professional network

a. I would have an improved professional network by becoming board certified.

b. I value an improved professional network.

25. Job requirement 
a. Board certification will become necessary for my job.

b. I value that my job will require board certification.

The following information was included as directions preceding Question 26 Expectation.

"This section is based on your opinion of the likelihood of completion of board certification upon expenditure of the effort. If you have no intention of pursuing board certification in a Pharmacy practice specialty please answer question 26.a. Please answer N/A as needed.

26. Expectancy

c.I am NOT currently board certified but I feel that if I expended the effort I would successfully complete the board certification process.

d. I AM currently board certified and PRIOR TO BEGINNING preparation for specialty certification I felt that if I expended the effort I would successfully complete the requirements for board certification.

e.I WAS formerly board certified and PRIOR TO BEGINNING preparation for specialty certification I felt that if I expended the effort I would successfully complete the requirements for board certification."

\section{$\underline{\text { Delphi Panel-Pilot Study }}$}

The ACI-P was presented to and evaluated by a Delphi panel-pilot study to establish face and content validity. This panel was made up of the faculty at the University of Tennessee College of Pharmacy and other faculty associated with the University of Tennessee College of Pharmacy. There were twenty one respondents to 
the survey. Eleven respondents were currently board certified, eight were never board certified and two were previously board certified. No material changes were made but two minor wording changes were made to the ACI-P survey instrument as a result of the pilot study. The survey was deployed with an understanding that face and content validity was established.

\section{$\underline{\text { Study Procedures }}$}

\section{Subject Identification}

All pharmacists in the United States, whether board certified by BPS or not, were subjects for this research. Since the survey was an internet based instrument, access was limited by access to computers and the internet. Internet connection speed may have also been a limiting factor for subjects. Pharmacy organizations, particularly the Board of Pharmaceutical Specialties, American Society of HealthSystem Pharmacists, American Pharmacists Association, American College of Clinical Pharmacy and the American Association of Colleges of Pharmacy were engaged by the investigator and encouraged to distribute the hyperlinks for the survey site. Hyperlinks are imbedded computer codes that allow a user to activate those links, which are uniform resource locators (URLs), by mouse or keyboard and be immediately directed to a location which is defined by the link. See Appendix B to view requests for participation and agreements to participate by the five participating organizations. 


\section{Internet Survey}

Enrollment was open and voluntary. At no time were the respondents asked their name or any personal questions other than demographics. No tracking of the location of the respondents was done and communication of the anonymity measures of the survey information was included in survey instructions. The survey was completed by internet at the respondent's convenience. The automated approach may have made the number of questions less intimidating as the length of the survey was long but unknown to the participants at the outset. The design and completion of the survey was completed by using the internet survey tools available at SurveyMonkey.com. ${ }^{86}$

\section{$\underline{\text { Data Analysis }}$}

Data collected for the study included:

A. Responses for items of the Advanced Certification Index for Pharmacists (ACI-P) as previously described.

B. Demographics based on previous BPS surveys were collected. This was for comparison purposes to previous studies and was not a primary endpoint of the study.

Data were analyzed via standard statistical analysis which included Student's t-tests, correlational analysis, exploratory factor analysis, parallel axis analysis, and

internal consistency and reliability measures. Validation of the survey constructs of the ACI-P instrument was completed with factor analysis and verified with parallel 
analysis utilizing SAS. Reliability of the ACI-P constructs were established with the Cronbach's alpha reliability coefficient utilizing SAS. ${ }^{87}$

There were at a minimum six extreme subsets of the data predicted as far as Instrumentality (Probability of occurrence) and Valence (Value):

a. High instrumentality $\mathrm{x}$ high value (sum of the products)

b. High instrumentality $\mathrm{x}$ low value (sum of the products)

c. Low instrumentality $\mathrm{x}$ high value (sum of the products)

d. Low instrumentality $\mathrm{x}$ low value (sum of the products)

e. Ambivalent instrumentality $\mathrm{x}$ ambivalent value (sum of the products

f. Large differences in value minus instrumentality (difference)

These of course could each be subdivided by various demographic differences to achieve other subsets of the data. Most of the findings fell between these extremes.

The VIE calculation, minus the "E" part since it was the same value for any individual respondent, became the Valence x Instrumentality score or the VI Score (VIS). Perceived Value Instrumentality groups (PVI groups or PVIGs) provided four different responses, two of which were directly reported and two of which were calculated. Using "Self Image" as an example the following four variables were seen:

- Selfimage_P Probability (instrumentality). This was directly reported.

- Selfimage_V Value to the individual. This was directly reported.

- Selfimage_VIS Instrumentality x value (VIS). This was calculated.

- Selfimage_Diff Value-instrumentality. This was calculated. 
The intent of the study was not to prove or disprove VIE theory but rather to compare groups to determine if there were differences in instrumentalities and valences, as well as expectations, between practicing and qualified pharmacists that were board certified and those that were not. The mathematical model of VIE provided a framework to evaluate multiple and interactive forces and perceptions simultaneously. Comparing currently board certified and non-board certified pharmacists with these various mathematical findings, based on the VIE model, demonstrated motivational factors and calculated motivational force for both groups.

\section{Consideration of Human Subjects}

This study was designed to determine the motivational forces leading certain health care professionals, in this case pharmacists, to seek specialty certification in their practice area. It was based on perceptions of benefits and beliefs of the respondents. Since establishing forces leading to an unrealized or not yet attained goal was too complex, a comparison of motivational force and motivating factors between board certified and non-board certified pharmacists was completed. Participating pharmacists were asked to provide information anonymously via an internet portal. Participation in the study by the pharmacists was voluntary. Exempt status was requested and granted by the University of Tennessee Institutional Review Board. 


\section{Chapter 4. Results and Findings}

\section{Survey Mechanics and Data Collection}

The Advanced Certification Index for Pharmacists (ACI-P) was deployed via electronic mail and webpage notification by four Pharmacy organizations and the Board of Pharmaceutical Specialties in the summer of 2007. The intent was to begin the survey on June 1, 2007 and leave it open for entry until the sample size projections needed were met or for a total of six weeks. Due to some issues with several of the organizations' communication systems, deployment was uneven and sporadic at the outset. Information about the importance, need and a request for participation was put forth by APhA, ASHP, ACCP, AACP and BPS. It was likely, and was intended, that this combined effort contributed to a good survey response. The collaboration and cooperation of these five organizations contributed considerably to both the numbers of respondents, as well as to a good cross section of various practitioner types and comparably matched ages and genders.

The first survey response was received at 5:38 PM on June 5, 2007 and the last survey was received at 8:23 AM on August 7, 2007. The survey was left open longer than the anticipated six weeks due to the slower than expected beginning date for several of the organizations and because the continued daily receipt rate was high. Total time open was 62 days and 15 hours.

In all, 2,274 pharmacists began the survey. Of those, 2,129 completed all of the 25 PVIG sets for a completion percentage of $93.7 \%$. The question regarding expectancy (question number 26) was apparently unclear as 2,095 of the 2,129 
(98.4\%) responded to the question but some answered all, or several, of the options. Recoding on this variable required manually comparing the data to demographic questions, or to other markers, to determine status of the pharmacist. Those that could not be positively identified as to board certification status were omitted from the research data set. A total of 2,057 of 2,129 completed surveys were retained for the research data representing a clean data rate of $96.6 \%$ of those completing all questions and $90.5 \%$ of those initiating the survey (See Table 4-1). All VIE calculations were based on the data set of 2,057 complete surveys. This data set was comprised of 496 (24.1\%) non-board certified pharmacists and 1,561 (75.9\%) board certified pharmacists (See Table 4-2). Responses from both groups were in excess of the calculated 395 per group sample size needed for statistical significance.

\section{$\underline{\text { Demographics }}$}

The demographic questions were optional and $1,940(94.3 \%$ of 2,057$)$ completed at least the gender question and $1,924(93.5 \%$ of 2,057$)$ completed the age question. There were 1,924 (93.5\%) respondents that answered both the age and gender questions ( $\mathrm{A}+\mathrm{G}$ respondents). The differences in age between genders in the sample population were significantly different with the mean of the female participants at 42.3 (SD 10.6) and the male participant mean of 37.9 (SD 8.5). The demographic statistics of gender and age are depicted in Table 4-3 and Table 4-4.

There was less variance in the age of the board certified pharmacists group which may have been due to the larger number of those pharmacists responding. The 
Table 4-1. Distribution of Pharmacist Respondents to 2007 ACI-P Survey

\begin{tabular}{lcc}
\hline Status & Number & \% of Began Survey \\
\hline Began Survey & 2,274 & $100 \%$ \\
Completed Survey & 2,129 & $93.7 \%$ \\
Retained Survey Dataset & 2,057 & $90.5 \%$ \\
\hline
\end{tabular}

ACI-P = Advanced Certification Index for Pharmacists

Table 4-2. Distribution of Retained Pharmacist Respondents from 2007 ACI-P Survey

\begin{tabular}{lcc}
\hline Sample & Number & $\begin{array}{c}\text { \% of Retained } \\
\text { Responses }\end{array}$ \\
\hline Non-Board Certified Pharmacists & 496 & $24.1 \%$ \\
Board Certified Pharmacists & 1,561 & $75.9 \%$ \\
Retained Pharmacist Respondents & 2,057 & $100 \%$ \\
\hline
\end{tabular}

ACI-P $=$ Advanced Certification Index for Pharmacists 
Table 4-3. Demographics of Respondent Sample in Retained Survey Dataset from 2007 ACI-P $(N=1924$ for Age + Gender $[\mathrm{A}+\mathrm{G}])$

\begin{tabular}{lccccc}
\hline Respondents & Number & $\%$ & Mean Age & SD & $95 \%$ CI \\
\hline Male & 1,176 & 61.1 & 37.9 & 8.5 & $37.4-38.4$ \\
$\begin{array}{l}\text { Female } \\
\text { Total }\end{array}$ & 748 & 38.9 & 42.3 & 10.6 & $41.5-43.0$ \\
$\begin{array}{l}\text { Age/Gender) } \\
\mathrm{p} \text { value M } \\
\text { Age/F Age }\end{array}$ & 1,924 & 100 & 39.6 & 9.6 & $39.2-40.0$ \\
\hline
\end{tabular}

Table 4-4. Respondent Groups by Age, Certification Status and Gender $(N=1,924$ for Age + Gender $[\mathrm{A}+\mathrm{G}]$ )

\begin{tabular}{lcccc}
\hline & $\begin{array}{c}\text { BCP } \\
\text { Male }\end{array}$ & $\begin{array}{c}\text { BCP } \\
\text { Female }\end{array}$ & $\begin{array}{c}\text { NONBCP } \\
\text { Male }\end{array}$ & $\begin{array}{c}\text { NONBCP } \\
\text { Female }\end{array}$ \\
\hline Number (\%) & $\begin{array}{c}892 \\
(46.4 \%)\end{array}$ & $\begin{array}{c}569 \\
(29.6 \%)\end{array}$ & $\begin{array}{c}284 \\
(14.8 \%)\end{array}$ & $\begin{array}{c}179 \\
\text { Mean Age }\end{array}$ \\
Std Dev & 38.2 & 42.0 & 37.2 & 43.1 \\
95\% CI & 8.3 & 9.7 & 9.0 & 13.0 \\
Age range & $37.7-38.7$ & $41.2-42.8$ & $36-38.2$ & $42.5-43.7$ \\
\hline
\end{tabular}

$\mathrm{BCP}=$ Board Certified pharmacists, NONBCP $=$ Non-Board certified pharmacists 
range for non-board certified pharmacists was 22 to 80 and for the board certified pharmacists the age range was 25 to 69 . There were no significant differences in the male and female subsets for the non-board certified pharmacists and the board certified pharmacists. However, there were differences among age by gender segments. The overall age mean for all respondents was 39.6 (SD 9.6, 95\% CI 39.2 40.0). Male respondents had a mean age of 37.9 (SD 8.5, 95\% CI $37.4-38.4$ ) and female respondents had a mean age of 42.3 (SD 10.6, 95\% CI $41.5-43.0$ ). These were significantly different and are depicted in Table 4-3.

The means for the ages, plus standard deviations were 39.4 (SD 11.1) for the total non-board certified pharmacists and 39.7 (SD 9.0) for the total board certified pharmacists. These were not statistically different $(t=-0.49, \mathrm{p}>0.63)$. The nonboard certified pharmacists had 284 male respondents (14.8\% of A+ G respondents) and 179 female respondents (9.3\% of $\mathrm{A}+\mathrm{G}$ respondents). The board certified pharmacists had 992 male respondents (46.4\% of A+ G respondents) and 569 female respondents (29.6\% of $\mathrm{A}+\mathrm{G}$ respondents). Table $4-4$ depicts segmentation of the pharmacists that answered both the age and gender questions on the ACI-P demographic section.

Within gender groups, ages were significantly different for males in the nonboard certified and board certified groups with means of 38.2 years of age (95\% CI 37.7 - 38.7] for NONBCP and 37.2 years ( $95 \%$ CI $36-38.2)$. The female comparison showed the NONBCP with a mean age of $43.1(95 \%$ CI $42.5-43.7)$ and 42 (95\% CI $41.2-42.8)$. These ages were significantly different between groups for female pharmacists. Although these groups were statistically different they were very 
close from a practical standpoint. The two male sub-groups were within 1 year of age and the two female sub-groups were within 1 year of each other and the confidence intervals were very close.

Other demographic responses were somewhat sporadic. In addition to the 16 demographic questions, a single comment question regarding the pharmacists' opinion of board certification in general was asked and 331 of the 2,274 (14.6\%) responded. The final retained dataset contained 324 of 2,057 (15.7\%) additional comment responses. Despite the relatively low response rate this provided some interesting viewpoints on pharmacists' perceptions of the current board certification process and their opinions of its status. The response rate may actually have been acceptable or appropriate considering it was the last of 67 questions and required free text entry. A full analysis of this separate data set was beyond the scope of this study but a categorical stratification of the data was completed and a total of 620 separate findings were categorized into 12 groupings. These are discussed at the end of this chapter.

The cleaned dataset was large at 6 megabytes ( 1 megabyte is about the amount of information in the text of a 600 page paperback book in the most efficient storage method). The primary and master data table was comprised of 2,057 data rows and 120 columns of information related to the VIE components (directly reported and calculated) which was 246,840 individual data elements. In addition, there were 53 columns of additional demographic information. This was a rich dataset that may be useful for future research. 
Use of the five-point Likert scales for the survey instrument presented some options for using a standard survey scale and adapting to the Expectancy Valence model (VIE) format. In the classic sense of the VIE model there can be zero values for value, instrumentality or expectancy. The purposes of this study were not to determine an actual or "real" value of motivation or to create a benchmark of value. It was to determine how a given set of Perceived Valence Instrumentality group components compared. For this reason, the five-point Likert scales with 1 being lowest and 5 being highest, were used for both populations and the usual use of a decimal equivalent was not necessary since the numbers were used for comparison only. By observing these two conventions, the zero effect on the product of the calculations in VIE was eliminated and a direct measure of statistics compared to the ACI-P methodology was made.

Utilizing this model, the lowest score that could be made on the ACI-P was 25 ( 1 for all valences, 1 for all instrumentalities [25 total for VIS] and 1 for expectancy, and the highest score was 3125 ( 5 for all valences, 5 for all instrumentalities [625 total for VIS] and 5 for expectancy).

The following were the PVI groups (each of which had four associated variables) that are addressed in the data tables to follow. Using the example discussed previously these basic variables exist within each PVIG:

- Selfimage_P Probability (instrumentality). This was directly reported.

- Selfimage_V Value to the individual. This was directly reported.

- Selfimage_VIS Instrumentality x value (VIS). This was calculated. 
- Selfimage_Diff Value-instrumentality. This was calculated.

These were the PVI group names:

1. Self image

2. Employable

3. Higher salary

4. Professional opportunities

5. Peer respect

6. Career advancement

7. Academic opportunities

8. Downsizing protection

9. Initial costs

10. Credibility

11. Professional respect (Colleagues)

12. Annual salary increases

13. Hiring influence

14. Financial incentive to SEEK board certification

15. Financial incentive to MAINTAIN board certification

16. Non-professional co-workers' respect

17. Practice skills confidence

18. Personal accomplishment

19. Increased responsibility

20. One time bonus

21. Paid certification costs 


\section{Promotion potential}

23. Public notification

24. Improved professional network

25. Job requirement

Expectancy responses were re-coded into two variables due to apparent complexities with the question based on some respondent's actions. The first of these was $\boldsymbol{A M} \_\boldsymbol{B} \boldsymbol{C}$ which had a binary classification of "Y" for yes if the respondent was currently board certified and an "N" if they were not. The second variable was $\operatorname{Exp}$ (expectancy) for the numerical value $(1-5)$ reported on the survey section on Question 26. Despite problems with some persons understanding the question, only 72 responses $(3.4 \%)$ were lost due to inability to confirm the expectancy value.

\section{Instrumentality}

Table 4-5 lists findings from the survey instrumentality questions in the order of the PVIG group listings on the ACI-P survey. In general, the board certified pharmacists had a higher perception that rewards would occur than did the non-board certified pharmacists and 20 of $25(80 \%)$ were different statistically at a significance level of $p<0.05$. The instrumentality differences were seen at the highest level for eight questions. These all had statistically significant differences between means demonstrated by a t-score lower than negative 7.0 and a $p$ of $<0.0001$. These eight question response differences are listed in descending order based on t values:

a. I would hire a board certified practitioner over another non-board certified practitioner with otherwise equal qualifications. 
Table 4-5. Differences in Instrumentalities, $(S D)$, between Board Certified (BCP) and Non-Board Certified Pharmacists (NONBCP)

\begin{tabular}{|c|c|c|c|c|c|}
\hline Instrumentality Item & $\begin{array}{l}\text { Non-Board } \\
\text { Certified } \\
\text { (SD) }\end{array}$ & $\begin{array}{l}\text { Board } \\
\text { Certified } \\
\text { (SD) }\end{array}$ & $\begin{array}{c}\text { NONBCP } \\
\text { minus } \\
\text { BCP } \\
\text { difference }\end{array}$ & $t$ value & $\begin{array}{l}\mathrm{p} \text { two- } \\
\text { tailed }\end{array}$ \\
\hline $\begin{array}{l}\text { My self image will be improved } \\
\text { by becoming board certified. }\end{array}$ & $\begin{array}{c}3.43 \\
(1.25)\end{array}$ & $\begin{array}{c}4.02 \\
(0.92)\end{array}$ & -0.59 & -9.74 & $<.0001 *$ \\
\hline $\begin{array}{l}\text { I would become more employable } \\
\text { if I were board certified. }\end{array}$ & $\begin{array}{l}3.07 \\
(1.13)\end{array}$ & $\begin{array}{c}3.7 \\
(0.93)\end{array}$ & -0.63 & -11.16 & $<.0001 *$ \\
\hline $\begin{array}{l}\text { I will receive a higher annual } \\
\text { salary if I am board certified. }\end{array}$ & $\begin{array}{l}2.55 \\
(1.09)\end{array}$ & $\begin{array}{l}2.61 \\
(1.14)\end{array}$ & -0.06 & -1.1 & 0.27 \\
\hline $\begin{array}{l}\text { My professional opportunities } \\
\text { will improve with board } \\
\text { certification. }\end{array}$ & $\begin{array}{l}3.28 \\
(1.16)\end{array}$ & $\begin{array}{c}3.7 \\
(0.93)\end{array}$ & -0.42 & -7.35 & $<.0001^{*}$ \\
\hline $\begin{array}{l}\text { I will have increased peer respect } \\
\text { by becoming board certified. }\end{array}$ & $\begin{array}{c}3.52 \\
(1.04)\end{array}$ & $\begin{array}{c}3.93 \\
(0.83)\end{array}$ & -0.41 & -9.0 & $<.0001 *$ \\
\hline $\begin{array}{l}\text { My career will be positively } \\
\text { advanced by becoming board } \\
\text { certified. }\end{array}$ & $\begin{array}{l}3.21 \\
(1.16)\end{array}$ & $\begin{array}{l}3.56 \\
(0.97)\end{array}$ & -0.35 & -6.16 & $<.0001 *$ \\
\hline $\begin{array}{l}\text { My academic opportunities will } \\
\text { improve if I am board certified. }\end{array}$ & $\begin{array}{l}3.23 \\
(1.16)\end{array}$ & $\begin{array}{l}3.44 \\
(1.0)\end{array}$ & -0.21 & -3.87 & $<.0001 *$ \\
\hline $\begin{array}{l}\text { In a workplace that is downsizing, } \\
\text { board certification will protect my } \\
\text { job. }\end{array}$ & $\begin{array}{c}2.61 \\
(1.03)\end{array}$ & $\begin{array}{l}2.76 \\
(0.96)\end{array}$ & -0.15 & -3.02 & $<.0001 *$ \\
\hline $\begin{array}{l}\text { My initial certification costs will } \\
\text { be paid by my employer. }\end{array}$ & $\begin{array}{l}2.38 \\
(1.32)\end{array}$ & $\begin{array}{c}2.92 \\
(1.68)\end{array}$ & -0.54 & -7.47 & $<.0001 *$ \\
\hline $\begin{array}{l}\text { Board certification credentials } \\
\text { will add credibility to my } \\
\text { opinions. }\end{array}$ & $\begin{array}{c}3.3 \\
(1.13)\end{array}$ & $\begin{array}{c}3.52 \\
(0.98)\end{array}$ & -0.22 & -3.92 & $<.0001^{*}$ \\
\hline $\begin{array}{l}\text { Other practitioners within my } \\
\text { profession will respect my board } \\
\text { certification status. }\end{array}$ & $\begin{array}{l}3.57 \\
(0.97)\end{array}$ & $\begin{array}{l}3.87 \\
(0.82)\end{array}$ & -0.3 & -6.27 & $<.0001^{*}$ \\
\hline $\begin{array}{l}\text { If I am board certified I will } \\
\text { receive higher annual salary } \\
\text { increases. }\end{array}$ & $\begin{array}{l}2.33 \\
(1.0)\end{array}$ & $\begin{array}{c}2.14 \\
(0.96)\end{array}$ & 0.19 & 3.79 & $0.002 *$ \\
\hline
\end{tabular}

*=Statistically Significant 
Table 4-5. Continued.

\begin{tabular}{|c|c|c|c|c|c|}
\hline Instrumentality Item & $\begin{array}{l}\text { Non-Board } \\
\text { Certified } \\
\text { (SD) }\end{array}$ & $\begin{array}{l}\text { Board } \\
\text { Certified } \\
\quad(S D)\end{array}$ & $\begin{array}{l}\text { NONBCP } \\
\text { minus } \\
\text { BCP } \\
\text { difference }\end{array}$ & $t$ value & $\begin{array}{l}\mathrm{p} \text { two- } \\
\text { tailed }\end{array}$ \\
\hline $\begin{array}{l}\text { I would hire a board certified } \\
\text { practitioner over another non- } \\
\text { board practitioner with otherwise } \\
\text { equal qualifications. }\end{array}$ & $\begin{array}{l}3.32 \\
(1.1)\end{array}$ & $\begin{array}{l}3.93 \\
(0.85)\end{array}$ & -0.61 & -11.28 & $<.0001 *$ \\
\hline $\begin{array}{l}\text { Increased financial incentive from } \\
\text { my employer would cause me to } \\
\text { SEEK board certification status. }\end{array}$ & $\begin{array}{c}3.54 \\
(1.18)\end{array}$ & $\begin{array}{l}3.65 \\
(1.14)\end{array}$ & -0.11 & -1.98 & $0.049 *$ \\
\hline $\begin{array}{l}\text { Increased financial incentive from } \\
\text { my employer would cause me to } \\
\text { MAINTAIN board certification. }\end{array}$ & $\begin{array}{c}3.8 \\
(1.09)\end{array}$ & $\begin{array}{c}3.84 \\
(1.17)\end{array}$ & -0.04 & -0.67 & 0.50 \\
\hline $\begin{array}{l}\text { Non-professional co-workers will } \\
\text { respect board certification status. }\end{array}$ & $\begin{array}{c}2.64 \\
(1.08)\end{array}$ & $\begin{array}{c}2.7 \\
(0.99)\end{array}$ & -0.06 & -1.09 & 0.27 \\
\hline $\begin{array}{l}\text { I will have increased confidence } \\
\text { in my practice skills as a result of } \\
\text { being board certified. }\end{array}$ & $\begin{array}{c}3.43 \\
(1.23)\end{array}$ & $\begin{array}{c}3.59 \\
(1.08)\end{array}$ & -0.16 & -2.58 & $0.01 *$ \\
\hline $\begin{array}{l}\text { I will feel a sense of personal } \\
\text { accomplishment by becoming } \\
\text { board certified. }\end{array}$ & $\begin{array}{l}4.24 \\
(1.0)\end{array}$ & $\begin{array}{l}4.66 \\
(0.6)\end{array}$ & -0.42 & -8.94 & $<.0001^{*}$ \\
\hline $\begin{array}{l}\text { I will have increased } \\
\text { responsibility in my job role after } \\
\text { becoming board certified. }\end{array}$ & $\begin{array}{c}2.64 \\
(1.18)\end{array}$ & $\begin{array}{c}2.72 \\
(1.12)\end{array}$ & -0.08 & -1.37 & 0.17 \\
\hline $\begin{array}{l}\text { I will receive a one time pay } \\
\text { bonus upon completion of board } \\
\text { certification. }\end{array}$ & $\begin{array}{l}1.88 \\
(0.98)\end{array}$ & $\begin{array}{l}1.75 \\
(1.1)\end{array}$ & 0.13 & 2.56 & $0.01 *$ \\
\hline $\begin{array}{l}\text { My recertification costs will be } \\
\text { paid by my employer. }\end{array}$ & $\begin{array}{l}2.12 \\
(1.09)\end{array}$ & $\begin{array}{c}2.32 \\
(1.43)\end{array}$ & -0.2 & -3.22 & $0.001 *$ \\
\hline $\begin{array}{l}\text { I will be more likely to be } \\
\text { promoted by my employer if I am } \\
\text { board certified. }\end{array}$ & $\begin{array}{l}2.57 \\
(1.09)\end{array}$ & $\begin{array}{c}2.68 \\
(1.08)\end{array}$ & -0.11 & -1.91 & 0.056 \\
\hline $\begin{array}{l}\text { There would be a public } \\
\text { notification of my achievement } \\
\text { and status if I become board } \\
\text { certified. }\end{array}$ & $\begin{array}{l}2.72 \\
(1.14)\end{array}$ & $\begin{array}{c}2.2 \\
(1.31)\end{array}$ & -0.2 & -3.35 & $0.001 *$ \\
\hline $\begin{array}{l}\text { I would have an improved } \\
\text { professional network by } \\
\text { becoming board certified. }\end{array}$ & $\begin{array}{l}3.09 \\
(1.07)\end{array}$ & $\begin{array}{l}3.24 \\
(1.05)\end{array}$ & -0.15 & -2.86 & $0.003 *$ \\
\hline $\begin{array}{l}\text { Board certification will become } \\
\text { necessary for my job. }\end{array}$ & $\begin{array}{c}2.42 \\
(1.07)\end{array}$ & $\begin{array}{c}2.83 \\
(1.18)\end{array}$ & -0.41 & -7 & $<.0001^{*}$ \\
\hline
\end{tabular}

*=Statistically Significant 
b. I would become more employable if I were board certified.

c. My self image will be improved by becoming board certified.

d. I will have increased peer respect by becoming board certified.

e. I will feel a sense of personal accomplishment by becoming board certified.

f. My initial certification costs will be paid by my employer.

g. My professional opportunities will improve with board certification.

h. Board certification will become necessary for my job.

For this particular group of comparative instrumentalities there was a more pronounced difference than in the others. As noted, 20 of 25 (80\%) of the instrumentality comparisons demonstrated statistically significant differences. The group identified in the list above, however, may have more practical relevance since they have a much larger degree of difference.

In five of the questions the instrumentalities reported by the BCP's were about the same as those listed by the NONBCP group due to no statistically significant differences.

This group is listed below (mean ranges in parentheses):

i. Increased financial incentive from my employer would cause me to MAINTAIN board certification (Both about 3.8).

j. I will receive a higher annual salary if I am board certified (Both about 2.6).

k. Non-professional co-workers will respect my board certification status (Both about 2.7).

1. I will have increased responsibility in my job after becoming board certified (Both about 2.7). 
m. I will be more likely to be promoted by my employer if I am board certified (both about 2.6).

Four of these items had values for both groups below 3.0. As a result, both groups perceived instrumentalities lower than the mid-point ( 3 on the 5 point scale). Although the responses were not very different statistically, the findings in the four below 3 were on the negative side of the scale. In other words, despite that fact that they did not differ very much between groups, the overall perception of these instrumentalities was negative in both groups.

The question regarding an increased employer financial incentive to maintain board certification had a relatively high score from both groups indicating that this was an area of high perception of instrumentality.

Since all the responses captured on the instrumentality questions were able to be summed, the accumulated overall instrumentality was compared. This is an important concept as the products of all instrumentality multiplied by the valences are accumulated and summed in the VIE equation. The mean for the accumulated nonboard certified pharmacists (NONBCP) instrumentalities was 74.9 (95\% CI 73.6 76.5) compared to the mean for the board certified pharmacists (BCP) of 81.0 (95\% CI $80.3-81.7)$ so overall this group scored at a neutral or near midpoint range. The NONBCP and BCP groups were significantly different $(\mathrm{t}=-6.9, p<0.0001)$.

A neutral accumulated instrumentality score would have been 75 (25 questions $\mathrm{x} 3$; on the 1-5 scale) and the highest attainable accumulated score would have been 125 ( $25 \times 5$; on the $1-5$ scale). Both groups were closer to the midpoint 
than to the higher end and the NONBCP group was essentially neutral at 74.9 compared to an actual midpoint of 75 .

Similarly, taking a mean of the means for the instrumentalities shows the mean of all for the accumulated non-board certified pharmacists (NONBCP) instrumentalities at $3.0(95 \%$ CI $2.93-3.06)$ compared to the instrumentality mean for the board certified pharmacists of 3.24 (95\% CI $3.21-3.27)$. These were significantly different $(\mathrm{t}=-6.9 ; \mathrm{p}<0.0001)$.

Even though the BCP group was just slightly higher than the NONBCP group, both groups were very near neutral, or near the midpoint, in their instrumentality. Their general impression that there would be a reward for effort put forth for board certification was nearly ambivalent.

In the VIE equation, scores calculated from the instrumentality questions would likely have had a neutral or negative pull on the calculations. However, the values that were on the extremes of the instrumentality scores may have had a greater overall effect since they were not neutral. The eleven statistically significant differences in means demonstrated that, in this large survey population, they were indeed different statistically but perhaps not to a degree that made them actually practically relevant. Final determination of that position was examined by evaluating the differences in value and instrumentality (VI_Diff) and the products of the value and instrumentality scores (VIS). 


\section{Valence}

Findings from the valence (value) questions and the differences between nonboard certified pharmacists and board certified pharmacists are displayed in Table 46. In general, 23 of $25(92 \%)$ of board certified pharmacists had a higher perception of value (valence) than did the non-board certified pharmacists and these were significantly different. The valence differences were seen at the highest level for four questions. These all had practically and statistically significant differences between means demonstrated by a t-score lower than negative 7.0 and a $p$ of $<0.0001$.

These four item responses are listed in descending order from the most difference noted:

1. I value that my job will require board certification.

2. I value board certification enough to positively influence a hiring decision.

3. I value personal accomplishment demonstrated by a board certification.

4. I value promotions based on board certification.

For this particular group of comparative valences there was a more pronounced difference than in the others. As noted, 23 of $25(92 \%)$ of the valence comparisons demonstrated statistically significant differences, but the group identified in the list above may have had more relevance since they had a much larger degree of difference.

In three of the questions, the valences reported by the BCP's were about the same as those listed by the NONBCPs, i.e. they were not statistically different. This group was, in order of descending from highest to lowest: 
Table 4-6. Differences in Valences, (SD), between Board Certified (BCP) and NonBoard Certified Pharmacists (NONBCP)

\begin{tabular}{|c|c|c|c|c|c|}
\hline Valence Question/Statement & $\begin{array}{l}\text { Non-Board } \\
\text { Certified } \\
\text { (SD) }\end{array}$ & $\begin{array}{l}\text { Board } \\
\text { Certified } \\
(S D)\end{array}$ & $\begin{array}{l}\text { NONBCP } \\
\text { minus BCP } \\
\text { difference }\end{array}$ & $t$ value & $\begin{array}{l}\mathrm{p} \text { two- } \\
\text { tailed }\end{array}$ \\
\hline I value my self image. & $\begin{array}{c}4.59 \\
(0.66)\end{array}$ & $\begin{array}{c}4.58 \\
(0.63)\end{array}$ & 0.01 & 0.22 & 0.83 \\
\hline $\begin{array}{l}\text { I value becoming more } \\
\text { employable. }\end{array}$ & $\begin{array}{c}4.39 \\
(0.89)\end{array}$ & $\begin{array}{c}4.64 \\
(0.64)\end{array}$ & -0.25 & -5.75 & $<.0001^{*}$ \\
\hline I value a higher annual salary. & $\begin{array}{c}4.32 \\
(0.85)\end{array}$ & $\begin{array}{c}4.44 \\
(0.77)\end{array}$ & -0.12 & -2.9 & $0.004 *$ \\
\hline I value professional opportunities. & $\begin{array}{l}4.55 \\
(0.67)\end{array}$ & $\begin{array}{l}4.65 \\
(0.57)\end{array}$ & -0.1 & -2.8 & $0.005^{*}$ \\
\hline I value peer respect. & $\begin{array}{c}4.22 \\
(0.84)\end{array}$ & $\begin{array}{c}4.39 \\
(0.74)\end{array}$ & -0.17 & -3.96 & $<.0001^{*}$ \\
\hline I value career advancement. & $\begin{array}{c}4.36 \\
(0.83)\end{array}$ & $\begin{array}{c}4.51 \\
(0.68)\end{array}$ & -0.15 & -3.42 & $0.0007^{*}$ \\
\hline I value academic opportunities. & $\begin{array}{c}3.7 \\
(1.13)\end{array}$ & $\begin{array}{c}3.8 \\
(1.03)\end{array}$ & -0.1 & -3.87 & $0.0001^{*}$ \\
\hline $\begin{array}{l}\text { I value a protective effect from } \\
\text { downsizing. }\end{array}$ & $\begin{array}{c}4.1 \\
(0.99)\end{array}$ & $\begin{array}{l}4.26 \\
(0.92)\end{array}$ & -0.16 & -3.02 & $0.0026^{*}$ \\
\hline $\begin{array}{l}\text { I value my initial certification } \\
\text { costs being paid by my employer. }\end{array}$ & $\begin{array}{c}3.94 \\
(1.22)\end{array}$ & $\begin{array}{l}4.07 \\
(1.1)\end{array}$ & -0.13 & -2.38 & $0.0175^{*}$ \\
\hline $\begin{array}{l}\text { I value credentials to improve my } \\
\text { credibility. }\end{array}$ & $\begin{array}{c}3.99 \\
(0.99)\end{array}$ & $\begin{array}{c}4.13 \\
(0.93)\end{array}$ & -0.14 & -3.07 & $0.0022 *$ \\
\hline $\begin{array}{l}\text { I value professional respect from } \\
\text { my colleagues. }\end{array}$ & $\begin{array}{l}4.27 \\
(0.79)\end{array}$ & $\begin{array}{c}4.39 \\
(0.69)\end{array}$ & -0.12 & -3.01 & $0.0027 *$ \\
\hline $\begin{array}{l}\text { I value higher annual salary } \\
\text { increases. }\end{array}$ & $\begin{array}{c}4.28 \\
(0.86)\end{array}$ & $\begin{array}{l}4.37 \\
(0.79)\end{array}$ & -0.09 & -2.05 & $0.0406^{*}$ \\
\hline $\begin{array}{l}\text { I value board certification enough } \\
\text { to positively influence a hiring } \\
\text { decision between candidates with } \\
\text { otherwise equal qualifications. }\end{array}$ & $\begin{array}{c}3.48 \\
(1.13)\end{array}$ & $\begin{array}{l}4.05 \\
(0.87)\end{array}$ & -0.57 & -10.3 & $<.0001^{*}$ \\
\hline $\begin{array}{l}\text { I value a financial incentive from } \\
\text { my employer based on SEEKING } \\
\text { board certification. }\end{array}$ & $\begin{array}{l}3.73 \\
(1.13)\end{array}$ & $\begin{array}{l}3.93 \\
(1.03)\end{array}$ & -0.2 & -3.5 & $0.0005^{*}$ \\
\hline
\end{tabular}

\section{*Statistically Significant}


Table 4.6. Continued

\begin{tabular}{|c|c|c|c|c|c|}
\hline Valence Question/Statement & $\begin{array}{l}\text { Non-Board } \\
\text { Certified } \\
(S D)\end{array}$ & $\begin{array}{c}\text { Board } \\
\text { Certified } \\
(S D)\end{array}$ & $\begin{array}{c}\text { NONBCP } \\
\text { minus BCP } \\
\text { difference }\end{array}$ & $t$ value & $\begin{array}{l}\mathrm{p} \text { two- } \\
\text { tailed }\end{array}$ \\
\hline $\begin{array}{l}\text { I value a financial incentive from } \\
\text { my employer to MAINTAIN } \\
\text { board certification status. }\end{array}$ & $\begin{array}{l}3.93 \\
(1.04)\end{array}$ & $\begin{array}{c}4.14 \\
(0.96)\end{array}$ & -0.21 & -4.19 & $<.0001^{*}$ \\
\hline $\begin{array}{l}\text { I value a non-professional co- } \\
\text { workers' respect of board } \\
\text { certification status. }\end{array}$ & $\begin{array}{c}3.12 \\
(1.15)\end{array}$ & $\begin{array}{c}3.27 \\
(1.08)\end{array}$ & -0.15 & -2.76 & $0.0058^{*}$ \\
\hline $\begin{array}{l}\text { I value increased confidence in } \\
\text { my practice skills. }\end{array}$ & $\begin{array}{l}4.42 \\
(0.79)\end{array}$ & $\begin{array}{l}4.47 \\
(0.69)\end{array}$ & -0.05 & -1.26 & 0.2082 \\
\hline $\begin{array}{l}\text { I value personal accomplishment } \\
\text { demonstrated by a board } \\
\text { certification credential. }\end{array}$ & $\begin{array}{c}4.19 \\
(1.02)\end{array}$ & $\begin{array}{l}4.55 \\
(0.72)\end{array}$ & -0.36 & -7.31 & $<.0001^{*}$ \\
\hline $\begin{array}{l}\text { I value increased responsibility in } \\
\text { my job role. }\end{array}$ & $\begin{array}{l}3.75 \\
(0.99)\end{array}$ & $\begin{array}{l}3.85 \\
(0.91)\end{array}$ & -0.1 & -1.98 & $0.0482 *$ \\
\hline $\begin{array}{l}\text { I value a one time pay bonus for } \\
\text { completion of board certification. }\end{array}$ & $\begin{array}{l}3.4 \\
(1.27)\end{array}$ & $\begin{array}{c}3.62 \\
(1.24)\end{array}$ & -0.22 & -3.45 & $0.0006^{*}$ \\
\hline $\begin{array}{l}\text { I value that my employer would } \\
\text { pay for my recertification costs. }\end{array}$ & $\begin{array}{l}3.76 \\
(1.19)\end{array}$ & $\begin{array}{l}4.08 \\
(1.06)\end{array}$ & -0.32 & -5.45 & $<.0001 *$ \\
\hline $\begin{array}{l}\text { I value promotions based on board } \\
\text { certification. }\end{array}$ & $\begin{array}{l}3.2 \\
(1.22)\end{array}$ & $\begin{array}{c}3.64 \\
(1.06)\end{array}$ & -0.44 & -7.05 & $<.0001 *$ \\
\hline $\begin{array}{l}\text { I value a public notification of my } \\
\text { achievement and status. }\end{array}$ & $\begin{array}{c}2.84 \\
(1.24)\end{array}$ & $\begin{array}{c}3.05 \\
(1.18)\end{array}$ & -0.21 & -3.48 & $0.0005^{*}$ \\
\hline $\begin{array}{l}\text { I value an improved professional } \\
\text { network. }\end{array}$ & $\begin{array}{c}3.87 \\
(1.01)\end{array}$ & $\begin{array}{l}3.93 \\
(0.9)\end{array}$ & -0.06 & -1.33 & 0.1827 \\
\hline $\begin{array}{l}\text { I value that my job will require } \\
\text { board certification. }\end{array}$ & $\begin{array}{c}2.59 \\
(1.19)\end{array}$ & $\begin{array}{c}3.27 \\
(1.16)\end{array}$ & -0.68 & -11.42 & $<.0001^{*}$ \\
\hline
\end{tabular}

*Statistically Significant 
a. I value my self image.

b. I value increased confidence in my practice skills.

c. I value an improved professional network.

All three of these questions had responses above 3.8; placing values attributed to all three issues higher than the mid-point ( 3 on the 5 point scale). Although these responses are not very different statistically, the findings in the three above 3.8 are on the positive side of the scale. In other words, despite that fact that they don't differ very much, the overall perceptions of these valences were positive in both groups.

Since all the responses captured on the valence items could be summed, the accumulated overall valence was compared. As noted in the instrumentality section, this is an important concept as the products of all instrumentality multiplied by the valences are accumulated and summed in the VIE equation. The mean of all for the accumulated non-board certified pharmacists (NONBCP) instrumentalities was 97.1 (95\% CI 95.8 to 98.4 ) compared to the mean for the board certified pharmacists (BCP) of 102.2 (95\% CI 101 to 103). Overall, this group scored in the positive range although they were significantly different $(\mathrm{t}=-7.1, p<0.0001)$.

A neutral accumulated valence score would have been 75 (25 questions x 3; on the 1-5 scale) and the highest attainable accumulated score would have been 125 ( $25 \times 5$; on the $1-5$ scale). Both groups were on the higher end with the NONBCP group at 95.8 compared to 75 (higher than neutral,) and the BCP group was 102.2 compared to 75 (higher than neutral).

Similarly, taking a mean of the means for the valences shows the mean of all for the accumulated non-board certified pharmacists (NONBCP) instrumentalities at 
3.9 (95\% CI of 3.8 to 3.95) compared to the valence mean for the board certified pharmacists (BCP) of 4.09 (95\% CI of 4.06 to 4.11). These were different and statistically significant.

The BCP group was slightly higher but both groups were on the positive side of the scale for valence, i.e. their general impression of values for these questions were relatively high.

In the VIE equation, scores calculated for the valence scores would have had a positive pull on the calculations, i.e. since they were above neutral they would have contributed more to the products since they were of a higher value. Final determination of that position was examined by evaluating the differences in value and instrumentality (V_Diff) and the products of the value and instrumentality scores (VIS). Extremes of differences on either end of the scales may have had a pronounced affect on overall variance on the factor model.

\section{Valence Minus Instrumentality (VI Diff)}

Valence is the same as value. This comparison evaluates the valence or value item within a PVI group against the instrumentality item by subtracting the instrumentality from the valence. During the literature search and design of the survey instrument (ACI-P) it was considered that the product of instrumentality and valence, as defined in the VIE equation, would produce useable results. Additionally, it was considered that if certain PVI groups showed larger differences than others it could be a beneficial addition to the evaluation of these PVIGs. To accomplish this comparison each respondent's instrumentality score was subtracted 
from each valence score to achieve a difference score known as VI_Diff $(\mathrm{V}-\mathrm{I}=$ VI_Diff). This was done for each PVI group and the scores were summed. The comparison of the instrumentality and valence tables demonstrated that this further evaluation was worth examining as the overall valence responses were higher than the instrumentality responses.

The point of examining the VI_Diff calculations was to look for extremes where board certified pharmacists may have had much higher values compared to instrumentalities and to evaluate areas where the inverse was true. Table 4-7 lists the VI_Diff means, standard deviations, t-test values and the probability (two-tailed $p$ ) values for each. The probability values indicate that 13 of 25 (52\%) did not differ statistically. Therefore the differences in valence and instrumentality were about the same for both groups. Within this group, five of the PVI group overall responses had at least one mean value (in one of the VI_Diff measures) greater than 0.9 , or nearly one full level of response higher for the valence than the instrumentality. These represented a higher level of perception of values versus what may have been the reward (instrumentality).

The five PVI groups that were not significant, but interesting were:
a. Paid recertification costs
b. Higher salary
c. Downsizing protection
d. Increased responsibility
e. Practice skills confidence 
Table 4-7. Differences in Valences Minus Instrumentality Scores (V_Diff), (SD), between Board Certified (BCP) and Non-Board Certified Pharmacists (NONBCP)

\begin{tabular}{|c|c|c|c|c|c|}
\hline PVI Groups (VI_Diff) & $\begin{array}{l}\text { Non-Board } \\
\text { Certified } \\
(S D)\end{array}$ & $\begin{array}{c}\text { Board } \\
\text { Certified } \\
(S D)\end{array}$ & $\begin{array}{l}\text { NONBCP } \\
\text { minus BCP } \\
\text { difference }\end{array}$ & $t$ value & $\begin{array}{l}\mathrm{p} \text { two- } \\
\text { tailed }\end{array}$ \\
\hline Self Image & $\begin{array}{l}1.16 \\
(1.43)\end{array}$ & $\begin{array}{c}0.56 \\
(0.99)\end{array}$ & 0.6 & 8.7 & $<.0001 *$ \\
\hline Employable & $\begin{array}{c}1.32 \\
(1.22)\end{array}$ & $\begin{array}{c}0.94 \\
(0.99)\end{array}$ & 0.38 & 6.31 & $<.0001^{*}$ \\
\hline Higher Salary & $\begin{array}{c}1.77 \\
(1.34)\end{array}$ & $\begin{array}{l}1.83 \\
(1.3)\end{array}$ & -0.06 & -0.8 & 0.42 \\
\hline Professional Opportunities & $\begin{array}{l}1.28 \\
(1.23)\end{array}$ & $\begin{array}{c}0.95 \\
(0.96)\end{array}$ & 0.33 & 5.43 & $<.0001^{*}$ \\
\hline Peer Respect & $\begin{array}{c}0.71 \\
(1.13)\end{array}$ & $\begin{array}{c}0.46 \\
(0.87)\end{array}$ & 0.25 & 4.45 & $<.0001 *$ \\
\hline Career Advancement & $\begin{array}{l}1.16 \\
(1.21)\end{array}$ & $\begin{array}{l}0.95 \\
(1.0)\end{array}$ & 0.21 & 3.94 & $<.0001 *$ \\
\hline Academic Opportunities & $\begin{array}{l}0.47 \\
(1.5)\end{array}$ & $\begin{array}{c}0.37 \\
(1.17)\end{array}$ & 0.1 & 1.36 & 0.17 \\
\hline Downsizing Protection & $\begin{array}{l}1.56 \\
(1.29)\end{array}$ & $\begin{array}{l}1.53 \\
(1.2)\end{array}$ & 0.03 & 0.28 & 0.778 \\
\hline Initial Costs & $\begin{array}{l}1.55 \\
(1.63)\end{array}$ & $\begin{array}{l}1.15 \\
(1.69)\end{array}$ & 0.4 & 4.72 & $<.0001 *$ \\
\hline Credibility & $\begin{array}{c}0.69 \\
(1.14)\end{array}$ & $\begin{array}{c}0.62 \\
(0.95)\end{array}$ & 0.07 & 1.26 & 0.2066 \\
\hline Professional Respect & $\begin{array}{c}0.7 \\
(1.07)\end{array}$ & $\begin{array}{c}0.52 \\
(0.89)\end{array}$ & 0.18 & 3.43 & $0.0006^{*}$ \\
\hline Annual Salary Increase & $\begin{array}{l}1.96 \\
(1.3)\end{array}$ & $\begin{array}{c}2.23 \\
(1.25)\end{array}$ & -0.27 & -4.23 & $<.0001 *$ \\
\hline Hiring Influence & $\begin{array}{c}0.15 \\
(0.77)\end{array}$ & $\begin{array}{c}0.12 \\
(0.59)\end{array}$ & 0.03 & 1.01 & 0.3143 \\
\hline $\begin{array}{l}\text { Financial Incentive to SEEK } \\
\text { Board Certification }\end{array}$ & $\begin{array}{c}0.2 \\
(1.06)\end{array}$ & $\begin{array}{c}0.28 \\
(0.93)\end{array}$ & -0.08 & -1.56 & 0.1206 \\
\hline
\end{tabular}

*=Statistically Significant 
Table 4-7. Continued.

\begin{tabular}{|c|c|c|c|c|c|}
\hline PVI Groups (VI_Diff) & $\begin{array}{l}\text { Non-Board } \\
\text { Certified } \\
(S D)\end{array}$ & $\begin{array}{c}\text { Board } \\
\text { Certified } \\
(S D)\end{array}$ & $\begin{array}{l}\text { NONBCP } \\
\text { minus BCP } \\
\text { difference }\end{array}$ & $t$ value & $\begin{array}{l}\mathrm{p} \text { two- } \\
\text { tailed }\end{array}$ \\
\hline $\begin{array}{l}\text { Financial Incentive to } \\
\text { MAINTAIN Board Certification }\end{array}$ & $\begin{array}{c}0.13 \\
(0.92)\end{array}$ & $\begin{array}{c}0.3 \\
(1.02)\end{array}$ & -0.17 & -3.35 & $0.0008^{*}$ \\
\hline Non-Professional Respect & $\begin{array}{l}0.48 \\
(1.1)\end{array}$ & $\begin{array}{c}0.58 \\
(1.06)\end{array}$ & -0.1 & -1.79 & 0.0735 \\
\hline Practice Skills Confidence & $\begin{array}{c}0.99 \\
(1.22)\end{array}$ & $\begin{array}{l}0.88 \\
(1.0)\end{array}$ & 0.11 & 1.8 & 0.0725 \\
\hline Personal Accomplishment & $\begin{array}{l}-0.05 \\
(0.82)\end{array}$ & $\begin{array}{l}-0.11 \\
(0.52)\end{array}$ & 0.06 & 1.59 & 0.1135 \\
\hline Increased Responsibility & $\begin{array}{l}1.11 \\
(1.3)\end{array}$ & $\begin{array}{c}1.13 \\
(1.16)\end{array}$ & -0.02 & -0.24 & 0.8137 \\
\hline One Time Bonus & $\begin{array}{l}1.52 \\
(1.5)\end{array}$ & $\begin{array}{l}1.87 \\
(1.5)\end{array}$ & -0.35 & -4.61 & $<.0001^{*}$ \\
\hline Paid Recertification Costs & $\begin{array}{c}1.64 \\
(1.46)\end{array}$ & $\begin{array}{c}1.77 \\
(1.53)\end{array}$ & -0.13 & -1.68 & 0.0929 \\
\hline Promotion Potential & $\begin{array}{c}0.64 \\
(1.24)\end{array}$ & $\begin{array}{c}0.96 \\
(1.19)\end{array}$ & -0.32 & -5.23 & $<.0001^{*}$ \\
\hline Public Notification & $\begin{array}{l}0.12 \\
(1.2)\end{array}$ & $\begin{array}{c}0.13 \\
(1.35)\end{array}$ & -0.01 & -0.18 & 0.8579 \\
\hline Improved Professional Network & $\begin{array}{c}0.78 \\
(1.15)\end{array}$ & $\begin{array}{c}0.69 \\
(0.97)\end{array}$ & 0.09 & 1.54 & 0.1246 \\
\hline Job Requirement & $\begin{array}{c}0.17 \\
(1.07)\end{array}$ & $\begin{array}{c}0.44 \\
(1.13)\end{array}$ & -0.27 & -4.75 & $<.0001 *$ \\
\hline
\end{tabular}

$*=$ Statistically Significant 
There were also two extreme findings on the VI-Diff scale where there were statistically different groups. These were where $\mathrm{BCP}$ responses were higher than NONBCP and where NONBCP responses were higher than BCP. The BCP higher than NONBCP VI_Diff statistically significant end of the responses showed four PVI groups. These, listed in order of greatest difference descending to lowest, were;
a. Promotion potential
b. Job requirement
c. One time bonus
d. Annual salary increase

All values were negative for this group. This means that the perceptions of value for the board certified pharmacists were higher compared to the non-board certified pharmacists.

On the other end of the scale for comparison within this group were the positive t-test values where the NONBCP scores were higher than the BCP. The following seven PVI groups showed areas where the non-board certified pharmacists had a higher difference in valence minus instrumentality (VI_Diff) responses than did the board certified pharmacists. These, listed in order of greatest t-test value difference descending to lowest, with difference in VI_Diff level noted in parentheses, are:
a. Self image (0.6)
b. Employability $(0.38)$
c. Professional opportunities $(0.33)$
d. Initial costs $(0.4)$ 
e. Peer respect $(0.25)$

f. Career advancement (0.21)

g. Professional respect $(0.18)$

Of this group, five had at least a VI_Diff mean greater than 0.9 in at least one of the groups. These were self image, employability, professional opportunities, initial costs, and career advancement.

The purpose of the VI_Diff evaluation was to further examine the differences seen on overall comparison of valences and instrumentalities in the preceding sections.

\section{Valence Times Instrumentality (VI Score)}

Using an Expectancy Valence (VIE) mathematical approach to development of a survey instrument had as a basis the position that the product of the instrumentalities and the valences (values) would be more representative of the actual propensity of motivational force than either of the independent item types or scales. Additionally, the accumulation of these products provided the opportunity to not have the selection of some factor on an extreme end of one of the scales of the findings overly influence interpretation. Thus far, a focus of the discussion has been on the areas where one overall propensity was noted for instrumentality, valence or the difference between valence and instrumentality. These are all worthwhile examinations and lend some credence to the argument for evaluating those sections of the PVI groupings. However, the most important of the four different components of 
the PVI groups, each of which consists of instrumentality, valence, VI_Diff and the product of the valence and instrumentality (VI_Score), was the latter.

The valence times instrumentality score (VI_Score) was derived by multiplying the PVI group valence by the instrumentality within that group. Each of the 25 PVI groups has a VI_Score. The advantage of using this variable for evaluation of components of motivational force, aside from the fact that it was the basis for the VIE mathematical model, was that it had the potential advantage of smoothing out extremes on either the valence or instrumentality scales and may be more representative of a more realistic measure of perception.

An examination of Table 4-8 demonstrates that 22 of 25 of the VI scores were different statistically and only one of 25 had a higher VIS for NONBCP than for BCP. The PVI group that showed a higher VIS mean for NONBCP was annual salary increase and it was statistically significant at $p<0.05$.

Evaluation of the instrumentality and valence responses demonstrated some interesting findings on extreme ends of each scale and also showed an overall tendency to be near a neutral point ( 3 on the 5 point scale) of instrumentality. However, the overall valence scores, although statistically different from each other as far as NONBCP and BCP, were nearer a 4 on the 5 point scale. The lower and higher means overall were used to establish some parameters for low and higher end VI Scores (VIS).

If we consider all the VIS means below a product of 9.0 ( 3 of 5 for instrumentality $\mathrm{x} 3$ of 5 for valence) to be in negative range, and all means with 
Table 4-8. Differences in Valences Times Instrumentality Scores (VI_Score), (SD), between Board Certified (BCP) and Non-Board Certified Pharmacists (NONBCP)

\begin{tabular}{|c|c|c|c|c|c|}
\hline PVI Groups (VI_Score) & $\begin{array}{l}\text { Non-Board } \\
\text { Certified } \\
(S D)\end{array}$ & $\begin{array}{c}\text { Board } \\
\text { Certified } \\
(S D)\end{array}$ & $\begin{array}{c}\text { NONBCP } \\
\text { minus BCP } \\
\text { difference }\end{array}$ & $t$ value & $\begin{array}{l}\mathrm{p} \text { two- } \\
\text { tailed }\end{array}$ \\
\hline Self Image & $\begin{array}{l}15.72 \\
(6.28)\end{array}$ & $\begin{array}{l}18.58 \\
(5.3)\end{array}$ & -2.86 & -9.99 & $<.0001 *$ \\
\hline Employable & $\begin{array}{l}13.78 \\
(6.25)\end{array}$ & $\begin{array}{c}17.3 \\
(5.25)\end{array}$ & -3.52 & -11.36 & $<.0001^{*}$ \\
\hline Higher Salary & $\begin{array}{l}11.09 \\
(5.49)\end{array}$ & $\begin{array}{l}11.72 \\
(5.78)\end{array}$ & -0.63 & -2.13 & $0.033^{*}$ \\
\hline Professional Opportunities & $\begin{array}{l}15.08 \\
(6.09)\end{array}$ & $\begin{array}{l}17.3 \\
(5.18)\end{array}$ & -2.22 & -7.43 & $<.0001^{*}$ \\
\hline Peer Respect & $\begin{array}{l}15.1 \\
(5.9)\end{array}$ & $\begin{array}{l}17.45 \\
(5.21)\end{array}$ & -2.35 & -7.94 & $<.0001^{*}$ \\
\hline Career Advancement & $\begin{array}{l}14.28 \\
(6.34)\end{array}$ & $\begin{array}{l}16.24 \\
(5.53)\end{array}$ & -1.96 & -6.19 & $<.0001^{*}$ \\
\hline Academic Opportunities & $\begin{array}{c}12.15 \\
(6.1)\end{array}$ & $\begin{array}{l}13.45 \\
(5.98)\end{array}$ & -1.3 & -4.22 & $<.0001^{*}$ \\
\hline Downsizing Protection & $\begin{array}{l}11.1 \\
(5.5)\end{array}$ & $\begin{array}{r}12.05 \\
(5.2)\end{array}$ & -0.95 & -3.53 & $0.0004 *$ \\
\hline Initial Costs & $\begin{array}{l}9.65 \\
(6.59)\end{array}$ & $\begin{array}{l}12.5 \\
(8.48)\end{array}$ & -2.85 & -7.83 & $<.0001^{*}$ \\
\hline Credibility & $\begin{array}{l}13.63 \\
(6.57)\end{array}$ & $\begin{array}{l}15.01 \\
(6.05)\end{array}$ & -1.38 & -4.34 & $<.0001^{*}$ \\
\hline Professional Respect & $\begin{array}{l}15.45 \\
(5.62)\end{array}$ & $\begin{array}{l}17.195 \\
(5.038)\end{array}$ & -1.745 & -6.16 & $<.0001^{*}$ \\
\hline Annual Salary Increase & $\begin{array}{c}10 \\
(4.94)\end{array}$ & $\begin{array}{l}9.33 \\
(4.63)\end{array}$ & 0.67 & 2.76 & $0.0058^{*}$ \\
\hline Hiring Influence & $\begin{array}{l}12.52 \\
(6.79)\end{array}$ & $\begin{array}{l}16.48 \\
(6.1)\end{array}$ & -3.96 & -11.6 & $<.0001^{*}$ \\
\hline $\begin{array}{l}\text { Financial Incentive to SEEK } \\
\text { Board Certification }\end{array}$ & $\begin{array}{l}13.99 \\
(7.16)\end{array}$ & $\begin{array}{l}15.12 \\
(6.96)\end{array}$ & -1.13 & -3.15 & $0.0017 *$ \\
\hline
\end{tabular}

VI_Score is the product of multiplying the valence score times the instrumentality score for each I group ${ }^{*}=$ Statistically significant. 
Table 4-8. Continued

\begin{tabular}{|c|c|c|c|c|c|}
\hline PVI Groups (VI_Score) & $\begin{array}{l}\text { Non-Board } \\
\text { Certified } \\
(S D)\end{array}$ & $\begin{array}{c}\text { Board } \\
\text { Certified } \\
(S D)\end{array}$ & $\begin{array}{c}\text { NONBCP } \\
\text { minus BCP } \\
\text { difference }\end{array}$ & $t$ value & $\begin{array}{l}\mathrm{p} \text { two- } \\
\text { tailed }\end{array}$ \\
\hline $\begin{array}{l}\text { Financial Incentive to } \\
\text { MAINTAIN Board Certification }\end{array}$ & $\begin{array}{l}15.65 \\
(6.97)\end{array}$ & $\begin{array}{l}16.5 \\
(7.07)\end{array}$ & -0.85 & -2.44 & $0.0146^{*}$ \\
\hline Non-Professional Respect & $\begin{array}{l}8.86 \\
(5.75)\end{array}$ & $\begin{array}{c}9.35 \\
(5.47)\end{array}$ & -0.49 & -1.7 & 0.0899 \\
\hline Practice Skills Confidence & $\begin{array}{l}15.49 \\
(6.73)\end{array}$ & $\begin{array}{l}16.37 \\
(6.14)\end{array}$ & -0.88 & -2.69 & $0.0072 *$ \\
\hline Personal Accomplishment & $\begin{array}{l}18.45 \\
(6.93)\end{array}$ & $\begin{array}{l}21.54 \\
(5.03)\end{array}$ & -3.09 & -9.18 & $<.0001^{*}$ \\
\hline Increased Responsibility & $\begin{array}{l}10.28 \\
(5.95)\end{array}$ & $\begin{array}{c}10.83 \\
(5.9)\end{array}$ & -0.55 & -1.83 & 0.0689 \\
\hline One Time Bonus & $\begin{array}{c}6.55 \\
(4.49)\end{array}$ & $\begin{array}{c}6.58 \\
(5.26)\end{array}$ & -0.03 & -0.1 & 0.9187 \\
\hline Paid Recertification Costs & $\begin{array}{c}8.2 \\
(5.33)\end{array}$ & $\begin{array}{c}9.88 \\
(7.22)\end{array}$ & -1.68 & -5.55 & $<.0001^{*}$ \\
\hline Promotion Potential & $\begin{array}{c}8.84 \\
(5.84)\end{array}$ & $\begin{array}{c}10.2 \\
(5.74)\end{array}$ & -1.36 & -4.57 & $<.0001^{*}$ \\
\hline Public Notification & $\begin{array}{c}8.38 \\
(5.97)\end{array}$ & $\begin{array}{c}9.55 \\
(6.52)\end{array}$ & -1.17 & -3.56 & $0.004 *$ \\
\hline Improved Professional Network & $\begin{array}{l}12.36 \\
(5.99)\end{array}$ & $\begin{array}{l}13.21 \\
(5.95)\end{array}$ & -0.85 & -2.78 & $0.0055^{*}$ \\
\hline Job Requirement & $\begin{array}{c}6.95 \\
(5.53)\end{array}$ & $\begin{array}{c}10 \\
(6.39)\end{array}$ & -3.05 & -10.28 & $<.0001 *$ \\
\hline
\end{tabular}

VI_Score is the product of multiplying the valence score times the instrumentality score for each I group $*=$ Statistically significant. 
product of 16.0 ( 4 of 5 for instrumentality and 4 of 5 for valence) to be in the positive range, as indicated by the valence scores, we can then examine more closely the two ends of the scale. However, regardless of how the scale extremes occur with the VI scores, each of the contributory VIS products were accumulated and summed in the VIE methodology. Therefore, even if many of the VIS products did not measure as being on the high or low end, they did accumulate to a summary score. Consequently each had some additive contribution to the final result.

There were a total of 6 of 25 (24\%) of the VI scores for PVI groups that had at least one mean (NONBCP or BCP) below 9.0 (i.e. negative). These were:
a. Job requirement
b. Paid certification costs
c. Promotion potential
d. Public notification
e. Non-professional respect $(p=0.09$, not significant $)$
f. One time bonus ( $p=0.9$, not significant)

Of these, only non-professional respect and one time bonus were not significantly different. But all of these VI score means fell into the negative range. Within the VIE calculation they made a contribution to the sums of all the VI scores but their impact was less than those that were more positive, i.e. above a 9.0 product. There were 10 of $25(40 \%)$ that had at least one VI score mean for either NONBCP or BCP above 16.0. All 10 of those were different statistically. These are, in descending order from highest difference of means to lowest difference (with NONBCP minus BCP differences noted in parentheses): 

a. Hiring influence (-3.96)
b. Employability $(-3.52)$
c. Self image (-2.86)
d. Personal accomplishment (-3.09)
e. Peer respect (-2.35)
f. Professional opportunities (-2.2)
g. Career advancement (-1.96)
h. Professional respect [colleagues] $(-1.75)$
i. Practice skills confidence $(-0.88)$
j. Financial incentive to MAINTAIN board certification (-0.85)
The more negative a number for a difference the more the BCP VI score means were higher than the NONBCP VI score means. These higher end composites, i.e. valence times instrumentality (VI scores), added more to the accumulated VIE equation.

An evaluation of the VI scores that may have had the most impact on the overall differences between NONBCP and BCP shows eight of $25(32 \%)$ that had ttest values lower than negative -0.7 . These are listed in decreasing order of impact, i.e. the most extreme difference as reflected by t-test value:
a. Hiring influence
b. Employability
c. Job requirement
d. Self image
e. Personal accomplishment 


\section{f. Peer respect}

g. Initial costs

h. Professional opportunities

These values represent the most variance between all the VI score means. It would be expected that after completion of the VIE calculation that this latter group would have contributed in a large way to the overall VIE motivational force determined.

Figure 4-1 shows a spatial diagram of where respective VI scores fell on the score range of 1 to 25 . Note that two midpoint responses of 3 for the instrumentality and 3 for the valence item would produce a product of 9.0 and this line is marked on the diagram.

\section{Force of Motivation}

Instrumentality, valence, the differences between valence and instrumentality (VI_Diff) and the product of instrumentality and valence (VIS) are all contributing factors to the force of motivation. Up to this point, certain contributory effects on the upper, middle and lower ends of the respective scales have been evaluated. The ultimate goal of this study was to not only determine the differences between instrumentality and valence but to also compare the overall force of motivation between non-board certified pharmacists and those that are board certified. To complete this goal the force of motivation was calculated by the VIE model using the ACI-P methodology. 


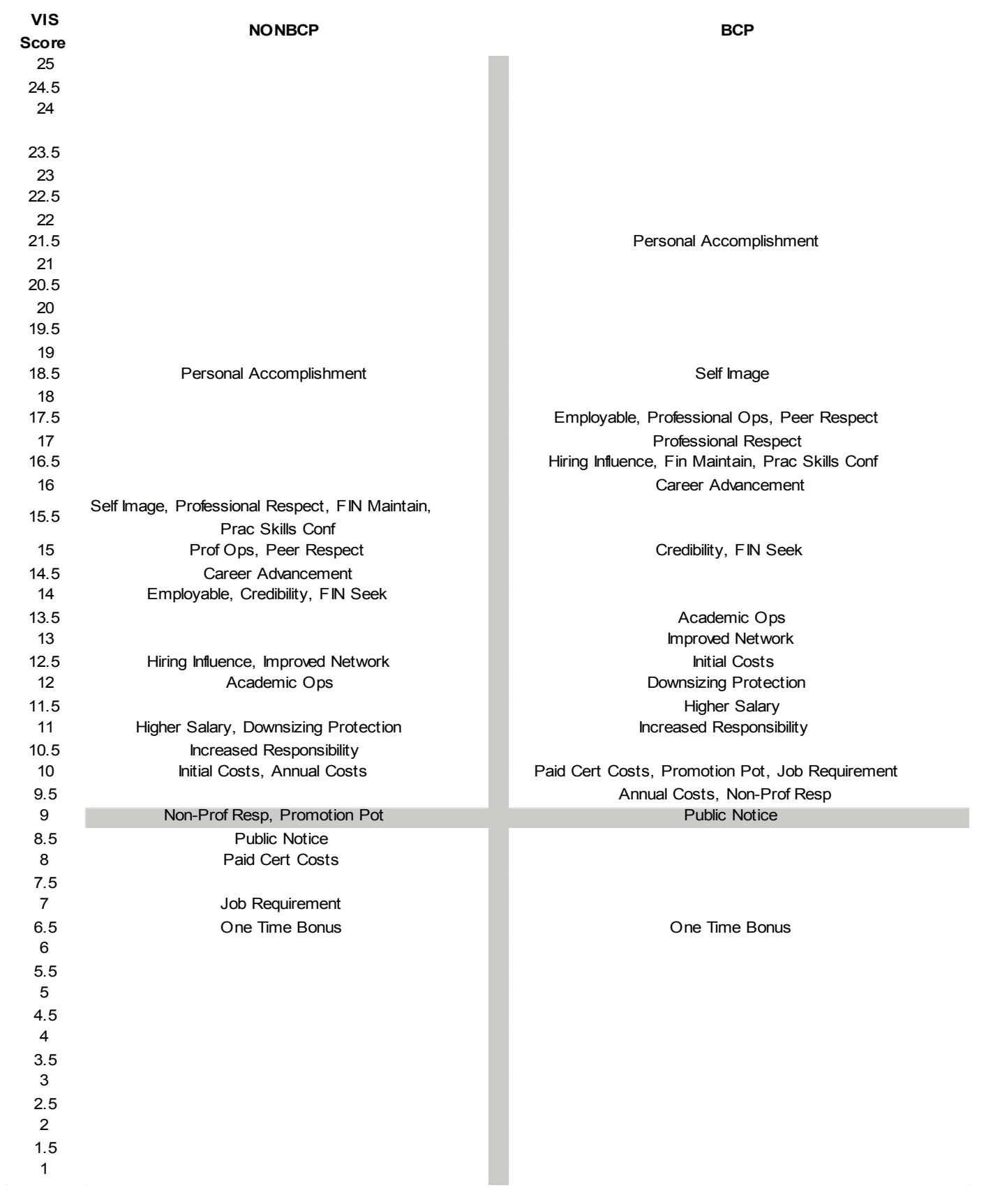

Figure 4-1. VIS Score Relative Values for Non-Board Certified and Board Certified Pharmacists from 2007 ACI-P Survey. VIS= Valence-timesInstrumentality score, ACI-P = Advanced Certification Index for Pharmacists. Midpoint is 9.0 . 
Table 4-9 examines the components needed to complete this final step of the calculation and to determine if there was a tipping point, i.e. a point where a prediction could be made as to whether a pharmacist was board certified or non-board certified. If so, that knowledge and methodology may be used to determine if a qualified pharmacist would have proper motivational force to pursue board certification.

Expectancy, as defined earlier, refers to the expectation, or anticipated chance of success of an effort leading to successful performance. In this case that would be the exertion of effort leading to achievement of the designation of board certified in a specialty by BPS. In the VIE equation it has a pivotal role in that it can contribute enough negative or positive influence to change the overall VIE motivational force (MF) outcome. For example:

a. If the summed VIS is a total of 400 , which would be a high score representing a response of 4 for an instrumentality and 4 for a response on valence and the multiplied to reach 16 and then those 16 scores were summed to make $25 \times 16=400$;

b. and there were two expectancy scores of 2 and 5;

c. the resultant products for the overall VIE calculation would be;

d. $2 \times 400=800$ for the low end of the expectancy (Exp) and;

e. $5 \times 400=2000$;

With the same high level of VIS, the resultant VIE (MF) score could be as much as $250 \%$ larger based on the expectancy contribution. There were examples of this type of occurrence in the survey findings just as there were examples where a 
Table 4-9. Differences in Expectancy, Sums of VIS and Motivational Force as Calculated by ACI-P, $(S D)$, between Board Certified (BCP) and NonBoard Certified Pharmacists (NONBCP)

\begin{tabular}{|c|c|c|c|c|c|}
\hline $\begin{array}{l}\text { Measures of ACI-P Scoring } \\
\text { Methodology }\end{array}$ & $\begin{array}{l}\text { Non-Board } \\
\text { Certified } \\
(S D)\end{array}$ & $\begin{array}{c}\text { Board } \\
\text { Certified } \\
(S D)\end{array}$ & $\begin{array}{l}\text { NONBCP } \\
\text { minus BCP } \\
\text { difference }\end{array}$ & $t$ value & $\begin{array}{l}\mathrm{p} \text { two- } \\
\text { tailed }\end{array}$ \\
\hline Expectancy & $\begin{array}{l}4.05 \\
(0.95)\end{array}$ & $\begin{array}{c}4.4 \\
(0.66)\end{array}$ & -0.35 & -9.16 & $<.0001^{*}$ \\
\hline $\begin{array}{l}\text { Sums of all Valence } \mathrm{x} \\
\text { Instrumentality Calculations }\end{array}$ & $\begin{array}{c}303.54 \\
(101)\end{array}$ & $\begin{array}{c}343.82 \\
(83)\end{array}$ & -40.28 & -8.03 & $<.0001 *$ \\
\hline $\begin{array}{l}\text { Motivational Force (MF) based } \\
\text { on ACI-P }\end{array}$ & $\begin{array}{c}1248.8 \\
(540)\end{array}$ & $\begin{array}{c}1521.0 \\
(457)\end{array}$ & -272.2 & 10.15 & $<.0001^{*}$ \\
\hline $\begin{array}{l}\text { Confidence Intervals (95\%) of } \\
\text { MF from ACI-P Score }\end{array}$ & $1201-1296$ & $1499-1544$ & & & \\
\hline
\end{tabular}

$*=$ Statistically Significant 
lower level of VIS, e.g. a neutral score of 3 for instrumentality times a 3 for valence across the board yielded a VIS low sum score, e.g. 225, but the expectation of success $(\operatorname{Exp}=5)$ was high and that yielded a relatively high VIE $(\mathrm{MF})$ score, e.g. $1125(225 \times 225=1125)$. These are very simple examples to demonstrate the effects of the Exp (expectancy) component of the VIE calculation. The VIS scores were much more complicated than what was demonstrated here and, since they were an accumulated (summed) result of 25 separate VI scores, the variance within those 25 separate PVI groups was considerable.

Table 4-9 depicts that there was a significant difference between the mean expectancy (Exp) for the NONBCP and the BCP. The NONBCP mean was 4.05 and the BCP mean was 4.4. The difference between these was -0.35 . The overall impact on the VIE, or motivational force (MF), calculations had a higher contribution by the board certified pharmacists than did the expectancy of the non-board certified pharmacists. So, in addition to being statistically significant the difference in these two means had a material impact on the final calculated MF.

Table 4-9 also shows a significant difference between the summed VI scores. The NONBCP mean was 303.5 and the BCP mean was 344 . The difference between these was -40.3 . The overall impact on the VIE (MF) calculations had a higher contribution by the board certified pharmacists than did the VI score accumulations (sums) of the non-board certified pharmacists. This shows that, in addition to being statistically significant, the difference in these two means had a material impact on the final calculated MF. 
The final calculated motivational force (MF) via the VIE calculation yielded a mean of 1249 (95\% CI 1201 - 1296) for NONBCP and a mean of $1521(95 \%$ CI $1499-1544)$. These were different statistically at a $p<0.0001$. The difference between the means was $-272(95 \%$ CI -321 to -224$)$.

There were significant differences in every measure of the VIE components throughout the data. In addition, these were material to the final calculation and there was a clear separation of the $95 \%$ confidence intervals for the calculated MF for NONBCP and BCP. Pharmacists scoring an ACI-P score on this survey between 1201 and 1206 were $95 \%$ of the time NONBCP. Pharmacists scoring an ACI-P score on this survey between 1499 and 1544 were $95 \%$ of the time BCP. There was a tipping point at approximately 1500 where a pharmacist would be likely to be a board certified pharmacist. At this point the ACI-P appears to be an accurate predictor of a pharmacist's board certification status. ACI-P scores are stratified by BCP and NONBCP and the scores are different between groups.

\section{$\underline{\text { Validity of Survey Instrument }}$}

Validity is a measure of the amount to which a survey instrument is actually measuring what it is intended to measure. There are different types of validity. One type is called face validity. This is the degree to which an instrument appears to measure a construct or what it is intended to measure. Face and content validity for the ACI-P was established by using a Delphi panel in a pilot survey prior to the primary research. 
Construct validity is a measure of how well a survey instrument measures a pre-defined or hypothesized pattern predicted by a model, theory or an a priori assumption. If the position of the research is to validate a structure, or constructs, then the comparison would be to determine if the predicted matched the actual and this would be performed by confirmatory factor analysis. Table 4-10 demonstrates the findings from the data on the four proposed domains, or constructs, from the ACIP. These were in fact established not to prove but as a basis for development of questions that had instrumentality and valence pairs within each of these domains. There were statistically significant differences in each of the four compared a priori domains.

These a priori domains were calculated by summing the instrumentality and valences products from each PVI group within the items that belonged to that domain. The relative values of each within the NONBCP or BCP groups were not pivotal and not very meaningful since they had different numbers of questions within that domain and therefore would have had different anticipated sum scores. The differences between the NONBCP and BCP groups are meaningful because they do have the same number of questions within each domain.

All four of the proposed domains do demonstrate a considerable difference. Therefore, as components of the overall VI scores, the items within each of these contributed in the same general direction, i.e. with the NONBCP lower on every measure than the BCP.

An exploratory factor analysis (EFA) was performed on the data to determine measurement constructs. The initial loading on the factors demonstrated a one factor 
Table 4-10. Differences in VIS for a priori Proposed Domains, $(S D)$, between Board Certified (BCP) and Non-Board Certified Pharmacists (NONBCP)

\begin{tabular}{|c|c|c|c|c|c|}
\hline VIS a priori Domains & $\begin{array}{l}\text { Non-Board } \\
\text { Certified } \\
\text { (SD) }\end{array}$ & $\begin{array}{l}\text { Board } \\
\text { Certified } \\
(S D)\end{array}$ & $\begin{array}{l}\text { NONBCP } \\
\text { minus BCP } \\
\text { difference }\end{array}$ & $t$ value & $\begin{array}{l}\mathrm{p} \text { two- } \\
\text { tailed }\end{array}$ \\
\hline VIS - Professional & $\begin{array}{l}66.85 \\
(23.6)\end{array}$ & $\begin{array}{l}74.5 \\
(20)\end{array}$ & -7.65 & -6.53 & $<.0001^{*}$ \\
\hline VIS - Personal & $\begin{array}{l}71.67 \\
(25.3)\end{array}$ & $\begin{array}{l}81.05 \\
(20.9)\end{array}$ & -9.38 & -7.47 & $<.0001^{*}$ \\
\hline VIS - Career & $\begin{array}{c}89.9 \\
(37.4)\end{array}$ & $\begin{array}{l}106.6 \\
(31.8)\end{array}$ & -16.7 & -8.97 & $<.0001^{*}$ \\
\hline VIS - Financial & $\begin{array}{l}75.14 \\
(27.6)\end{array}$ & $\begin{array}{c}81.7 \\
(27.9)\end{array}$ & -6.56 & -4.56 & $<.0001^{*}$ \\
\hline
\end{tabular}

*Statistically significant. 
solution, which is not uncommon. Rotating the PVI group elements using Varimax (orthogonal) rotation and evaluating the instrumentality, valence and VI scores demonstrated a possibility for a 2, 3 and 4 factor solution. If, as is customary, Eigenvalues below 1.0 were dropped, meaning that no factor was accounting for more variance than any single variable, and any factor that contained less than two variables were dropped, the solutions were simplified to either a 2 or 3 factor solution.

Since the intent of this research was to determine the applicability of the VIE model, and the expectancy (Exp, E) component is the same for any individual respondent, it was decided to use the VIS variables for the factor analysis. In all factor solutions there were four variables that factored together. These were all from the a priori domain called "Financial". The 3 factor solution from exploratory factor analysis was further examined with a parallel axis analysis and was simplified to a 2 factor solution as the third factor's Eigenvalue which was marginal did not meet criteria for inclusion. Table 4-11 shows the two factor solution, the factor loadings on each factor, and suggests names for the factors.

The two factor solution had a financial and an "other" factor. A two factor solution explained $45 \%$ of the variance which was reasonable considering that there were 25 variables.

It was expected that the explanatory abilities or "lines" between the proposed domains would not be clear. One particular variable, or PVI group, higher salary, which was proposed as existing in the financial domain did not load with any of the 
Table 4-11. Two Factor Solution from Factor Analysis and Parallel Axis, Analysis from ACI-P Survey Findings

\begin{tabular}{|c|c|c|c|}
\hline PVI Group Variable & $\begin{array}{l}\text { Factor } 1 \\
\text { Loading } \\
\text { (PCP) }\end{array}$ & $\begin{array}{c}\text { Factor } 2 \\
\text { Loading } \\
\text { (FS) }\end{array}$ & $\begin{array}{l}\text { a priori } \\
\text { domain }\end{array}$ \\
\hline Career Advancement & 0.7669 & 0.2118 & Career \\
\hline Professional Opportunities & 0.7658 & 0.1477 & Professional \\
\hline Peer Respect & 0.7621 & 0.1152 & Professional \\
\hline Respect of Clinical Colleagues & 0.7406 & 0.1008 & Professional \\
\hline Credibility & 0.7125 & 0.2551 & Personal \\
\hline Personal Accomplishment & 0.7114 & 0.1446 & Personal \\
\hline Employable & 0.7010 & 0.1735 & Career \\
\hline Increased Confidence in Skills & 0.6643 & 0.1266 & Personal \\
\hline Self Image & 0.6500 & 0.0925 & Personal \\
\hline Improved Professional Network & 0.6479 & 0.1708 & Professional \\
\hline Responsibility & 0.6366 & 0.2512 & Career \\
\hline Hire Board Certified Pharmacists & 0.6327 & 0.1722 & Career \\
\hline Academic Opportunities & 0.6065 & 0.1597 & Career \\
\hline Promotion Potential & 0.5958 & 0.4219 & Career \\
\hline Downsizing Protection & 0.5809 & 0.2808 & Career \\
\hline NON Prof Respect & 0.5538 & 0.2993 & Professional \\
\hline
\end{tabular}


Table 4-11. Continued.

\begin{tabular}{lccc}
\hline PVI Group Variable & $\begin{array}{c}\text { Factor 1 } \\
\text { Loading } \\
\text { (PCP) }\end{array}$ & $\begin{array}{c}\text { Factor } 2 \\
\text { Loading } \\
\text { (FS) }\end{array}$ & $\begin{array}{c}\text { a priori } \\
\text { domain }\end{array}$ \\
\hline Necessary for Job & 0.5155 & 0.2217 & Career \\
Public Notice of Completion & 0.4679 & 0.1708 & Personal \\
Higher Salary & 0.4539 & 0.3690 & Financial \\
Financial SEEK & 0.1970 & 0.6717 & Financial \\
Financial MAINTAIN & 0.2026 & 0.6592 & Financial \\
Recertification Costs Paid by Employer & 0.0316 & 0.6328 & Financial \\
Initial Costs Paid & 0.0422 & 0.5453 & Financial \\
One Time Bonus paid & 0.2251 & 0.5236 & Financial \\
Annual Salary Increase & & & Financial \\
\hline
\end{tabular}

Note: $\mathrm{PCP}=$ Professional, Career and Personal, FS=Financial Support, ACI$\mathrm{P}=$ Advanced Certification Index for Pharmacists, $\mathrm{PVI}=$ Perceived Valence Instrumentality. 
other financial factors and may have been regarded by pharmacists as a perception of work "worth" rather than a financial consideration. It was close to being a split factor loading but did meet the criteria for inclusion since the factor loading was $>0.4$. The two factor solution fit the survey findings.

These two constructs and number of PVI group variables associated with them were:

1. Professional, Career and Personal (PCP), 19 PVI groups

2. Financial Support (FS), 6 PVI groups

In both of the final factors, PCP and FS, the same general pattern was seen, i.e. the relative comparison of cumulative VI scores shows that the NONBCP scores (means) was between $87-92 \%$ of the $\mathrm{BCP}$. The PCP has the greatest difference where NONBCP was $87 \%$ of BCP group. The FS group was slightly closer with the NONBCP at $92 \%$ of the BCP group. Table 4-12 lists differences between NONBCP and $\mathrm{BCP}$ for the two factors.

\section{$\underline{\text { Reliability of Survey Instrument }}$}

The ACI-P is a survey instrument created specifically for this research. As such, it had not been evaluated for reliability. Reliability is essentially the extent to which a survey will provide the same results with repeated measurements or would this same test given in the future produce reliable results.

A method of the measurement of reliability for a survey instrument is

Cronbach's alpha ${ }^{83,87,88}$. There are three measures of reliability; they are stability, equivalence and consistency. Cronbach's coefficient alpha measures consistency. 
Table 4-12. PCP and FS Comparisons Derived with Parallel Axis Analysis from ACI-P Survey Findings, VI Scores (VIS) for Two Factor Solution (Sum of $\mathrm{V}^{*} \mathrm{I}$ per Domain)

\begin{tabular}{lccccc}
\hline Construct / Factor & $\begin{array}{c}\text { NOT } \\
\text { Board } \\
\text { Certified }\end{array}$ & $\begin{array}{c}\text { Board } \\
\text { Certified }\end{array}$ & Difference & $t$ value & $\begin{array}{c}\text { p two- } \\
\text { tailed }\end{array}$ \\
\hline VIS - Professional, & 239.49 & 273.86 & -34.37 & -8.21 & $<.0001^{*}$ \\
Career, Personal & $(84.8)$ & $(68.9)$ & & & \\
& & & & & \\
VIS - Financial Support & 64.05 & 69.96 & -5.91 & -4.57 & $<.0001^{*}$ \\
& $(24.3)$ & $(25.3)$ & & & \\
\hline
\end{tabular}

$\mathrm{PCP}=$ Professional, Career, and Personal, FS=Financial Support, VI=Valence times instrumentality, VIS $=$ Valence times instrumentality scores, ${ }^{*}=$ statistically significant 
This test is frequently the primary measure of estimating internal consistency with a test or survey instrument. ${ }^{88}$

The Cronbach's alpha reliability coefficient was computed using SAS on the measures of the ACI-P that were directly reported and not computed. These were the recorded responses for questions and were related to instrumentality and valence for the overall measures within each factor. Cronbach's alpha has not been confirmed to be accurate using two measures reported and then computed based on responses on a test or survey. The responses on the valence and instrumentality questions were used to compute the valence $\mathrm{x}$ instrumentality score (VIS) which was used for the primary factor analysis.

The value of raw versus standardized alpha coefficients is, at times, a point of contention so both values are supplied in Table 4-13. They were nearly the same to two decimal points in most of the alpha calculations. No questions from either the instrumentality or valence sections had to be removed to increase alpha.

There was no posited level of Cronbach's alpha that would be judged acceptable to establish reliability for this survey instrument. For the purposes of this research and for this instrument the questions existing in PVI groups are the most important aspect because neither of the individual scales (instrumentality or valence) is used alone and they are in fact presented in pairs on the ACI-P. The combined instrumentality plus valence values in Table 4-9 are the most important.

Table 4-13 lists the Cronbach's alpha for several measures. The standardized alpha for all was above the established baseline of an alpha of 0.7 , which is a commonly accepted conservative level. Reliability coefficients of 0.5 are acceptable 
Table 4-13. Reliability Calculated with Cronbach's Alpha for ACI-P Survey Instrument

\begin{tabular}{lcc}
\hline & $\begin{array}{c}\text { Alpha coefficient } \\
\text { (Raw) }\end{array}$ & $\begin{array}{c}\text { Alpha coefficient } \\
\text { (Standardized) }\end{array}$ \\
\hline All ACI-P Instrumentality Questions & 0.94 & 0.94 \\
Valence Questions Only & 0.90 & 0.91 \\
Instrumentality Questions Only & 0.91 & 0.92 \\
Valence PLUS Instrumentality - PCP & 0.94 & 0.94 \\
Valence PLUS Instrumentality - FS & 0.79 & 0.81 \\
\hline
\end{tabular}

ACI-P = Advance Certification Index for Pharmacists, $\mathrm{PCP}=$ Professional, Career and Professional, FS= Financial Support, Alpha=Cronbach's alpha reliability coefficient 
in some areas of research. The final alpha coefficient for each of the 2 factor

solutions, listed by ACI-P domain constructs, and based on instrumentality PLUS valence questions and responses were:

1. Professional, Career and Personal -0.94

2. Financial Support -0.81

Additionally, the overall standardized Cronbach's alpha for the questions related to the overall survey, instrumentality, and valence were:

3. All PVI groups -0.94

4. Instrumentality -0.91

5. Valence -0.90

The overall test items within the instrumentality and valence groups were found reliable. The two factored constructs of professional, career and personal (PCP), and financial support (FS) were reliable via calculated internal consistency with the alpha reliability coefficient.

\section{Comparison of 2004 BPS Survey Findings and 2007 ACI-P Findings}

Table 1-1 showed the responses listed in 2004 by board certified pharmacists as tangible and intangible benefits that BPS certification may bring to the pharmacist. The ACI-P survey included these same question concepts. These were not directly asked but were the same as the PVI groups which contained an instrumentality and valence question. The ACI-P VI Scores were used for comparison.

The differences in survey findings from the BPS 2004 survey and findings from the ACI-P survey in 2007 are listed in Table 4-14 and in Table 4-15 which is a 
Table 4-14. Items and Responses from Board Certified Pharmacists from 2007 ACI-P Survey Reported and Matched to Categories from 2004 BPS Survey $(N=1561)$

\begin{tabular}{lcc}
\hline Survey Item & VI Scores & $\%$ of Maximum (25) \\
\hline Hiring Priority & 16.48 & $66 \%$ \\
(Employer) Pay Certification Costs & 15.12 & $60 \%$ \\
Salary Increase (Higher Salary Now) & 11.72 & $47 \%$ \\
Increased Responsibility & 10.83 & $43 \%$ \\
Promotion Potential (Priority from & 10.2 & $41 \%$ \\
BPS) & 9.88 & $40 \%$ \\
(Employer) Pay Recertification Costs & 9.88 & $40 \%$ \\
Financial Incentive to Maintain BC & 9.55 & $38 \%$ \\
Public Notice & 9.33 & $37 \%$ \\
Salary Increase (Annual) & 6.58 & $26 \%$ \\
One time Pay Bonus & 0 & $0 \%$ \\
No Recognition & & \\
\hline
\end{tabular}

Table 4-14 Note: There was no option for No Recognition in the 2007 ACI-P survey. Scoring was done on various aspects of recognition. ACI-P=Advanced Certification Index for Pharmacists. 
Table 4-15. Tangible and Intangible Benefits That BPS Certification May Bring To the Pharmacist as Reported in BPS Online Survey Results 2004 (Redisplay of Table 1-1) 63, $64^{2}$

\begin{tabular}{lcc}
\hline Survey Item & Number of Responses & $\%$ of Responses \\
\hline Pay Certification Costs & 686 & $34 \%$ \\
No Recognition & 618 & $31 \%$ \\
Pay Recertification Costs & 433 & $22 \%$ \\
Public Notice & 325 & $16 \%$ \\
Hiring Priority & 324 & $16 \%$ \\
Salary Increase & 302 & $15 \%$ \\
Pay BPS Annual Fee & 296 & $15 \%$ \\
Increased Responsibility & 224 & $11 \%$ \\
Promotion Priority & 137 & $7 \%$ \\
One-time Pay Bonus & 98 & $5 \%$ \\
\hline BPS Board & & \\
\hline
\end{tabular}

BPS $=$ Board of Pharmaceutical Specialties 
repeat of information seen in Table 1-1 but sorted in descending order to facilitate comparison.

Comparison of this data was problematic. The top five findings in both groups were similar. Table 4-16 shows a side by side comparison of relative sequence. There were no easily discernible patterns observed by comparing these two as the 2004 BPS survey allowed multiple answers, as did the 2007 ACI-P survey, but with different question or item types.

\section{Comparison of Additional Comments from 2007 ACI-P Survey}

At the conclusion of the fifty-one questions that covered instrumentality, valence and expectations for the ACI-P and the 16 questions related to pharmacist demographics was a single comment opportunity. This final section was in the form of a statement and said simply, "Additional comments related to board certification in Pharmacy practice:" This was not addressed or referred to in the directions. The purpose of this question was to allow users to offer their candid comments on board certification in Pharmacy.

Of the 2,057 total survey respondents, 324 (15.8\%) offered additional comments. These comments were in form of narrative and more than one subject was addressed or offered by many of the pharmacists resulting in a total of 620 comments recorded and these divided by the two groups into 228 responses from 115 pharmacists (36.8\% of responses and $35.5 \%$ of pharmacists) for the non-board certified pharmacists. The board certified pharmacists responding recorded 392 responses from 209 pharmacists (63\% of responses and 64.5\% of pharmacists). 
Table 4-16. Comparison of Relative Sequence of Findings from 2004 BPS Survey and 2007 ACI-P Survey, Highest to Lowest Based on the 2004 BPS Survey.

\begin{tabular}{|c|c|c|}
\hline Survey Item & $\begin{array}{c}2004 \text { BPS Responses } \\
\text { (Descending Order) } \\
N=1995\end{array}$ & $\begin{array}{c}2007 \text { ACI-P Responses } \\
\text { (Sequence Number) } \\
N=1561\end{array}$ \\
\hline Pay Certification Costs & 1 & 2 \\
\hline No Recognition & 2 & 0 \\
\hline Pay Recertification Costs & 3 & 6 \\
\hline Hiring Priority & 4 & 1 \\
\hline Public Notice & 4 & 7 \\
\hline Pay BPS Annual Fee & 5 & 6 \\
\hline Salary Increase & 5 & 3 \\
\hline Increased Responsibility & 6 & 4 \\
\hline Promotion Priority & 7 & 5 \\
\hline One-time Pay Bonus & 8 & 9 \\
\hline
\end{tabular}

ACI-P=Advanced Certification Index for Pharmacists 
A review and analysis of the data suggested that the responses fell into some general areas. These are listed in Table 4-17. These comments were thought to be a large or medium effect, because they were offered by the respondent and therefore did not have to depend on interpretation of a pre-defined scale, an amount to be statistically meaningful in each group would be 27 respondents and a total of 54 for a large effect or 65 respondents in each group for a total of 130 for a medium effect per Cohen's $d^{81}$

It was determined that a "large effect" sample size was sufficient for this additional finding group and the number to be included within each group was 27 respondents. It was determined that the overall responses that were over 27 in either group were the most important. This list included the items found in Table 4-18.

If a further reduction in the findings were focused on the items from Table 418 that had 27 responses in both groups then the most important overall findings were those listed in Table 4-19. Essentially, these three would be the ones that are the most important. 
Table 4-17. Comparison of Non-Board Certified (NONBCP) and Board Certified Pharmacists (BCP) Findings from Additional Comments and Questions (Responses $=620$, Respondents $=324)$

\begin{tabular}{|c|c|c|}
\hline Findings from Additional Comments & $\begin{array}{l}\text { NONBCP } \\
(N=228)\end{array}$ & $\begin{array}{c}\mathrm{BCP} \\
(N=392)\end{array}$ \\
\hline $\begin{array}{l}\text { Need more Specialization / Board Certification } \\
\text { Process Has Not Kept Pace }\end{array}$ & $55 \%$ & $34 \%$ \\
\hline $\begin{array}{l}\text { Value Unrecognized / Academic Preparation is } \\
\text { Sufficient }\end{array}$ & $50 \%$ & $38 \%$ \\
\hline $\begin{array}{l}\text { Costs too High / Not enough Return on } \\
\text { Investment }\end{array}$ & $23 \%$ & $27 \%$ \\
\hline Makes No Difference in my Practice & $17 \%$ & $8 \%$ \\
\hline Test Not Equal to Ability & $13 \%$ & $8 \%$ \\
\hline Commentary on Survey / Questions & $13 \%$ & $29 \%$ \\
\hline Don't See Better Practice in Other BCPs & $10 \%$ & $1 \%$ \\
\hline $\begin{array}{l}\text { Board Certification is the way to / Easiest way } \\
\text { to get Additional Letters after Name }\end{array}$ & $9 \%$ & $28 \%$ \\
\hline $\begin{array}{l}\text { Method to Make Money / CE Needed for } \\
\text { Retesting }\end{array}$ & $6 \%$ & $10 \%$ \\
\hline Required & $4 \%$ & $1 \%$ \\
\hline Too Specialized / Not General Enough & $1 \%$ & $2 \%$ \\
\hline Too Much US Practice Focus & $0 \%$ & $1 \%$ \\
\hline
\end{tabular}

$\mathrm{BCP}=$ Board Certification in Pharmacy practice, $\mathrm{CE}=$ Continuing Education. 
Table 4-18. General Findings from Additional Comments; Responses Greater than 27 per Item in either NONBCP or BCP group $(N=591)$

\begin{tabular}{lcc}
\hline Findings from Additional Comments & $\begin{array}{c}\text { Number of } \\
\text { Responses }\end{array}$ & $\begin{array}{c}\text { Percent of } \\
\text { Responses }\end{array}$ \\
\hline $\begin{array}{l}\text { Need More Specialization / } \\
\text { Board Certification Process Has Not Kept Pace }\end{array}$ & 135 & $41.7 \%$ \\
Value Unrecognized/Academic Preparation is Sufficient & 135 & $41.7 \%$ \\
Costs Too High/ Not Enough Return on Investment & 83 & $25.6 \%$ \\
Commentary on Survey/Questions & 76 & $23.5 \%$ \\
$\begin{array}{l}\text { Board Certification is The Way to Go/ } \\
\text { Easiest way to get Additional Letters after Name } \\
\text { Makes No Difference in My Practice }\end{array}$ & 68 & $21.0 \%$ \\
Test Not Equal to Ability & 35 & $10.8 \%$ \\
Method to Make Money/CE Needed for Retesting & 31 & $9.6 \%$ \\
\hline CE = Continuing Education & 28 & $8.6 \%$
\end{tabular}


Table 4-19. General Findings from Additional Comments: Responses Greater than 27 in NONBCP and BCP groups $(N=353)$

\begin{tabular}{lcc}
\hline Findings from Additional Comments & $\begin{array}{c}\text { Number of } \\
\text { Responses }\end{array}$ & $\begin{array}{c}\text { Percent of } \\
\text { Responses }\end{array}$ \\
\hline $\begin{array}{l}\text { Need More Specialization / BC Has Not Kept } \\
\text { Pace }\end{array}$ & 135 & $41.7 \%$ \\
Value Unrecognized / Academic Prep OK & 135 & $41.7 \%$ \\
Costs Too High / Not Enough ROI & 83 & $25.6 \%$ \\
\hline
\end{tabular}

$\mathrm{BC}=$ Board certification in Pharmacy practice, $\mathrm{ROI}=$ Return on investment. 


\title{
Chapter 5. Study Discussion and Conclusions
}

"All human actions have one or more of these seven causes: chance, nature, compulsion, habit, reason, passion, desire."

\author{
--Aristotle
}

\section{$\underline{\text { Discussion }}$}

The passions, interests and/or influences that cause people to take action have been the subjects of study through the ages. The study of motivation has seen pioneers, many of whom were reviewed earlier, make attempts to either explain or quantify these influences. Categorization and a qualitative approach is a convenient way to attempt to summarize or encapsulate these influences. Quantification of these influences, i.e. motivational forces, has been somewhat more elusive. This study has posited that the Expectancy Valence (VIE) model could be applied to equivalently qualified pharmacists that were eligible to pursue specialty certification in Pharmacy practice known as board certification, via the Board of Pharmaceutical Specialties, to determine why some would choose this path and others would not. This was found to be true in that the motivational force calculated by the Advanced Certification Index for Pharmacists (ACI-P) showed a significant difference between the two groups.

The realms of medication management and clinical Pharmacy practice continue to get more and more complicated. The impact of pharmacists on the economic, clinical, and humanistic outcomes of patients has been increasing. With the current, and anticipated escalating, level of new drugs and treatment modalities, as well as biotechnology drugs, the need for advanced knowledge levels 
for these new advents is considerable. Some would argue that the role of formal traditional Pharmacy education is to prepare pharmacists for that knowledge level. Pharmacy continuing education would then continue the process of assuring that pharmacists stay current.

But that presupposes that the education received, as well as training in the customary curricula, covers all the specifics of any particular practice area within the profession. Some would argue that the difficulty in achieving this level of specific training in itself supports specialization. Board Certification on the other hand is designed to define the parameters by which a pharmacist could be validated as a specialty practitioner. Differences in opinion of the needs to be a pharmacy practitioner exist and some of the fundamental issues revolve around the types of education, training, residencies, certifications and degrees one must hold to be classified as an expert in a particular field of practice.

\section{$\underline{\text { Additional Comments Analysis }}$}

The additional comments section at the end of the ACI-P survey had a fair response rate $(N=324,15.8 \%$ of all respondents). A considerable number of pharmacists in this survey who were asked to offer their opinions of board certification in general felt that the board certification process is either excessive or that specialization is not specialized enough and therefore does not meet their needs. These were diametrically opposed opinions. Pharmacists responding to this commentary based survey question, as listed in Table 5-1, reported that about $42 \%$ 
Table 5-1. Summarized Findings from Additional Comments with Combined Groups $(N=461)$

\begin{tabular}{lcc}
\hline Findings from Additional Comments & $\begin{array}{c}\text { Number of } \\
\text { Responses }\end{array}$ & $\begin{array}{c}\text { Percentage of } \\
\text { Responses }\end{array}$ \\
\hline $\begin{array}{l}\text { Need More Specialization / BC Has Not Kept } \\
\text { Pace }\end{array}$ & 135 & $41.7 \%$ \\
Value recognized / Academic Prep OK & 135 & $41.7 \%$ \\
Financial Perceptions & 111 & $34.3 \%$ \\
Not Proven in Practice & 80 & $24.7 \%$ \\
\hline BC = Board Certified in Pharmacy practice & &
\end{tabular}


(135 of 324) of the time there was a need for more specialization and that perhaps the process of board certification in Pharmacy had not kept pace with their needs. Others reported at the same rate, $42 \%$ (135 of 324), that the value was unrecognized for board certification and that academic preparation was adequate. Another important result from these narrative responses was that about $26 \%$ (83 of 324$)$ of the respondents found the costs for board certification to be too high or that the costs did not return enough on investment. These three areas are important focal points for any future messages developed to convey the importance and need for board certification. Some findings from the comments entries that did not make inclusion, since these were categorized differently, would be important if they were combined as "not proven in practice". These would be "makes no difference in my practice", "test not equal to ability" and "don't see better practice in other BCPs". With this new combined group the percentage of overall pharmacists falling into this "not proven in practice" would be $24.7 \%(35+32+13 / 324)$. This may be important to the process of board certification since this sentiment was a more exaggerated finding in the nonboard certified pharmacist group (Table 4.13). An additional combination group could be the "financial perceptions". These would include "costs too high/not enough ROI" and "method to make money/CE needed to for recertification". As a combined variable of financial perceptions this group, which just fell under the 27 cut point on one of the four previously included groups, would represent 34\% (111 of 324) of findings. A summary of the findings from these responses is listed in Table 5-1. 


\section{$\underline{\text { Instrumentality }}$}

Instrumentality differences were noted between the non-board certified pharmacists and the board certified pharmacists. Instrumentality is a perceived or known probability that a performance will lead to an outcome. It is also called a performance-to-outcome expectancy $(P \rightarrow O)$. The board certified pharmacists had a higher instrumentality on 20 of $25(80 \%)$ of the instrumentality measures in the survey and these were statistically significant.

The responses to these eight questions were the most pronounced:

a. I would hire a board certified practitioner over another non-board certified practitioner with otherwise equal qualifications.

b. I would become more employable if I were board certified.

c. My self image will be improved by becoming board certified.

d. I will have increased peer respect by becoming board certified.

e. I will feel a sense of personal accomplishment by becoming board certified.

f. My initial certification costs will be paid by my employer.

g. My professional opportunities will improve with board certification.

h. Board certification will become necessary for my job.

If this research was based on the instrumentality scale alone these items would be the points of most interest. They would also perhaps offer a window on areas to improve the perception of board certification. The most interesting finding in this comparison may be that despite statistically significant differences in the two groups the overall accumulated instrumentality scores was near the neutral score for both 
groups. This means that the perceived likelihood of reward of each of the PVI groups was nearly neutral.

There was also a group that was about the same. The items and responses in this group were:

a. Increased financial incentive from my employer would cause me to MAINTAIN board certification (Both about 3.8).

b. I will receive a higher annual salary if I am board certified (both about 2.6).

c. Non-professional co-workers will respect my board certification status (both about 2.7).

d. I will have increased responsibility in my job after becoming board certified (both about 2.7)

e. I will be more likely to be promoted by my employer if I am board certified (both about 2.6)

Only one of the members of this grouping was not different statistically and was positive (3.8). That one however is quite telling. Financial incentive from an employer seems important to both the non-board certified and board certified pharmacists to an equivalent degree. This is an important finding and may be the basis for an important communication regarding board certification. The other four of the non-different group were about the same for the BCP and NONBCP groups, however they were all on the negative side $(<3.0)$. If these issues are to be considered important to the profession and to the status of board certification, they will need to be addressed as they are obviously not considered likely to occur. 


\section{Valence}

Valence differences were more pronounced than those seen with the instrumentality items. Instrumentality may be something outside of the control of the pharmacist. It is in essence a measure of the current environment in which they work, live, and operate. Perhaps responses on these items were a pragmatic statement of their reality. It was not surprising that the instrumentality scores were relatively neutral, with some exceptions, since these findings may be a true measure of pharmacist's thoughts on rewards associated with board certification. These perceptions of low reward may be linked to the large numbers of pharmacists that have not sought board certification.

In general the valence scores were higher than the instrumentality scores. There were 23 of 25 that were statistically different between the non-board certified pharmacists and those that were board certified. The valence differences were seen at the highest level for four items. These were, in descending order of the most difference noted:

a. I value that my job will require board certification.

b. I value board certification enough to positively influence a hiring decision.

c. I value personal accomplishment demonstrated by a board certification.

d. I value promotions based on board certification.

For this particular group of comparative valences there was a more pronounced difference than in the others. These are definitely areas where either addressing the extreme differences in non-board certified pharmacist's perceived value would be indicated or where actions should be taken to achieve work place 
acceptance and reward for board certification. Alternatively, it may indicate that board certification does not have a place and is not valued by many pharmacists.

In three of the questions, the valences reported by the BCP's were about the same as those listed by the NONBCP group and were not statistically different. This group was:

a. I value my self image.

b. I value increased confidence in my practice skills.

c. I value an improved professional network.

All three of these questions had responses above 3.8 so values attributed to all three issues were higher than the mid-point ( 3 on the 5 point scale). Although these responses are not very different statistically, the findings in the three above 3.8 are on the positive side of the scale. In other words, despite the fact that they don't differ greatly, the overall perception of these valences, in both groups, was positive indicating a potential opportunity area for perfecting communication and a clear message regarding the value of board certification to pharmacists and to some extent employers.

All of the responses captured on the valence items were summed. Both groups were on the higher end with the NONBCP group at 95.8 versus 75 (higher than neutral) and the BCP group at 102.2 versus 75 (higher than neutral).

Similarly, taking a mean of the means for the valences shows that the BCP group is slightly higher but both groups are on the positive side of the scale for valence, i.e. their general impression of values for these items was high. 
In the VIE equation, scores calculated for the valence scores had a positive influence, i.e. $>3.0$, effect on the calculations.

\section{Valence Times Instrumentality (VI Score)}

Two breakpoints were established for the low and high end means of the VI scores (VIS). These were a product of $<9.0$ for the negative range and product of 16.0 for valence in the high positive range. Regardless of how the scale extremes occur with the VIS each of the contributory VIS products are accumulated and summed in the VIE methodology. Therefore, even if many of the VIS products did not measure as being on the high or low end, they did accumulate to a summary score and each had some additive contribution to the summary score.

There were a total of 6 of 25 (24\%) of the VI scores for PVI groups that had at least one mean (NONBCP or BCP) below 9.0. These were:
a. Job requirement
b. Paid certification costs
c. Promotion potential
d. Public notification
e. Non-professional respect ( $p=0.09$, not significant)
f. One time bonus ( $p=0.9$, not significant $)$

Of these, only non-professional respect and one-time bonus were not statistically different. All of these VI score means fell into the negative range. Within the VIE calculation they made a contribution to the sums of all the VI scores but their impact was less than those that are more positive, i.e. above a 9.0 product. 
There were 10 of $25(40 \%)$ that had at least one VI score mean for either NONBCP or BCP above 16.0. All 10 of those were different statistically between the non-board and board certified pharmacists. These were, in descending order from highest difference of means to lowest difference (with NONBCP minus BCP differences in means noted in parentheses):
a. Hiring influence (-3.96)
b. Employability (-3.52)
c. Self image (-2.86)
d. Personal accomplishment (-3.09)
e. Peer respect (-2.35)
f. Professional opportunities $(-2.2)$
g. Career advancement (-1.96)
h. Professional respect [colleagues] (-1.75)
i. Practice skills confidence $(-0.88)$
j. Financial incentive to MAINTAIN board certification (-0.85)

The more negative a number for a difference the more the BCP VI score means were higher than the NONBCP VI score means. This higher end composite, i.e. valence times instrumentality (VI) scores added more to the accumulated VIE calculation.

An evaluation of the VI scores showed that 8 of $25(32 \%)$ had the most impact on the overall differences between NONBCP and BCP. These are listed in decreasing order of impact, i.e. the most extreme difference as indicated by t value to the lowest level within the group. 

a. Hiring influence
b. Employability
c. Job requirement
d. Self image
e. Personal accomplishment
f. Peer respect
g. Initial costs
h. Professional opportunities

These values represent the most variance between all the VI score means. This group contributed more to the completion of the VIE calculation and to the resultant calculation of motivational force.

\section{Valence Minus Instrumentality (VI Diff)}

The valence-minus-instrumentality scores were covered in detail in Chapter IV. This was a computation to determine the extremes of the differences in the two scales. There were 13 of $25(52 \%)$ that did not differ statistically. Therefore the differences in valence and instrumentality were about the same for both groups. Within this group, five of the PVI group overall responses had at least one mean value greater than 0.9 , or nearly one full level of response higher for the valence than the instrumentality. These represented a higher level of perception of value than for instrumentality (reward).

The five PVI groups falling into this group listed by PVI group name were: 

a. Paid recertification costs
b. Higher salary
c. Downsizing protection
d. Increased responsibility
e. Practice skills confidence

There were also two extreme findings on the VI_Diff scale where there were statistically different groups; these were where BCP responses were higher than NONBCP and where NONBCP responses were higher than BCP.

The BCP higher than NONBCP VI_Diff statistically significant end of the responses showed four PVI groups. These, listed in order of greatest difference descending to lowest, were:

f. Promotion potential

g. Job requirement

h. One time bonus

i. Annual salary increase

All values were negative for this group, which means that the perceptions of value for the board certified pharmacists were higher compared to the non-board certified pharmacists. Three of these, promotion potential, one time bonus and annual salary increase, had at least one mean value of 0.9 or greater representing almost a full level higher (on the 1-5 scale) for the valence than for the instrumentality.

On the other end of the scale for comparison of this group were the positive values where the non-board certified pharmacists' perceptions of value were higher than the board certified pharmacists. The following PVI groups showed areas where 
the non-board certified pharmacists had a higher difference in valence-minusinstrumentality responses than did the board certified pharmacists.
a. Self image (0.6)
b. Employability (0.38)
c. Professional opportunities $(0.33)$
d. Initial costs $(0.4)$
e. Peer respect $(0.25)$
f. Career advancement $(0.21)$
g. Professional respect $(0.18)$

Of this group, five had at least a one VI_Diff mean in one of the groups greater than 0.9 . These were self image, employability, professional opportunities, initial costs, and career advancement. In all of these, particularly the five with the highest differences, there may be an opportunity to close the gap between perceived value and instrumentality. A focus here would be to improve the likelihood that some of the things that the non-board certified pharmacists held in high value but that they felt would not come to pass would actually be realized. This area may represent an opportunity to refine the message of board certification to employers and emphasize the importance and value of a board certification.

The purpose of the VI_Diff evaluation was to further examine the differences seen on overall comparison of valences and instrumentalities in the preceding sections. The VI differences were not used in the computation of any values for the final motivational force. 


\section{Motivational Force Computations}

A methodology to calculate and compare motivational force between groups was a primary endpoint of this research. Instrumentality, valence and the product of instrumentality and valence were all contributing factors to the force of motivation within the VIE model. Expectancy, as defined earlier, refers to the expectation, or anticipated chance of success of an effort leading to successful performance. In this case that would be exertion of effort leading to achievement of the designation of board certification in a specialty by BPS. In the VIE equation it has a pivotal role in that it can contribute enough negative or positive influence to change the overall VIE (motivational force $[\mathrm{MF}]$ ) outcome. There was a statistically significant difference between the mean expectancy (Exp) for NONBCP and BCP. The NONBCP mean was 4.05 and the BCP mean was 4.4. The difference between these was -0.35 . The overall impact on the VIE, or motivational force (MF), calculations was a higher contribution by the board certified pharmacists than was the expectancy of the nonboard certified pharmacists. In addition to being statistically significant the difference in these two means had a material impact on the final calculated MF.

The final calculated motivational force (MF) via the VIE calculation yielded a mean of 1249 (95\% CI 1201 - 1296) for NONBCP and a mean of 1521 (95\% CI 1499 - 1544). These were statistically and materially different. The difference between the means was $-272(95 \%$ CI -321 to -224$)$ indicating a large separation between the two groups (22\% of the NONBCP mean and $18 \%$ of the BCP mean).

Pharmacists scoring an ACI-P score in this data between 1201 and 1206 were 95\% of the time NONBCP. Pharmacists scoring an ACI-P score on this survey 
between 1499 and 1544 were $95 \%$ of the time BCP. There was a tipping point at approximately 1500 (1500 - 1520) where a pharmacist would be found to be board certified in Pharmacy practice $95 \%$ of the time.

\section{$\underline{\text { Validity and Reliability of ACI-P }}$}

The Advanced Certification Index for Pharmacists (ACI-P) proved to be a valid and reliable tool. Validation of constructs demonstrated that there were two factors, or domains, rather than the four proposed. These were:

1. Professional, Career and Personal

\section{Financial Support}

Construct validity was established with these two factors. Face and content validity was established by a pilot survey. Reliability was confirmed for the two factors using Cronbach's alpha with alpha reliability coefficient values of 0.94 for the professional, career and personal (PCP) construct and 0.81 for financial support (FS). Additionally, the overall ACI-P had an alpha coefficient of 0.94 , the instrumentality scale had an alpha of 0.91 and the valence scale had an alpha of 0.9. All of these were equal to or above the criterion established of 0.7 and therefore demonstrate internal consistency of the test items.

There were material differences in certain areas of instrumentality, expectancy and VI scores. Expectancy of successful completion of the board certification process weighed heavily in establishing motivational force. The two factors (domains) found in the structure of the ACI-P were professional, career and personal (PCP), and financial support (FS). These were different than the a priori proposed 
domains but still include the initial classifications, only they are combined rather than in existence separately as originally proposed. The standardized alpha for all was above the established conservative baseline of alpha of 0.7 which is a commonly

accepted level, although minimum levels as low as 0.5 are accepted by some. ${ }^{83,84}$ The final alpha for each of the 2 factor solutions, listed by ACI-P domain constructs, and based on instrumentality PLUS valence questions and responses were:

1. Professional, Career and Personal -0.94

2. Financial Support -0.81

The overall Cronbach's alpha reliability coefficient for the ACI-P was 0.94 .

\section{Tipping Point Confirmed}

A tipping point of a score of 1500 on the ACI-P exists. Pharmacists scoring between 1499 and 1544 on the ACI-P are $95 \%$ of the time board certified pharmacists. The ACI-P was not intended as a predictive indicator but the data suggests that given at the appropriate point in a pharmacist's career it could indicate whether they will or will not pursue board certification. Since that "career point" may move or change based on external endpoints or by changes in the acceptance of board certification's importance or value, a point in time score for a pharmacist would not be expected to be accurate for any length of time. The length of time of accuracy for scores and findings from the ACI-P is a point for future research. 


\section{Limitations of the Study}

1. There was no way to control duplicate entries by pharmacists as the survey instrument was internet based and did not limit one user to one entry.

2. There was no way to prevent non-pharmacists from completing the survey.

3. It could be argued that non-board certified pharmacists have no specialty area of practice and therefore may have a different point of reference than those that are board certified in a specialty.

4. There are no totals of board certified and non-board certified pharmacists that received notification of the survey and therefore no response rate could be calculated.

5. Access to the internet could have provided information on what was not truly a cross section of the pharmacist population.

6. Members of the participating pharmacy organizations may not have been truly representative of the pharmacist population in the United States.

\section{Conclusions}

This research was enhanced by the cooperation, support and participation by four major Pharmacy organizations and the Board of Pharmaceutical Specialties. No surveys of this magnitude including this many Pharmacy organizations were found in the literature. The cooperative nature and high interest given this project by these different, and sometimes disparate organizations, demonstrates that there is high interest in this particular area. 
If board certification is to move into a leadership role for advancing the practice of Pharmacy and establishing the standards from which it originated, there are 12 points that must be addressed. The separate recommendations listed below are based on approximately five years of study on this issue, research findings from this study on the numerical scales, free text commentary captured for $16 \%$ of the respondents, voluntary offers of opinions from thought leaders during this research and 27 years of work place experience.

\section{Recommendations for the Future of Board Certification in Pharmacy}

- Recommendation 1. Employer recognition of the value of board certification in Pharmacy practice must be improved.

- Recommendation 2. Tangible and intangible rewards for pharmacists achieving board certification must be identified and improved.

- Recommendation 3. The significant differences between board certified and non-board certified pharmacists as far as perceptions of value must be addressed via promotion, communication and/or engagement of non-board certified pharmacists.

- Recommendation 4. The essentially neutral perception of rewards by both board certified and non-board certified pharmacists must be addressed via promotion, communication and/or engagement by other means.

- Recommendation 5. The relatively high range of perceptions of value for both board certified and non-board certified pharmacists form a strength and should be used as a basis for fashioning a positive promotional message. 
- Recommendation 6. Financial aspects related to board certification must be addressed. These include perceptions in general of costs to reward or return on investment. Solutions should be sought for shifting the costs from the individual practitioner.

- Recommendation 7. Proof of superiority of practice skills and/or improved patient outcomes by board certified practitioners is a fundamental need and must be proven.

- Recommendation 8. Evaluations of current applicability of board certification categories and recommendations for future needs must be undertaken.

- Recommendation 9. Some consideration should be given to bringing pharmacists that have been practicing for many years into the fold of board certification. Peer evaluation along with specified didactic material completion seems reasonable. A non-test mechanism for this effort should be evaluated.

- Recommendation 10. All Pharmacy organizations must financially support and endorse board certification in Pharmacy practice for this credentialing to have a growing future. A one time endowment of monies may be needed to establish a higher base number of board certified pharmacists.

- Recommendation 11. The Advanced Certification Index for Pharmacists (ACI-P) should be used as a tracking mechanism to see how actions taken with regard to board certification affect the motivational force over time of qualified pharmacists to seek board certification in Pharmacy practice. Temptation to simplify the tool should be avoided as the specifics of the 
survey instrument tool may help simultaneously and specifically track minor changes on several scales.

- Recommendation 12. Additional efforts by BPS to ensure that its processes remain current and credible, and to educate the profession and the public about Board Certification in Pharmacy, will be resource-intensive. In order for BPS to be successful and accomplish these goals, sufficient resources, both financial and personnel, must be made available.

In this study, the investigator has developed an important survey instrument for the study of motivational force with pharmacists and has made findings that are both interesting and important to the profession of Pharmacy and to the future of Pharmacy practice.

\section{Contributions of this Research}

Considerable contributions of this research included, but were not limited to, the following:

- A survey instrument, the ACI-P, was developed based on a mathematical model of motivation. This tool allows a quantification of motivational force and motivating factors.

- The survey instrument was validated and the constructs of the validation were found to be reliable.

- A survey that included cooperation of APhA, ASHP, ACCP and AACP as well as the Board of Pharmaceutical Specialties was deployed. This cooperative participation indicated a high level of interest and perhaps a 
willingness to pursue a joint approach to the issues related to board certification in Pharmacy practice.

- The survey instrument was deployed and all data retrieval was done using an internet-based electronic communication and data collection methods. A good response to the survey was achieved.

- Statistically significant differences in board certified and non-board pharmacists were found for most measures of instrumentality. Information was gleaned from this data that suggested changes in message and perhaps direction for the profession of Pharmacy.

- Statistically significant differences in board certified and non-board pharmacists were found for most measures of valence. Information was gleaned from this data that suggested changes in message and perhaps direction for the profession of Pharmacy.

- Statistically significant differences in board certified and non-board pharmacists were found for most measures of valence-times-instrumentality (VIS). Information was gleaned from this data that suggested changes in message and perhaps direction for the profession of Pharmacy.

- Statistically significant differences in board certified and non-board pharmacists were found for the calculated motivational force (MF). Information was gleaned from this data that suggested changes in message and perhaps direction for the profession of Pharmacy.

- Narrative based commentary offered by 324 pharmacists produced 620 meaningful findings that were classified and stratified into useable groups and 
further enhanced the findings of the mathematical scales of the ACI-P. The narrative component should be retained as a part of the survey instrument. The findings in this research present opportunities as well as challenges for Pharmacy practitioners, colleges of Pharmacy, professional organizations, and the Board of Pharmaceutical Specialties. Specifically, pharmacists may wish to reevaluate the importance of specialty certification, while colleges of Pharmacy may wish to address curricula and their support of post-doctoral training programs. Also, professional Pharmacy organizations may wish to enhance membership services, programming, etc. that relate to and support the process of specialty certification via board certification in Pharmacy practice.

\section{Recommendations for Future Research}

This study revealed a great deal of information regarding the differences between board certified and non-board certified pharmacists. There are several research projects that could be pursued based on the findings and conclusions of this study. These could include the data collected from this research, use of the ACI- P survey instrument, or be completely new directions for study. Some recommendations for future research are:

- A cross sectional review of a comparison between BPS survey type questions regarding demographic nuances between former surveys completed, particularly the one BPS 2004 of only board certified pharmacists which was not anonymous, and the findings from the 2007 ACI-P survey for board certified and non-board certified pharmacists, which was anonymous. 
- An evaluation of the ACI-P applied to various student class levels, particularly the last two years and during residencies, to focus on changing motivational factors during these years for a given set of students. Tracking changes perceived in this population could establish a baseline for change implementation effect.

- A broader test of ACI-P with full cooperation of all Pharmacy organizations and the schools of Pharmacy to corroborate the findings from the ACI-P 2007 survey would be of great interest.

- A five year annual ACI-P survey process to determine if changes in support of the board certification process are affecting motivation. This should be paralleled with a tracking of number of pharmacists seeking and attaining board certification in Pharmacy practice.

- Evaluation of the impact of extended board certification categories on acceptance and propagation of board certification for pharmacists.

- Evaluation of the impact of a continuing education approach on recertification retention rate.

- Evaluation of ACI-P 2007 compared to subsequent years to determine specific profiles of pharmacists to establish a demographic profile of the highly motivated pharmacist.

- Evaluation of regional, state, city, rural and urban influences on perceptions of board certification and motivation may be an important research topic. Evaluation should determine if influences are based on geographic or economic area or on schools and colleges of Pharmacy. 
- The ACI-P Survey Instrument and methodology could be used for other health care or other disciplines, where a specialty certification is attainable but not necessary, to determine force of motivation. Licensure requirements may make this a more complex evaluation but it could be done. Validation is needed in other disciplines.

- Additional data analysis and focus on sub-groups could provide valuable insight and pave the way for the future of board certification in Pharmacy practice and for the way Pharmacy is practiced in the future.

There are many other things to consider and study with the information gleaned from the 2007 ACI-P survey. This is an exciting frontier for Pharmacy research that has little precedent. A renewed focus and interest on specialty certification in Pharmacy practice could help propel the Pharmacy profession into the next century at the forefront of healthcare.

The Advanced Certification Index for Pharmacists is a valuable tool and its creation and validation will benefit the profession of Pharmacy. Tracking specific areas of pharmacist's perceptions can provide the profession with insights into particular strengths or needs. Acting and addressing these needs and using strengths as a basis could lead to a material increase in the numbers of board certified pharmacists. Likewise, not acting on the needs identified by the differences in perceptions, as indicated by the motivational factors and calculated motivational level as indicated by the ACI-P, may result in specialty certification in Pharmacy practice continuing to be an exception that is pursued and maintained by only a very small segment of practicing pharmacists. 


\section{List of References}

1. Long D. 2003 U.S. pharmaceutical market: trends, issues, forecasts. Available from http://www.imshealth.com. Accessed December 4, 2004.

2. Outlook 2003. Boston: Tufts Center for the Study of Drug Development; 2003.

3. 418 biotechnology medicines in testing promise to bolster the arsenal against disease. Medicines in Development-Biotechnology. Available from http://www.phrma.org/new_medicines_in_development_for_biotechnology. Accessed January 10, 2007.

4. Board certification and you. Board of pharmaceutical specialties: over 20 years of service to the public and the Pharmacy profession: Report from Board of Pharmaceutical Specialties; 1995:17.

5. Over 20 years of service to the public and the Pharmacy profession: the Pharmacy specialty certification program. Available from http://www.bpsweb.org/About.BPS/About.BPS.shtml. Accessed February 6, 2005.

6. Gourley DR. Accreditation and certification programs: who benefits? Paper presented at: NABP's Executive Officer's Conference; October 2, 1995; Loew's L'enfant Plaza, Washington, DC.

7. Fenniger LD. Specialization and specialty recognition in the healing professions. Am J Hosp Pharm. 1991(48):476-480.

8. 2007 Candidate's Guide. Specialty certification in: nuclear Pharmacy, nutrition support Pharmacy, oncology Pharmacy, pharmacotherapy, psychiatric Pharmacy. Available from http://www.bpsweb.org/04_Exams.html. Accessed September 6, 2007.

9. Talbert RL, Bertin RJ. Specialization in Pharmacy practice. Remingtons Pharmaceutical Sciences; 2005.

10. Calder G. Motivating pharmacists. Pharmaceutical Journal. May 13 2000;264(7096):729-731.

11. Turnley W. Chapter 16 Managing employee motivation and performance. Available from http://info.cba.ksu.edu/turnleys/MANGT420/ch16.ppt. Accessed September 5, 2007. 
12. Vroom VH. Work and Motivation. New York: Wiley; 1964.

13. AMA Council on Medical Education Home page. Available from http://www.ama-assn/ama/pub/category/2954.html. Accessed July 5, 2005.

14. American Board of Medical Specialties Home Page. Available from http://www.abms.org. Accessed July 5, 2005.

15. Subspecialization in Pharmacy: A Report from the 1993-1994 ACCP Task Force on Subspecialization: American College of Clinical Pharmacy; 4/10/1995 1995 .

16. Credentialing in Pharmacy. Council on Credentialing in Pharmacy White Paper on Pharmacy Credentialing. Available from http://www.Pharmacycredentialing.org/ccp/CCPWhitePaper2003.pdf. Accessed January 9, 2005.

17. Board Certification and You, Board of Pharmaceutical Specialties. http://www.bpsweb.org/BPS/faq.html. Accessed December 20, 2004.

18. Hepler CD, Strand LM. Opportunities and responsibilities in pharmaceutical care. Am J Hosp Pharm. 1990;47:533-543.

19. American Pharmacists Association Home page. Available from http://www.aphanet.org/AM/Template.cfm?Section=About_APhA. Accessed July 5, 2005.

20. About ASHP. Available from http://www.ashp.org/s_ashp/cat2cn.asp?CID=8\&DID=8. Accessed March 10, 2007, 2007.

21. About ACCP. Available from http://www.accp.com/about.php. Accessed September 2, 2007, 2007.

22. About AACP. Available from http://www.aacp.org/site/page.asp?TrackID=\&VID=1\&CID=48\&DID=3052. Accessed September 7, 2007, 2007.

23. Accreditation Council for Pharmacy Education. Available from http://www.acpe-accredit.org/about/default.asp. Accessed July 4, 2005.

24. SAS. Version 9.1. Cary, NC: SAS.

25. Keely JL. Pharmacist scope of practice. Ann Intern Med. 2002;136:79-85. 
26. Bertin RJ. Results of previous BPS post-examination surveys. In: Tankersley M, ed. Memphis, TN: Board of Pharmaceutical Specialties; 2004.

27. Fenniger LD. Specialization and specialty recognition in the healing professions. Am J Hosp Pharm. 1991;(48):476-480.

28. Stevens R. American medicine and the public interest; a history of specialization. Berkeley: Univ of California Press; 1998.

29. American Board of Medical Specialists. Available from http://www.abms.org/about.asp. Accessed November 13, 2004.

30. Slogoff S, Hughes FP, Hug CC, et al. A demonstration of validity for certification by the American Board of Anesthesiology. Acad Med. 1994;69:740-746.

31. Sharp LK, Bashook PG, Lipsky MS, et al. Specialty board certification and outcomes: the missing link. Acad Med. 2002;77:534-542.

32. Bond AC, Raehl CL, Franke T. Clinical Pharmacy services and hospital mortality rates. Pharmacotherapy 1999;19:556-564.

33. Report on the Status of Board Certification in Pharmacy. Washington, DC: Board of Pharmaceutical Services; 2005.

34. The Pharmacy professsion: transitioning from prescription provider to health care manager. American Pharmaceutical Association. http://www.Pharmacyandyou.org/about/pharmcarefacts.html. Accessed December 21, 2004.

35. Outcomes of pharmaceutical outcomes research-impact of studies funded: final report. Rockville, MD: Agency for Health Care Policy and Research; October 2001. Publication No. 02-R201.

36. Brophy GM, Tesoro EP, Schrote GL, Garnett WR. Pharmacist impact on posttraumatic seizure prophylaxis in patients with head injury. Pharmacotherapy. 2002;22(2):251-255.

37. McAllister D, Schrommer JC, McAuley JW, et al. Comparison of skilled nursing and assisted living residents to determine potential benefits of pharmacist intervention. Consultant Pharmacist. 2000;15:1110-1116.

38. Bootman JL, Harrison DL, Cox E. The health care cost of drug-related morbidity and mortality in nursing facilities. Arch Intern Med. 1997;157:2089-2096. 
39. Willett MS, Bertch KE, Rich DS, Ereshefsky L. ACCP Official Position Statement: Prospectus on the economic value of clinical Pharmacy services. Pharmacotherapy. November 1, 1989 1989;9(1):45-56.

40. Hatoum HT, Catizone C, Hutchinson RA, Purohit A. An eleven-year review of the Pharmacy literature: documentation of the value and acceptance of clinical Pharmacy. Drug Intell Clin Pharm. 1986(20):33-48.

41. Reid LD, McKenna DA, Horn JR. Meta-analysis of research on the effect of clinical pharmacokinetics services on therapeutic drug monitoring. Am J Hosp Pharm. 1989(46):945-951.

42. Tett SE, Higgins GM, Armour CL. Impact of pharmacist interventions on medication management by the elderly: a review of the literature. Ann Pharmacotherapy. 1993(27):80-86.

43. Hatoum HT, Akhras K. 1993 Bibliography: a 32-year literature review on the value and acceptance of ambulatory care provided by pharmacists. Ann Pharmacotherapy. 1993(27):1106-1119.

44. Peterson AM, Taklya L, Finley R. Meta-analysis of trials of interventions to improved medication adherence. Am J Hosp Pharm. 2003;60(7):657-665.

45. Machado M, Bajcar J, Guzzo GC, Einarson TR. Sensitivity of patient outcomes to pharmacist interventions. Part I: Systematic review and metaanalysis in diabetes management. Ann Pharmacother; 2007.

46. Jenkins $\mathrm{MH}$, Bond CA. The impact of clinical pharmacists on psychiatric patients. Pharmacotherapy. 1996(16):708-714.

47. Lipton HL, Bero LA, Bird JA, McPhee SJ. The impact of clinical pharmacists' consultations on physician's geriatric drug prescribing. Med Care. 1992(30):646-658.

48. Saseen JJ, Grady SE, Hansen LB, Hodges BM, Kovacs SJ, al e. Future clinical Pharmacy practitioners should be board-certified specialists. Pharmacotherapy. 2006;26(12):1816-1825.

49. Schumock GT, Butler MG, Meek PD. Evidence of the economic benefit of clinical Pharmacy services: 1996-2000. Pharmacotherapy. 2003(23):113-132.

50. Helling DK, Nelson KM. How to develop and implement a program to continuously demonstrate the value of clinical Pharmacy services. Pharmacotherapy. 2000;20 (10 PT 2)(S340-343). 
51. McMullin ST, Hennenfent JA, Ritchie DJ, et al. A prospective randomized trial to assess the cost impact of pharmacist-initiated interventions. Arch Int Med. 1999;159:2306-2309.

52. Evidence of the value of the pharmacist. Alliance for pharmaceutical care. Partners to improve health outcomes. Available from http://www.accp.com/position/paper6.pdf. Accessed December 8, 2003.

53. Carmichael JM, O'Connell MB, Devine B, et al. Collaborative drug therapy management by pharmacists. Pharmacotherapy. 1997;17:1050-1061.

54. Berringer R, Shibley MC, Cary CC, Pugh CB, Powers PA, Rafi JA. Outcomes of a community Pharmacy-based diabetes monitoring program. J Am Pharm Assoc. 1999;39:791-797.

55. Gattis WA, Hasselblad V, Whelan DJ, O'Conner CM. Reduction in heart failure events by addition of a clinical pharmacist to the heart failure management team: Results of the Pharmacist in Heart Failure Assessment Recommendation and Monitoring (PHARM) Study. Arch Int Med. 1999;159:1938-1945.

56. Leape LL, Cullen DJ, Clapp MD, et al. Pharmacist participation on physician rounds and adverse drug events in the intensive care unit. JAMA. 1999;282:267-270.

57. Farris KB, Kumbera P, Halterman T, Fang G. Outcomes-based pharmacist reimbursement: reimbursing pharmacists for cognitive services, part 1 . J Manag Care Pharm. 2002(8):383-393.

58. Snella KA, Trewyn RR, Hansen LB, Bradberry JC. Pharmacist compensation for cognitive services: focus on the physician office and the community Pharmacy. Pharmacotherapy. 2004(24):372-388.

59. Bertin RJ. Employer Information Profile of BPS Pharmacists. In: Tankersley M, ed. Memphis, TN; 2006.

60. "Fast Facts" for Certification. Available from http://www.bpsweb.org/04_Exams.html. Accessed September 7, 2007.

61. Bertin RJ. Results of previous BPS post-examination surveys. In: Tankersley M, ed. Memphis, TN: Board of Pharmaceutical Specialties; 2004.

62. Bertin RJ. Sanity Check. In: Tankersley M, ed; 2007. 
63. Results of 2004 BPS Examinations Announced. Pharmacy Specialization. Vol $14 ; 2004: 6$.

64. Bertin RJ. In: Tankersley M, ed. Memphis; 2005:Electronic mail correction of data from 2004 BPS Newsletter.

65. Huitt W. Maslow's hierarchy of needs. Educational Psychology Interactive. Available from http://chiron.valdosta.edu/whuitt/col/regsys/maslow.html. Accessed January 9, 2007.

66. Maslow AH. A theory of human motivation. Psychological Review. July 1943:370-396.

67. Alderfer C. Existence, relatedness, \& growth. New York: Free Press; 1972.

68. Schermerhorn JR. PowerPoint Presentation to Accompany Chapter 14 of Management, 8/e. Available from http://www.mime.eng.utoledo.edu/people/faculty/rbennett/engineering_manag ement/Powerpoint\%20Slides/ch14.ppt. Accessed September 3, 2007.

69. Existence, relatedness, growth - ERG theory. Available from http://www.valuebasedmanagement.net/methods_alderfer_erg_theory.html. Accessed February 10, 2007, 2007.

70. McClelland's theory of needs. Available from http://www.netmba.com/mgmt/ob/motivation/mcclelland. Accessed August 21, 2007.

71. Herzberg F, Mausner B, Snyderman BB. The motivation to work. New York: John Wiley \& Sons; 1959.

72. Lawler EE. Motivation in Work Organizations. Monterey, CA: Brooks/Cole; 1973.

73. Herzberg's Motivation-Hygiene Theory (Two Factor Theory). Available from http://www.netmba.com/mgmt/ob/motivation/herzberg/. Accessed September 7, 2007.

74. Adams JS. Inequity in social exchange. Adv Exp Soc Psychol. 1965;62:333343.

75. Huseman RC, Hatfield JD, Miles EW. A new perspective on equity theory: the equity sensitivity construct. The Academy of Management Review. 1987;12(2):222-234. 
76. Lathem G, Locke E. Building a practically useful theory of goal setting and task motivation. American Psychologist. 2002;57(9):705-717.

77. Locke EA. Motivation through conscious goal setting. Applied and Preventive Psychology. 1996;5(117-124).

78. Antoni C. Management by Objectives - an effective tool for teamwork? The International Journal of Human Resource Management. February 2005;16(2):174-184.

79. Lawler EE. Pay and organization effectiveness: a psychological view. New York: McGraw-Hill; 1971.

80. Tabachnick BG, Fidell LS. Using Multivariate Statistics. 4th ed. MA: Allyn and Bacon; 2001.

81. Cohen J. Statistical power analysis for the behavioral sciences. 2nd ed. New Jersey: Lawrence Erlbaum; 1988.

82. Costello AB, Osborne JW. Best practices in exploratory factor analysis: four recommendations for getting the most from your analysis. Practical Assessment, Research \& Evaluation. July 2005;10(7):3-4.

83. Gourley GK, Gourley DR, Rigolosi EL, Reed P, Solomon DK, Washington E. Development and validation of the pharmaceutical care satisfaction questionnaire. American Journal of Managed Care. May 2001;7(5):463.

84. Nunally J. Psychometric Theory. 2nd ed. New York, NY: McGraw-Hill Co; 1978.

85. 2005 Nuclear Pharmacy Examination; Demographic Survey: Board of Pharmacy Specialties; 2005:4.

86. Finley R. SurveyMonkey.com. Available from http://SurveyMonkey.com; Accessed July 5, 2007.

87. Cronbach LJ. Coefficient alpha and the internal structure of tests. Psychometricka. 1951;16:297-334.

88. Chong HY. An introduction to computing and interpreting Cronbach coefficient alpha in SAS. Available from www2.sas.com/proceedings/sugi26/p246-26.pdf. Accessed September 2, 2007. 
Appendix A 


\section{Advanced Certification Index for Pharmacists (ACI-P)}

Manual Version Adapted from Internet Based Survey

(C) Copyright Mark A. Tankersley, All Rights Reserved.

\section{Directions and Consent}

This survey seeks your opinions on the factors that may influence a pharmacist's decision to seek board certification in a Pharmacy specialty. The survey should take no more than 15 minutes.

Your input is important whether you have no intention of pursuing board certification in Pharmacy practice, intend to pursue in the future, have already completed the certification or were previously board certified.

This survey is based on two components of each factor that may be related to pursuit of specialty certification in Pharmacy practice. These components are: 1) the probability of occurrence as you perceive it, and 2) the value of that particular factor.

Definitions:

For the probability of occurrence (the first part of each question) the scale is a measure of perceived probability with the lower end "Will not occur" being the lowest probability of occurrence and "Will definitely occur" being the highest.

For the value assessment, the lower end value of "No value" means the lowest value to you as a pharmacist and "Highly valuable" means the highest value to you. Please check the corresponding bubble for each selection.

All questions are related to pursuit and achievement of board certification in Pharmacy by the Board of Pharmaceutical Specialties. 
Additional Information:

There are 16 demographic questions at the end of the survey that will be used in comparing this information with what has been collected by the Board of Pharmaceutical Specialties in previous surveys.

This study has been approved by the University of Tennessee Institutional Review Board. There is no consequence for refusing to take the survey or any direct benefit to you other than professional value to Pharmacy in general. Your identity will not be disclosed and no relational information regarding your demographics information will be attempted. The scope of this study is to characterize aggregate trends and not those of an individual. Summary data only will be made available to Pharmacy organizations. The results of this survey may be presented at a professional meeting, become published or become part of a Ph.D. dissertation.

Consent for Participation:

This survey is voluntary. By proceeding with this survey I consent to participate.

\section{Probabilities of Occurrence and Values}

\section{Self image}

A. My self image will be improved by becoming board certified.

\begin{tabular}{|c|c|c|c|c|}
\hline $\begin{array}{c}\text { Will definitely } \\
\text { not occur }\end{array}$ & $\begin{array}{c}\text { Unlikely to } \\
\text { occur }\end{array}$ & Unsure & $\begin{array}{c}\text { Likely to } \\
\text { occur }\end{array}$ & $\begin{array}{c}\text { Will definitely } \\
\text { occur }\end{array}$ \\
$\square$ & $\square$ & $\square$ & $\square$ & $\square$ \\
\hline
\end{tabular}


1. Self image (continued)

B. I value my self image.

\begin{tabular}{|c|c|c|c|c|}
\hline No value & Low value & $\begin{array}{c}\text { Mid range of } \\
\text { value }\end{array}$ & $\begin{array}{c}\text { Somewhat } \\
\text { valuable }\end{array}$ & $\begin{array}{c}\text { Highly } \\
\text { valuable }\end{array}$ \\
$\square$ & $\square$ & $\square$ & $\square$ & $\square$ \\
\hline
\end{tabular}

2. Employable

A. I would become more employable if I were board certified.

\begin{tabular}{|c|c|c|c|c|}
\hline $\begin{array}{c}\text { Will definitely } \\
\text { not occur }\end{array}$ & $\begin{array}{c}\text { Unlikely to } \\
\text { occur }\end{array}$ & Unsure & $\begin{array}{c}\text { Likely to } \\
\text { occur }\end{array}$ & $\begin{array}{c}\text { Will definitely } \\
\text { occur }\end{array}$ \\
$\square$ & $\square$ & $\square$ & $\square$ & $\square$ \\
\hline
\end{tabular}

B. I value becoming more employable.

\begin{tabular}{|c|c|c|c|c|}
\hline No value & Low value & $\begin{array}{c}\text { Mid range of } \\
\text { value }\end{array}$ & $\begin{array}{c}\text { Somewhat } \\
\text { valuable }\end{array}$ & $\begin{array}{c}\text { Highly } \\
\text { valuable }\end{array}$ \\
$\square$ & $\square$ & $\square$ & $\square$ & $\square$ \\
\hline
\end{tabular}

3. Higher salary

A. I will receive a higher annual salary if I am board certified.

\begin{tabular}{|c|c|c|c|c|}
\hline $\begin{array}{c}\text { Will definitely } \\
\text { not occur }\end{array}$ & $\begin{array}{c}\text { Unlikely to } \\
\text { occur }\end{array}$ & Unsure & $\begin{array}{c}\text { Likely to } \\
\text { occur }\end{array}$ & $\begin{array}{c}\text { Will definitely } \\
\text { occur }\end{array}$ \\
$\square$ & $\square$ & $\square$ & $\square$ & $\square$ \\
\hline
\end{tabular}


3. Higher salary (continued)

B. I value a higher annual salary.

\begin{tabular}{|c|c|c|c|c|}
\hline No value & Low value & $\begin{array}{c}\text { Mid range of } \\
\text { value }\end{array}$ & $\begin{array}{c}\text { Somewhat } \\
\text { valuable }\end{array}$ & $\begin{array}{c}\text { Highly } \\
\text { valuable }\end{array}$ \\
$\square$ & $\square$ & $\square$ & $\square$ & $\square$ \\
\hline
\end{tabular}

4. Professional opportunities

A. My professional opportunities will improve with board certification.

\begin{tabular}{|c|c|c|c|c|}
\hline $\begin{array}{c}\text { Will definitely } \\
\text { not occur }\end{array}$ & $\begin{array}{c}\text { Unlikely to } \\
\text { occur }\end{array}$ & Unsure & $\begin{array}{c}\text { Likely to } \\
\text { occur }\end{array}$ & $\begin{array}{c}\text { Will definitely } \\
\text { occur }\end{array}$ \\
$\square$ & $\square$ & $\square$ & $\square$ & $\square$ \\
\hline
\end{tabular}

B. I value professional opportunities.

\begin{tabular}{|c|c|c|c|c|}
\hline No value & Low value & $\begin{array}{c}\text { Mid range of } \\
\text { value }\end{array}$ & $\begin{array}{c}\text { Somewhat } \\
\text { valuable }\end{array}$ & $\begin{array}{c}\text { Highly } \\
\text { valuable }\end{array}$ \\
$\square$ & $\square$ & $\square$ & $\square$ & $\square$ \\
\hline
\end{tabular}

5. Peer respect

A. I will have increased peer respect by becoming board certified.

\begin{tabular}{|c|c|c|c|c|}
\hline $\begin{array}{c}\text { Will definitely } \\
\text { not occur }\end{array}$ & $\begin{array}{c}\text { Unlikely to } \\
\text { occur }\end{array}$ & Unsure & $\begin{array}{c}\text { Likely to } \\
\text { occur }\end{array}$ & $\begin{array}{c}\text { Will definitely } \\
\text { occur }\end{array}$ \\
$\square$ & $\square$ & $\square$ & $\square$ & $\square$ \\
\hline
\end{tabular}


5. Peer respect (continued)

B. I value peer respect.

\begin{tabular}{|c|c|c|c|c|}
\hline No value & Low value & $\begin{array}{c}\text { Mid range of } \\
\text { value }\end{array}$ & $\begin{array}{c}\text { Somewhat } \\
\text { valuable }\end{array}$ & $\begin{array}{c}\text { Highly } \\
\text { valuable }\end{array}$ \\
$\square$ & $\square$ & $\square$ & $\square$ & $\square$ \\
\hline
\end{tabular}

6. Career advancement

A. My career will be positively advanced by becoming board certified.

\begin{tabular}{|c|c|c|c|c|}
\hline $\begin{array}{c}\text { Will definitely } \\
\text { not occur }\end{array}$ & $\begin{array}{c}\text { Unlikely to } \\
\text { occur }\end{array}$ & Unsure & $\begin{array}{c}\text { Likely to } \\
\text { occur }\end{array}$ & $\begin{array}{c}\text { Will definitely } \\
\text { occur }\end{array}$ \\
$\square$ & $\square$ & $\square$ & $\square$ & $\square$ \\
\hline
\end{tabular}

B. I value career advancement.

\begin{tabular}{|c|c|c|c|c|}
\hline No value & Low value & $\begin{array}{c}\text { Mid range of } \\
\text { value }\end{array}$ & $\begin{array}{c}\text { Somewhat } \\
\text { valuable }\end{array}$ & $\begin{array}{c}\text { Highly } \\
\text { valuable }\end{array}$ \\
$\square$ & $\square$ & $\square$ & $\square$ & $\square$ \\
\hline
\end{tabular}

7. Academic opportunities

A. My academic opportunities will improve if I am board certified.

\begin{tabular}{|c|c|c|c|c|}
\hline $\begin{array}{c}\text { Will definitely } \\
\text { not occur }\end{array}$ & $\begin{array}{c}\text { Unlikely to } \\
\text { occur }\end{array}$ & Unsure & $\begin{array}{c}\text { Likely to } \\
\text { occur }\end{array}$ & $\begin{array}{c}\text { Will definitely } \\
\text { occur }\end{array}$ \\
$\square$ & $\square$ & $\square$ & $\square$ & $\square$ \\
\hline
\end{tabular}


7. Academic opportunities (continued)

B. I value academic opportunities.

\begin{tabular}{|c|c|c|c|c|}
\hline No value & Low value & $\begin{array}{c}\text { Mid range of } \\
\text { value }\end{array}$ & $\begin{array}{c}\text { Somewhat } \\
\text { valuable }\end{array}$ & $\begin{array}{c}\text { Highly } \\
\text { valuable }\end{array}$ \\
$\square$ & $\square$ & $\square$ & $\square$ & $\square$ \\
\hline
\end{tabular}

8. Downsizing protection

A. In a workplace that is downsizing, board certification will protect my job.

\begin{tabular}{|c|c|c|c|c|}
\hline $\begin{array}{c}\text { Will definitely } \\
\text { not occur }\end{array}$ & $\begin{array}{c}\text { Unlikely to } \\
\text { occur }\end{array}$ & Unsure & $\begin{array}{c}\text { Likely to } \\
\text { occur }\end{array}$ & $\begin{array}{c}\text { Will definitely } \\
\text { occur }\end{array}$ \\
$\square$ & $\square$ & $\square$ & $\square$ & $\square$ \\
\hline
\end{tabular}

B. I value a protective effect from downsizing.

\begin{tabular}{|c|c|c|c|c|}
\hline No value & Low value & $\begin{array}{c}\text { Mid range of } \\
\text { value }\end{array}$ & $\begin{array}{c}\text { Somewhat } \\
\text { valuable }\end{array}$ & $\begin{array}{c}\text { Highly } \\
\text { valuable }\end{array}$ \\
$\square$ & $\square$ & $\square$ & $\square$ & $\square$ \\
\hline
\end{tabular}

9. Initial costs

A. My initial certification costs will be paid by my employer.

\begin{tabular}{|c|c|c|c|c|}
\hline $\begin{array}{c}\text { Will definitely } \\
\text { not occur }\end{array}$ & $\begin{array}{c}\text { Unlikely to } \\
\text { occur }\end{array}$ & Unsure & $\begin{array}{c}\text { Likely to } \\
\text { occur }\end{array}$ & $\begin{array}{c}\text { Will definitely } \\
\text { occur }\end{array}$ \\
$\square$ & $\square$ & $\square$ & $\square$ & $\square$ \\
\hline
\end{tabular}


9. Initial costs (continued)

B. I value my initial certification costs being paid by my employer.

\begin{tabular}{|c|c|c|c|c|}
\hline No value & Low value & $\begin{array}{c}\text { Mid range of } \\
\text { value }\end{array}$ & $\begin{array}{c}\text { Somewhat } \\
\text { valuable }\end{array}$ & $\begin{array}{c}\text { Highly } \\
\text { valuable }\end{array}$ \\
$\square$ & $\square$ & $\square$ & $\square$ & $\square$ \\
\hline
\end{tabular}

10. Credibility

A. Board certification credentials will add credibility to my opinions.

\begin{tabular}{|c|c|c|c|c|}
\hline $\begin{array}{c}\text { Will definitely } \\
\text { not occur }\end{array}$ & $\begin{array}{c}\text { Unlikely to } \\
\text { occur }\end{array}$ & Unsure & $\begin{array}{c}\text { Likely to } \\
\text { occur }\end{array}$ & $\begin{array}{c}\text { Will definitely } \\
\text { occur }\end{array}$ \\
$\square$ & $\square$ & $\square$ & $\square$ & $\square$ \\
\hline
\end{tabular}

B. I value credentials to improve my credibility.

\begin{tabular}{|c|c|c|c|c|}
\hline No value & Low value & $\begin{array}{c}\text { Mid range of } \\
\text { value }\end{array}$ & $\begin{array}{c}\text { Somewhat } \\
\text { valuable }\end{array}$ & $\begin{array}{c}\text { Highly } \\
\text { valuable }\end{array}$ \\
$\square$ & $\square$ & $\square$ & $\square$ & $\square$ \\
\hline
\end{tabular}

11. Professional respect (Colleagues)

A. Other practitioners within my profession will respect my board certification status.

\begin{tabular}{|c|c|c|c|c|}
\hline $\begin{array}{c}\text { Will definitely } \\
\text { not occur }\end{array}$ & $\begin{array}{c}\text { Unlikely to } \\
\text { occur }\end{array}$ & Unsure & $\begin{array}{c}\text { Likely to } \\
\text { occur }\end{array}$ & $\begin{array}{c}\text { Will definitely } \\
\text { occur }\end{array}$ \\
$\square$ & $\square$ & $\square$ & $\square$ & $\square$ \\
\hline
\end{tabular}


11. Professional respect (Colleagues), (continued)

B. I value professional respect from my colleagues

\begin{tabular}{|c|c|c|c|c|}
\hline No value & Low value & $\begin{array}{c}\text { Mid range of } \\
\text { value }\end{array}$ & $\begin{array}{c}\text { Somewhat } \\
\text { valuable }\end{array}$ & $\begin{array}{c}\text { Highly } \\
\text { valuable }\end{array}$ \\
$\square$ & $\square$ & $\square$ & $\square$ & $\square$ \\
\hline
\end{tabular}

12. Annual salary increases

A. If I am board certified I will receive higher annual salary increases.

\begin{tabular}{|c|c|c|c|c|}
\hline $\begin{array}{c}\text { Will definitely } \\
\text { not occur }\end{array}$ & $\begin{array}{c}\text { Unlikely to } \\
\text { occur }\end{array}$ & Unsure & $\begin{array}{c}\text { Likely to } \\
\text { occur }\end{array}$ & $\begin{array}{c}\text { Will definitely } \\
\text { occur }\end{array}$ \\
$\square$ & $\square$ & $\square$ & $\square$ & $\square$ \\
\hline
\end{tabular}

B. I value higher annual salary increases.

\begin{tabular}{|c|c|c|c|c|}
\hline No value & Low value & $\begin{array}{c}\text { Mid range of } \\
\text { value }\end{array}$ & $\begin{array}{c}\text { Somewhat } \\
\text { valuable }\end{array}$ & $\begin{array}{c}\text { Highly } \\
\text { valuable }\end{array}$ \\
$\square$ & $\square$ & $\square$ & $\square$ & $\square$ \\
\hline
\end{tabular}

13. Hiring influence

A. I would hire a board certified practitioner over another non-board certified practitioner with otherwise equal qualifications.

\begin{tabular}{|c|c|c|c|c|}
\hline $\begin{array}{c}\text { Will definitely } \\
\text { not occur }\end{array}$ & $\begin{array}{c}\text { Unlikely to } \\
\text { occur }\end{array}$ & Unsure & $\begin{array}{c}\text { Likely to } \\
\text { occur }\end{array}$ & $\begin{array}{c}\text { Will definitely } \\
\text { occur }\end{array}$ \\
$\square$ & $\square$ & $\square$ & $\square$ & $\square$ \\
\hline
\end{tabular}


13. Hiring influence (continued)

B. I value board certification enough to positively influence a hiring decision between candidates with otherwise equal qualifications.

\begin{tabular}{|c|c|c|c|c|}
\hline No value & Low value & $\begin{array}{c}\text { Mid range of } \\
\text { value }\end{array}$ & $\begin{array}{c}\text { Somewhat } \\
\text { valuable }\end{array}$ & $\begin{array}{c}\text { Highly } \\
\text { valuable }\end{array}$ \\
$\square$ & $\square$ & $\square$ & $\square$ & $\square$ \\
\hline
\end{tabular}

14. Financial incentive to SEEK board certification

A. Increased financial incentive from my employer would cause me to SEEK board certification status.

\begin{tabular}{|c|c|c|c|c|}
\hline $\begin{array}{c}\text { Will definitely } \\
\text { not occur }\end{array}$ & $\begin{array}{c}\text { Unlikely to } \\
\text { occur }\end{array}$ & Unsure & $\begin{array}{c}\text { Likely to } \\
\text { occur }\end{array}$ & $\begin{array}{c}\text { Will definitely } \\
\text { occur }\end{array}$ \\
$\square$ & $\square$ & $\square$ & $\square$ & $\square$ \\
\hline
\end{tabular}

B. I value a financial incentive from my employer based on SEEKING board certification.

\begin{tabular}{|c|c|c|c|c|}
\hline No value & Low value & $\begin{array}{c}\text { Mid range of } \\
\text { value }\end{array}$ & $\begin{array}{c}\text { Somewhat } \\
\text { valuable }\end{array}$ & $\begin{array}{c}\text { Highly } \\
\text { valuable }\end{array}$ \\
$\square$ & $\square$ & $\square$ & $\square$ & $\square$ \\
\hline
\end{tabular}

15. Financial incentive to MAINTAIN board certification

A. Increased financial incentive from my employer would cause me to MAINTAIN board certification.

\begin{tabular}{|c|c|c|c|c|}
\hline $\begin{array}{c}\text { Will definitely } \\
\text { not occur }\end{array}$ & $\begin{array}{c}\text { Unlikely to } \\
\text { occur }\end{array}$ & Unsure & $\begin{array}{c}\text { Likely to } \\
\text { occur }\end{array}$ & $\begin{array}{c}\text { Will definitely } \\
\text { occur }\end{array}$ \\
$\square$ & $\square$ & $\square$ & $\square$ & $\square$ \\
\hline
\end{tabular}


15. Financial incentive to MAINTAIN board certification (continued)

B. I value a financial incentive from my employer to MAINTAIN board certification status.

\begin{tabular}{|c|c|c|c|c|}
\hline No value & Low value & $\begin{array}{c}\text { Mid range of } \\
\text { value }\end{array}$ & $\begin{array}{c}\text { Somewhat } \\
\text { valuable }\end{array}$ & $\begin{array}{c}\text { Highly } \\
\text { valuable }\end{array}$ \\
$\square$ & $\square$ & $\square$ & $\square$ & $\square$ \\
\hline
\end{tabular}

16. Non-professional co-workers' respect

A. Non-professional co-workers will respect board certification status.

\begin{tabular}{|c|c|c|c|c|}
\hline $\begin{array}{c}\text { Will definitely } \\
\text { not occur }\end{array}$ & $\begin{array}{c}\text { Unlikely to } \\
\text { occur }\end{array}$ & Unsure & $\begin{array}{c}\text { Likely to } \\
\text { occur }\end{array}$ & $\begin{array}{c}\text { Will definitely } \\
\text { occur }\end{array}$ \\
$\square$ & $\square$ & $\square$ & $\square$ & $\square$ \\
\hline
\end{tabular}

B. I value non-professional co-workers respect of board certification status.

\begin{tabular}{|c|c|c|c|c|}
\hline No value & Low value & $\begin{array}{c}\text { Mid range of } \\
\text { value }\end{array}$ & $\begin{array}{c}\text { Somewhat } \\
\text { valuable }\end{array}$ & $\begin{array}{c}\text { Highly } \\
\text { valuable }\end{array}$ \\
$\square$ & $\square$ & $\square$ & $\square$ & $\square$ \\
\hline
\end{tabular}

17. Practice skills confidence

A. I will have increased confidence in my practice skills as a result of being board certified.

\begin{tabular}{|c|c|c|c|c|}
\hline $\begin{array}{c}\text { Will definitely } \\
\text { not occur }\end{array}$ & $\begin{array}{c}\text { Unlikely to } \\
\text { occur }\end{array}$ & Unsure & $\begin{array}{c}\text { Likely to } \\
\text { occur }\end{array}$ & $\begin{array}{c}\text { Will definitely } \\
\text { occur }\end{array}$ \\
$\square$ & $\square$ & $\square$ & $\square$ & $\square$ \\
\hline
\end{tabular}


17. Practice skills confidence (continued)

B. I value increased confidence in my practice skills.

\begin{tabular}{|c|c|c|c|c|}
\hline No value & Low value & $\begin{array}{c}\text { Mid range of } \\
\text { value }\end{array}$ & $\begin{array}{c}\text { Somewhat } \\
\text { valuable }\end{array}$ & $\begin{array}{c}\text { Highly } \\
\text { valuable }\end{array}$ \\
$\square$ & $\square$ & $\square$ & $\square$ & $\square$ \\
\hline
\end{tabular}

18. Personal accomplishment

A. I will feel a sense of personal accomplishment by becoming board certified.

\begin{tabular}{|c|c|c|c|c|}
\hline $\begin{array}{c}\text { Will definitely } \\
\text { not occur }\end{array}$ & $\begin{array}{c}\text { Unlikely to } \\
\text { occur }\end{array}$ & Unsure & $\begin{array}{c}\text { Likely to } \\
\text { occur }\end{array}$ & $\begin{array}{c}\text { Will definitely } \\
\text { occur }\end{array}$ \\
$\square$ & $\square$ & $\square$ & $\square$ & $\square$ \\
\hline
\end{tabular}

B. I value personal accomplishment demonstrated by a board certification credential.

\begin{tabular}{|c|c|c|c|c|}
\hline No value & Low value & $\begin{array}{c}\text { Mid range of } \\
\text { value }\end{array}$ & $\begin{array}{c}\text { Somewhat } \\
\text { valuable }\end{array}$ & $\begin{array}{c}\text { Highly } \\
\text { valuable }\end{array}$ \\
$\square$ & $\square$ & $\square$ & $\square$ & $\square$ \\
\hline
\end{tabular}

19. Increased responsibility

A. I will have increased responsibility in my job role after becoming board certified.

\begin{tabular}{|c|c|c|c|c|}
\hline $\begin{array}{c}\text { Will definitely } \\
\text { not occur }\end{array}$ & $\begin{array}{c}\text { Unlikely to } \\
\text { occur }\end{array}$ & Unsure & $\begin{array}{c}\text { Likely to } \\
\text { occur }\end{array}$ & $\begin{array}{c}\text { Will definitely } \\
\text { occur }\end{array}$ \\
$\square$ & $\square$ & $\square$ & $\square$ & $\square$ \\
\hline
\end{tabular}


19. Increased responsibility (continued)

B. I value increased responsibility in my job role.

\begin{tabular}{|c|c|c|c|c|}
\hline No value & Low value & $\begin{array}{c}\text { Mid range of } \\
\text { value }\end{array}$ & $\begin{array}{c}\text { Somewhat } \\
\text { valuable }\end{array}$ & $\begin{array}{c}\text { Highly } \\
\text { valuable }\end{array}$ \\
$\square$ & $\square$ & $\square$ & $\square$ & $\square$ \\
\hline
\end{tabular}

20. One time bonus

A. I will receive a one time pay bonus upon completion of board certification.

\begin{tabular}{|c|c|c|c|c|}
\hline $\begin{array}{c}\text { Will definitely } \\
\text { not occur }\end{array}$ & $\begin{array}{c}\text { Unlikely to } \\
\text { occur }\end{array}$ & Unsure & $\begin{array}{c}\text { Likely to } \\
\text { occur }\end{array}$ & $\begin{array}{c}\text { Will definitely } \\
\text { occur }\end{array}$ \\
$\square$ & $\square$ & $\square$ & $\square$ & $\square$ \\
\hline
\end{tabular}

B. I value a one time pay bonus for completion of board certification.

\begin{tabular}{|c|c|c|c|c|}
\hline No value & Low value & $\begin{array}{c}\text { Mid range of } \\
\text { value }\end{array}$ & $\begin{array}{c}\text { Somewhat } \\
\text { valuable }\end{array}$ & $\begin{array}{c}\text { Highly } \\
\text { valuable }\end{array}$ \\
$\square$ & $\square$ & $\square$ & $\square$ & $\square$ \\
\hline
\end{tabular}

21. Paid certification costs

A. My recertification costs will be paid by my employer.

\begin{tabular}{|c|c|c|c|c|}
\hline $\begin{array}{c}\text { Will definitely } \\
\text { not occur }\end{array}$ & $\begin{array}{c}\text { Unlikely to } \\
\text { occur }\end{array}$ & Unsure & $\begin{array}{c}\text { Likely to } \\
\text { occur }\end{array}$ & $\begin{array}{c}\text { Will definitely } \\
\text { occur }\end{array}$ \\
$\square$ & $\square$ & $\square$ & $\square$ & $\square$ \\
\hline
\end{tabular}


21. Paid certification costs (continued)

B. I value that my employer would pay my recertification costs.

\begin{tabular}{|c|c|c|c|c|}
\hline No value & Low value & $\begin{array}{c}\text { Mid range of } \\
\text { value }\end{array}$ & $\begin{array}{c}\text { Somewhat } \\
\text { valuable }\end{array}$ & $\begin{array}{c}\text { Highly } \\
\text { valuable }\end{array}$ \\
$\square$ & $\square$ & $\square$ & $\square$ & $\square$ \\
\hline
\end{tabular}

22. Promotion potential

A. I will be more likely to be promoted by my employer by employer if I am board certified.

\begin{tabular}{|c|c|c|c|c|}
\hline $\begin{array}{c}\text { Will definitely } \\
\text { not occur }\end{array}$ & $\begin{array}{c}\text { Unlikely to } \\
\text { occur }\end{array}$ & Unsure & $\begin{array}{c}\text { Likely to } \\
\text { occur }\end{array}$ & $\begin{array}{c}\text { Will definitely } \\
\text { occur }\end{array}$ \\
$\square$ & $\square$ & $\square$ & $\square$ & $\square$ \\
\hline
\end{tabular}

B. I value promotions based on board certification.

\begin{tabular}{|c|c|c|c|c|}
\hline No value & Low value & $\begin{array}{c}\text { Mid range of } \\
\text { value }\end{array}$ & $\begin{array}{c}\text { Somewhat } \\
\text { valuable }\end{array}$ & $\begin{array}{c}\text { Highly } \\
\text { valuable }\end{array}$ \\
$\square$ & $\square$ & $\square$ & $\square$ & $\square$ \\
\hline
\end{tabular}

23. Public notification

A. There would be a public notification of my achievement and $\mathrm{s}$ status if I become board certified.

\begin{tabular}{|c|c|c|c|c|}
\hline $\begin{array}{c}\text { Will definitely } \\
\text { not occur }\end{array}$ & $\begin{array}{c}\text { Unlikely to } \\
\text { occur }\end{array}$ & Unsure & $\begin{array}{c}\text { Likely to } \\
\text { occur }\end{array}$ & $\begin{array}{c}\text { Will definitely } \\
\text { occur }\end{array}$ \\
$\square$ & $\square$ & $\square$ & $\square$ & $\square$ \\
\hline
\end{tabular}


23. Public notification (continued)

B. I value a public notification of my achievement and status.

\begin{tabular}{|c|c|c|c|c|}
\hline No value & Low value & $\begin{array}{c}\text { Mid range of } \\
\text { value }\end{array}$ & $\begin{array}{c}\text { Somewhat } \\
\text { valuable }\end{array}$ & $\begin{array}{c}\text { Highly } \\
\text { valuable }\end{array}$ \\
$\square$ & $\square$ & $\square$ & $\square$ & $\square$ \\
\hline
\end{tabular}

24. Improved professional network

A. I would have an improved professional network by becoming board certified.

\begin{tabular}{|c|c|c|c|c|}
\hline $\begin{array}{c}\text { Will definitely } \\
\text { not occur }\end{array}$ & $\begin{array}{c}\text { Unlikely to } \\
\text { occur }\end{array}$ & Unsure & $\begin{array}{c}\text { Likely to } \\
\text { occur }\end{array}$ & $\begin{array}{c}\text { Will definitely } \\
\text { occur }\end{array}$ \\
$\square$ & $\square$ & $\square$ & $\square$ & $\square$ \\
\hline
\end{tabular}

B. I value an improved professional network.

\begin{tabular}{|c|c|c|c|c|}
\hline No value & Low value & $\begin{array}{c}\text { Mid range of } \\
\text { value }\end{array}$ & $\begin{array}{c}\text { Somewhat } \\
\text { valuable }\end{array}$ & $\begin{array}{c}\text { Highly } \\
\text { valuable }\end{array}$ \\
$\square$ & $\square$ & $\square$ & $\square$ & $\square$ \\
\hline
\end{tabular}

25. Job requirement

A. Board certification will become necessary for my job.

\begin{tabular}{|c|c|c|c|c|}
\hline $\begin{array}{c}\text { Will definitely } \\
\text { not occur }\end{array}$ & $\begin{array}{c}\text { Unlikely to } \\
\text { occur }\end{array}$ & Unsure & $\begin{array}{c}\text { Likely to } \\
\text { occur }\end{array}$ & $\begin{array}{c}\text { Will definitely } \\
\text { occur }\end{array}$ \\
$\square$ & $\square$ & $\square$ & $\square$ & $\square$ \\
\hline
\end{tabular}


25. Job requirement (continued)

B. I value that my job will require board certification.

\begin{tabular}{|c|c|c|c|c|}
\hline No value & Low value & $\begin{array}{c}\text { Mid range of } \\
\text { value }\end{array}$ & $\begin{array}{c}\text { Somewhat } \\
\text { valuable }\end{array}$ & $\begin{array}{c}\text { Highly } \\
\text { valuable }\end{array}$ \\
$\square$ & $\square$ & $\square$ & $\square$ & $\square$ \\
\hline
\end{tabular}

\section{Expectancy}

This section is based on your opinion of the likelihood of completion of board certification upon expenditure of the effort. If you have no intention of pursuing board certification in a Pharmacy practice specialty please answer question 26.a.

Please answer N/A as needed.

\section{Expectancy}

A. I am NOT currently board certified but I feel that if I expended the effort I would successfully complete the board certification process.

\begin{tabular}{|c|c|c|c|c|c|}
\hline $\begin{array}{c}\text { Will } \\
\text { definitely } \\
\text { not occur }\end{array}$ & $\begin{array}{c}\text { Unlikely to } \\
\text { occur }\end{array}$ & Unsure & $\begin{array}{c}\text { Likely to } \\
\text { occur }\end{array}$ & $\begin{array}{c}\text { Will } \\
\text { definitely } \\
\text { occur }\end{array}$ & N/A \\
$\square$ & $\square$ & $\square$ & $\square$ & $\square$ & $\square$ \\
\hline
\end{tabular}


26. Expectancy (continued)

B. I AM currently board certified and PRIOR TO BEGINNING preparation for specialty certification I felt that if I expended the effort I would successfully complete the requirements for board certification.

\begin{tabular}{|c|c|c|c|c|c|}
\hline $\begin{array}{c}\text { Will } \\
\text { definitely } \\
\text { not occur }\end{array}$ & $\begin{array}{c}\text { Unlikely to } \\
\text { occur }\end{array}$ & Unsure & $\begin{array}{c}\text { Likely to } \\
\text { occur }\end{array}$ & $\begin{array}{c}\text { Will } \\
\text { definitely } \\
\text { occur }\end{array}$ & N/A \\
$\square$ & $\square$ & $\square$ & $\square$ & $\square$ & $\square$ \\
\hline
\end{tabular}

C. I WAS formerly board certified and PRIOR TO BEGINNING preparation for specialty certification I felt that if I expended the effort I would successfully complete the requirements for board certification.

\begin{tabular}{|c|c|c|c|c|c|}
\hline $\begin{array}{c}\text { Will } \\
\text { definitely } \\
\text { not occur }\end{array}$ & $\begin{array}{c}\text { Unlikely to } \\
\text { occur }\end{array}$ & Unsure & $\begin{array}{c}\text { Likely to } \\
\text { occur }\end{array}$ & $\begin{array}{c}\text { Will } \\
\text { definitely } \\
\text { occur }\end{array}$ & N/A \\
$\square$ & $\square$ & $\square$ & $\square$ & $\square$ & $\square$ \\
\hline
\end{tabular}

\section{Demographics}

The following are demographic questions modified from previous Board of

Pharmaceutical Specialties surveys. They are an important link from earlier studies findings and those from this study.

Responses are not required for this section but are important to this research. 
27. Please list your current memberships in professional Pharmacy organizations:

(Check all that apply, note these are in random order [in electronic version])

AACP

ASHP

ACCP

$\mathrm{APhA}$

None

Other (please specify):

28. Age?

29. Gender?

Male

Female

30. What is your current board certification status? (List all that apply)

None, Never Certified

Board Certified Nuclear Pharmacist (BCNP)

Board Certified Nutrition Support Pharmacist (BCNSP)

Board Certified Oncology Pharmacist (BCOP)

Board Certified Psychiatric Pharmacist (BCPP)

Board Certified Pharmacotherapy Specialist (BCPS)

Formerly Certified (BCNP)

Formerly Certified (BCNSP)

Formerly Certified (BCOP)

Formerly Certified (BCPP)

Formerly Certified (BCPS)

31. What is the CITY of your PRIMARY practice setting? 
32. What is the STATE, TERRITORY or LOCATION (e.g. international work location) of your PRIMARY practice setting?

(If not found in drop down menu please enter in box below that line:

\begin{tabular}{|c|c|c|c|c|}
\hline$\square$ & $\mathrm{AK}$ & $\square$ & ND & $\square$ \\
\hline$\square$ & $\mathrm{AL}$ & $\square$ & $\mathrm{NE}$ & $\square$ \\
\hline$\square$ & AR & $\square$ & $\mathrm{NH}$ & $\square$ \\
\hline$\square$ & $\mathrm{AZ}$ & $\square$ & $\mathrm{NJ}$ & $\square$ \\
\hline$\square$ & CA & $\square$ & NM & $\square$ \\
\hline$\square$ & $\mathrm{CO}$ & $\square$ & NV & $\square$ \\
\hline$\square$ & CT & $\square$ & NY & \\
\hline$\square$ & $\mathrm{DC}$ & $\square$ & $\mathrm{OH}$ & \\
\hline$\square$ & $\mathrm{DE}$ & $\square$ & OK & \\
\hline$\square$ & $\mathrm{FL}$ & $\square$ & OR & \\
\hline$\square$ & GA & $\square$ & PA & \\
\hline$\square$ & HI & $\square$ & RI & \\
\hline$\square$ & IA & $\square$ & $\mathrm{SC}$ & \\
\hline$\square$ & ID & $\square$ & SD & \\
\hline$\square$ & IL & $\square$ & $\mathrm{TN}$ & \\
\hline$\square$ & IN & $\square$ & $\mathrm{TX}$ & \\
\hline$\square$ & KS & $\square$ & UT & \\
\hline$\square$ & $\mathrm{KY}$ & $\square$ & VA & \\
\hline$\square$ & LA & $\square$ & VT & \\
\hline$\square$ & MA & $\square$ & WA & \\
\hline$\square$ & MD & $\square$ & WI & \\
\hline$\square$ & $\mathrm{ME}$ & $\square$ & WV & \\
\hline$\square$ & MI & $\square$ & WY & \\
\hline$\square$ & $\mathrm{MN}$ & $\square$ & AS & \\
\hline$\square$ & MO & $\square$ & GU & \\
\hline$\square$ & MS & $\square$ & MP & \\
\hline$\square$ & MT & $\square$ & PR & \\
\hline П & $\mathrm{NC}$ & $\square$ & VI & \\
\hline
\end{tabular}


33. Which of the following most closely classifies your position at your primary practice site? Multiple answers are allowed but please limit to two.

Staff Pharmacist

Clinical Staff Pharmacist

Clinical Manager

Pharmacy Manager

Pharmacy Director

Regional Manager

Corporate Position

Owner/Partner in Pharmacy Business

Educator

Researcher

34. Select the ONE area from those listed below, in which the MAJORITY of your practice takes place.

Academic Institution

Ambulatory Care Clinic

Cancer Center

Community Pharmacy, Chain

Community Pharmacy, Independent

Correctional Facility

Drug Information Center

Government/Military Hospital/Institution

Hospital, Community for Profit

Hospital, Community Not-for-Profit

Hospital, University

Hospital, University-Affiliated

Home Health Care

Intermediate Care Facility 
34. Select the ONE area from those listed below, in which the MAJORITY of your practice takes place (continued).

$\begin{array}{ll}\square & \text { Long Term Care } \\ \square & \text { Managed Health Care, HMO, PPO or other plan } \\ \square & \text { Managed Health Care, Pharmacy Benefits Manager } \\ \square & \text { Nuclear Pharmacy, Centralized, Independent } \\ \square & \text { Nuclear Pharmacy, Centralized, Chain } \\ \square & \text { Nuclear Pharmacy, Hospital/Academic } \\ \square & \text { Pharmaceutical Industry } \\ \square \quad \text { Psychiatric Hospital/Facility } \\ \square \quad \text { Specialty Pharmacy }\end{array}$

34. What is the average number of hours you typically work each week in the practice of Pharmacy?

$\begin{array}{ll}\square & \text { Less than } 20 \\ \square & 20-30 \\ \square & 31-40 \\ \square & 41-50 \\ \square & 51-60\end{array}$

35. What was your ENTRY LEVEL Pharmacy-related degree?

Bachelor's Degree

Pharm.D.

Other (please specify): 
36. What is the HIGHEST Pharmacy-related degree you have earned?

$\begin{array}{ll}\square & \text { Bachelor's Degree } \\ \square & \text { Master's Degree } \\ \square & \text { Pharm.D. } \\ \square & \text { PhD } \\ \square & \text { Other (please specify): }\end{array}$

37. If you earned a Pharm.D. degree, please indicate the TYPE of Pharm.D. program.

$\begin{array}{ll}\square & 6 \text { year, entry-level } \\ \square & 6 \text { year, track-in } \\ \square & 1 \text { year, post BS (Pharmacy) } \\ \square & 2 \text { year, post BS (Pharmacy) } \\ \square & 3 \text { year, post BS (Pharmacy) } \\ \square & 4 \text { year, post BS (Pharmacy) } \\ \square & \text { External/Non-Traditional } \\ \square & \text { Other (please specify): }\end{array}$

38. Have you completed a residency training program?

No

Yes, post BS

Yes, post Pharm.D.

Yes, as part of Pharm.D. program

Yes, as part of MS program

Other (please specify): 
39. In total, how many years have you worked full- and/or part-time as a licensed pharmacist?

$\begin{array}{ll}\square & \text { Less than } 3 \text { years } \\ \square & 3-5 \text { years } \\ \square & 6 \text {-8 years } \\ \square & 9 \text {-11 years } \\ \square & 12-14 \text { years } \\ \square & 15-17 \text { years } \\ \square & 18-20 \text { years } \\ \square & \text { More than } 20 \text { years }\end{array}$

40. In total, how many years have you worked full- and/or part-time in your current area of specialty or practice focus?

Less than 3 years

3-5 years

6-8 years

$\square \quad 9-11$ years

12-14 years

$15-17$ years

18-20 years

More than 20 years

41. Indicate your PRIMARY reason for seeking board certification.

I do not intend to pursue board certification in Pharmacy practice

Increase in salary or one time bonus (potential or actual)

Career advancement

Job requirement 
41. Indicate your PRIMARY reason for seeking board certification (continued).

Job security

Increase in professional status

Peer recognition

Other (please specify):

42. Indicate a SECONDARY reason for seeking board certification.

I do not intend to pursue board certification in Pharmacy practice

Increase in salary or one time bonus (potential or actual)

Career advancement

Job requirement

Job security

Increase in professional status

Peer recognition

Other (please specify):

\section{Additional Comments}

Additional comments related to board certification in Pharmacy practice: 
Appendix B 


\section{Letters to Pharmacy Organizations Seeking Assistance and Cooperation and}

\section{Communications of Agreement to Participate}

\section{THE UNIVERSITY OF TENNESSEE}

Health Science Center

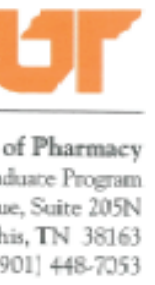

Tel: $(901) 446,106)$

Michasl S. Maddux, Pharm.D.

Executive Director

American College of Clinical Pharmacy

13000 W. 87th Street Pkwy

Lenexa, KS $66215-4530$

Dear Dr. Maddux:

Specialty certification in pharmacy has existed since 1978. Since the inception of the Board of Pharmaceutical Specialties in 1976 and the creation of board certification it has been an inherent mission to maximize the number of pharmacists that are board certified.

Despite efforts to promote the importance of specialty certification only a relatively small number of pharmacists choose to seek and maintain this status. Research regarding this process has focused on the benefit to the health care system. Despite some positive findings in these studies, major questions exist. Specifically, "what do the pharmacists that achieve board certification receive as a benefit from this activity?" also "what motivational factors can lead pharmacists to seek and maintain board certification?"

A research project is underway that seeks to answer these questions via a demonstrated survey instrument. This Ph.D. dissertation project at the University of Tennessee Health Science Center in Memphis, Tennessee, is entitled "Why do qualified pharmacists choose to seek or not seek board certification in pharmacy practice?" Expectations are that motivational factors leading to pursuit of board certification may demonstrate a proclivity to seek board certification in pharmacy practice and that this group, compared to a similar group of pharmacists that have chosen not to pursue (or maintain) board certification in pharmacy will be different.

It is proposed that an index can be directly calculated from the responding values on the survey instrument. This "score" will allow some direet measure and stratification within groups. These findings will be substantiated by way of statistical verification. Although the intent of the research is not to adjust pharmacy organization's methods to promote board certification that could be an ongoing project after the initial study.

We ask that your organization utilize the link to the survey, either as an e-mail attachment or an addition as a link on your website, to allow us to gather information on pharmacists that have not achieved board certification but that otherwise have all the qualifications. These will serve as a control group. The Board of Pharmaceutical Specialties has agreed to do likewise for those that are currently, or were formerly, so credentialed. Your endorsement of the research project and request for participation will be greatly appreciated. Oar research effort should provide useful information about pharmacists practitioners related to board certification. 
Please see the attached survey instrument which as stated can be deployed as a link in an e-mail message and/or a website link. This link will go to a third party survey tool which will be used to collect the data. Please advise as to your consideration and support of this important research endeavor.

We will gladly forward, upon your agreement to participate, the e-mail URL link and/or website code.

Sincerely,

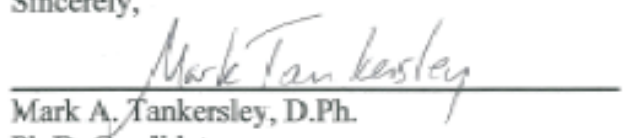

Ph.D. Candidate

Health Science Administration Graduate Program

College of Pharmacy

University of Tennessee Health Science Center, Memphis, Tennessee

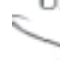

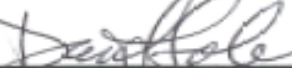

David K. Solomon, Pharm.D., FASHP

Research Committee Chair

Chief of Pharmacy, VA Medical Center-Memphis

Professor and Associate Dean

Director, Health System Pharmacy Management Graduate Program

College of Pharmacy

University of Tennessee Health Science Center, Memphis, Tennessee

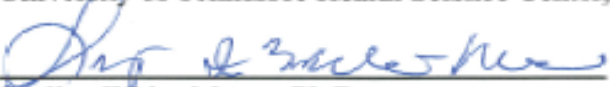

Shelley White-Means, Ph.D.

Department Chair, Health Science Administration Graduate Program

Professor and Vice-Chair, Department of Pharmaceutical Sciences

College of Pharmacy

University of Tenpessee Health Science Center, Memphis, Tennessee

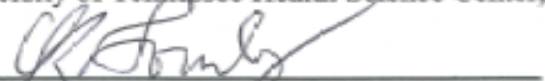

Dick R. Gourley, Pharm. D.

Professor and Dean

College of Pharmacy

University of Tennessee Health Science Center, Memphis, Tennessee

Srevend Restur

Richard J. Bertin, PhD, RPh

Executive Director, Boand of Pharmaceutical Spezialties

Consultant to the Graduate Research Committee 


\section{Mark Tankersley}

\section{From: Mike Maddux [mmaddux@accp.com] \\ Sent: Wednesday, March 14, 2007 6:09 PM \\ To: Mark Tankersley}

Subject: RE: Pharmacist Perceptions and Values Related to Specialty Certification

Excellent - if you have a draft of a newsletter story, just forward it to me and I'll incorporate into the April issue.

Thanks,

Mike Maddux

Michael S. Maddux, Pharm.D., FCCP

Executive Director

American College of Clinical Pharmacy

13000 W. 87 th Street Parkway

Lenexa, KS 66215-4530

Phone: (913) 492-3311

Fax: (913) 492-0088

From: Mark Tankersley [mailto:Mark.Tankersley@accredohealth.com]

Sent: Wednesday, March 14, 2007 5:00 PM

To: Mike Maddux

Cc: Bertin, Richard; David Solomon; david.solomon@med.va.gov

Subject: RE: Pharmacist Perceptions and Values Related to Specialty Certification

Thank you for your interest. It will be a couple of weeks before we can post the URL. In the meantime, perhaps I can assist with the short announcement for your newsletter.

From: Mike Maddux [mailto:mmaddux@accp.com]

Sent: Wednesday, March 14, 2007 3:39 PM

To: Mark Tankersley

Cc: 'Bertin, Richard'

Subject: Pharmacist Perceptions and Values Related to Specialty Certification

Dr. Tankersley,

Thank you for your recent letter and copy of your study survey. ACCP would be happy to endorse and partcipate in this research project. Please forward us the e-mail URL (which I presume includes the necessary e-mail text regarding the study) and Web site code. If you'd like, we will also run a short announcement in our newsletter about the study, including the appropriate survey link.

Sincerely,

Mike Maddux

Michael S. Maddux, Pharm.D., FCCP 
THE UNIVERSITY OF TENNESSEE

Health Science Center

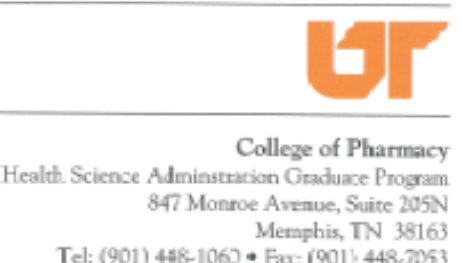

Tel: (901) 448-1060 • Fax: $(901)$ 448.7053

Henri R. Manasse, Jr., Ph.D., Sc.D.

Executive Vice President and CEO

American Society of Health-System Pharmacists

7272 Wisconsin Avenue

Bethesda, MD 20814

Dear Dr. Manasse:

Specialty certification in pharmacy has existed since 1978. Since the inception of the Board of Pharmaceutical Specialties in 1976 and the creation of board certification it has been an inherent mission to maximize the number of pharmacists that are board certified.

Despile efforts to promote the importance of specialty certification only a relatively small number of pharmacists choose to seek and maintain this status. Research regarding this process has focused on the benefit to the health care system. Despite some positive findings in these studies, major questions exist. Specifically, "what do the pharmacists that achieve board certification receive as a benefit from this activity?" also "what motivational factors can lead pharmacists to seek and maintain board certification?"

A research project is underway that seeks to answer these questions via a demonstrated survey instrument. This $\mathrm{Ph} \mathrm{D}$. dissertation project at the University of Tennessee Health Science Center in Memphis, Tennessee, is entitled "Why do qualified pharmacists choose to seek or not seek board certification in pharmacy practice?" Expectations are that motivational factors leading to pursuit of board certification may demonstrate a pcoclivity to seek board certification in pharmacy practice and that this group, compared to a similar group of pharmacists that have chosen not to pursue (or maintain) board certification in pharmacy will be diffenent.

It is proposed that an index can be directly calculated from the responding values on the survey instrument. This "score" will allow some direct measure and stratification within groups. These findings will be substantiated by way of statistical verification. Although the intent of the research is not to adjust pharmacy organization's methods to promote board certification that could be an ongoing project after the initial study.

We ask that your organization utilize the link to the survey, either as an e-mail attachment or an addition as a link on your website, to allow us to gather information on pharmacists that have not achieved board certification but that otherwise have all the qualifications. These will serve as a control group. The Bioard of Pharmaceutical Specialties has agreed to do likewise for those that are currently, or were formerly, so credentialed. Your endorsement of the research project and request for participation will be greatly appreciated. Our research effort should provide useful information about pharmacists practitioners related to board certification. 
Please see the attached survey instrument which as stated can be deployed as a link in an e-mail message and/or a website link. This link will go to a third party survey tool which will be used to collect the data. Please advise as to your consideration and support of this important research endeavor.

We will gladly forward, upon your agreement to participate, the e-mail URL link and/or website code.

Sincerely,

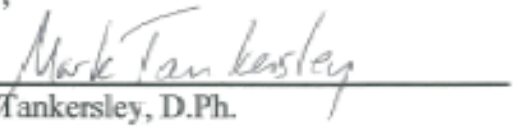

Mark A. Tankersley, D.Ph.

Ph.D. Candidate

Health Science Administration Graduate Program

College of Pharmacy

University of Tennessee Health Science Center, Memphis, Tennessee<smiles>C1CC1</smiles>

Preisterte

David K. Solomon, Pharm.D., FASHP

Research Committee Chair

Chief of Pharmacy, VA Medical Center-Memphis

Professor and Associate Dean

Director, Health System Pharmacy Management Graduate Program

College of Pharmacy

University of Tennessee Health Science Center, Memphis, Tennessee

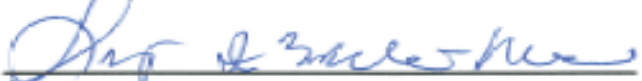

Shelley White-Means, Ph.D.

Department Chair, Health Science Administration Graduate Program

Professor and Vice-Chair, Department of Pharmaceutical Sciences

College of Pharmacy

University of Tennessee Health Science Center, Memphis, Tennessee

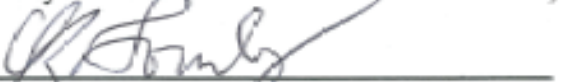

Dick R. Gourley, Pharm. D.

Professor and Dean

College of Pharmacy

University of Tennessee Health Science Center, Memphis, Tennessee

Srevend Restex

Richard J. Bertin, PhD, RPh

Executive Director, Boand of Pharmaceutical Specialties

Consultant to the Graduate Research Committee 
Mark Tankersley

$\begin{array}{ll}\text { From: } & \text { William Zellmer [wzellmer@ashp.org] } \\ \text { Sent: } & \text { Saturday, March 17, 2007 4:49 PM } \\ \text { To: } & \text { Mark Tankersley } \\ \text { Subject: } & \text { Question about your letter to Dr. Henri Manasse of ASHP }\end{array}$

Dear. Dr. Tankersley,

Henri Manasse has referred your recent letter to me for follow up. Does your inquiry boil down to the following request?:

ASHP is requested to publicize to its members your study on Specialty

Certification and encourage them to take your Web-based survey.

If we understand correctly, we could run an item about this in our weekly electronic news report to members, with a link to your survey.

William A. Zellmer, M.P.H.

Deputy Executive Vice President

American Society of Health-System Pharmacists

7272 Wisconsin Avenue

Bethesda, MD 20814

tel: $301-664-8623$

fax: $301-634-5723$

email: wzellmerkashp.org

Web: wow.ashp.org 
THE UNIVERSITY OF TENNESSEE

Health Science Center

College of Pharmacy
Health Sicience Adrainstration Graduare Program
847 Mon:ce Avenue, Suite 205N
Mernphis, TN 38163
Tel: (901) 446-1060 - Fas: [901] 448-7053

February 6, 2007

Tel: (901) 446-1060 - Fas: [901] 48-7053

John Gans, Pharm.D.

Executive Vice President and CEO

American Pharmacists Association

1100 Fifteenth Street, NW

Washington, DC 20005

Dear Dr. Gans:

Specialty certification in pharmacy has existed since 1978. Since the inception of the Board of Pharmaceutical Specialties in 1976 and the creation of board certification it has been an inherent mission to maximize the number of pharmacists that are board certified.

Despite efforts to promote the importance of specialty certification only a relatively small number of pharmacists choose to seek and maintain this status. Research regarding this process has focused on the benefit to the health care system. Despite some positive findings in these studies, major questions exist. Specifically, "what do the pharmacists that achieve board certification receive as a benefit from this activity?" also "what motivational factors can lead pharmacists to seek and maintain board certification?"

A research project is underway that seeks to answer these questions via a demonstrated survey instrument. This Ph.D. dissertation project at the University of Tennessee Health Science Center in Memphis, Tennessee, is entitled "Why do qualified pharmacists choose to seek or not seek board certification in pharmacy practice?" Expectations are that motivational factors leading to pursuit of board certification may demonstrate a proclivity to seek board certification in pharmacy practice and that this group, compared to a similar group of pharmacists that have chosen not to pursue (or maintain) board certification in pharmacy will be different.

It is pcoposed that an index can be directly calculated from the responding values on the survey instrument. This "score" will allow some direct measure and stratification within groups. These findings will be substantiated by way of statistical verification. Although the intent of the research is not to adjust pharmacy organization's methods to promote board certification that could be an ongoing project after the initial study.

We ask that your organization utilize the link to the survey, either as an e-mail attachment or an addition as a link on your website, to allow us to gather information on pharmacists that have not achieved board certification but that otherwise have all the qualifications. These will serve as a control group. The Board of P'narmaceutical Specialties has agreed to do likewise for those that are currently, or were formerly, so credentialed. Your endorsement of the research project and request for participation will be greatly appreciated. Our research effort should provide useful information about pharmacists practitioners related to board certification. 
Please see the attached survey instrument which as stated can be deployed as a link in an e-mail message and/or a website link. This link will go to a third party survey tool which will be used to collect the data. Please advise as to your consideration and support of this important research endeavor.

We will gladly forward, upon your agreement to participate, the e-mail URL link and/or website code.

Sincerely,

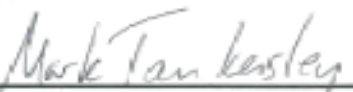

Mark A. Tankersley, D.Ph.

Ph.D. Candidate

Health Science Administration Graduate Program

College of Pharmacy

University of Tennessee Health Science Center, Memphis, Tennessee

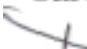

David K. Solomon, Pharm.D., FASHP

Research Committee Chair

Chief of Pharmacy, VA Medical Center-Memphis

Professor and Associate Dean

Director, Health System Pharmacy Management Graduate Program

College of Pharmacy

University of Tennessee Health Science Center, Memphis, Tennessee

Dntir incerke

Shelley White-Means, Ph.D.

Department Chair, Health Science Administration Graduate Program

Professor and Vice-Chair, Department of Pharmaceutical Sciences

College of Pharmacy

University of Tennessee Health Science Center, Memphis, Tennessee

Dick R. Gourley, Pharm. E.

Professor and Dean

College of Pharmacy

University of Tennessee Health Science Center, Memphis, Tennessee

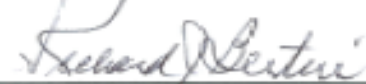

Richard J. Bertin, PhD, R.Ph

Executive Director, Boand of Pharmaceutical Spezialties

Consultant to the Graduate Research Committee 


\title{
Mark Tankersley
}

\author{
From: Bertin, Richard [RBertin@APHANET.ORG] \\ Sent: Tuesday, April 17, 2007 6:16 AM \\ To: Mark Tankersley \\ Subject: FW: Tankersley Letter
}

This is the latest I have learned. I expect it will work out. Just hang in there. Dick

Richard J. Bertin, $\mathrm{PhD}, \mathrm{RPh}$

Executive Director, Board of Pharmaceutical Specialties

1100 Fifteenth Street, NW Suite 400

Washington, DC 20005

202-223-7192 - FAX 202-429-6304

rbertin@aphanet.org

www.bpsweb.org

Please note new mailing address

From: Polley, Catherine

Sent: Thursday, April 12, 2007 11:52 AM

To: Gainey, Linda; Bertin, Richard

Cc: Burns, Anne; Bethea, Regina

Subject: RE: Tankersly Letter

Dick, we're good to go. At this very moment Daytona is making copies for me to share with Anne Burns and Reginia. (I briefly mentioned to Anne, but have not contacted Reginia other than by this email) They'll be the ones getting it out to our membership and Academy Leadership.

From: Gainey, Linda

Sent: Thursday, April 12, 2007 10:35 AM

To: Bertin, Richard

Cc: Polley, Catherine

Subject: Tankersly Letter

I apologize for not following up with you earlier in the week. I did locate the letter we discussed. Cathy Polley had it and was going to bring the matter before the Leadership Team for input. Quite possibly she has already followed up with you. Sorry!

Linda X. Gainey

Senior Director of Executive Office Operations \& Corporate Secretary

The American Pharmacists Association

110015 th Street, NW, Suite 400

Wasfington, $D C$ 20005-1707

1-800-237-APhA (2742)

Tel. (202) 429-7567; FAX (202) 429-6300

Ggainey@aphanet.ong

wurv.aphanet.org / wuvw.phanmacist.com

APGA2008 Annual Meeting -Manch 14-17 San Diego

wrvw.aphameeting.org

APh $\mathrm{A}$ was fourded in 1852 as the American Pharmaceutical Association. 
THE UNIVERSITY OF TENNESSEE

Health Science Center

$\begin{array}{lr}\text { College of Pharmacy } \\ \text { February 6, 2007 } & \begin{array}{r}\text { Health Science Adminstracion Graduare Program } \\ \text { 847 Monroe Avemue, Suite 205N } \\ \text { Memphis, TN 38163 }\end{array} \\ \text { Tel: (901) 448-106) * Fax: (901) 443.7053 }\end{array}$

Lucinda L. Maine, Fh.D.

Executive Vice President

American Association of Colleges of Pharmacy

1426 Prince Street

Alexandria, Virginia 22314

Dear Dr. Maine:

Specialty certification in pharmacy has existed sirce 1978 . Since the inception of the Board of Pharmaceutical Specialties in 1976 and the creation of board certification it has been an inherent mission to maximize the number of pharmacists that are board certified.

Despite efforts to promote the importance of specialty certification only a relatively small number of pharmacists choose to seek and maintain this status. Research regarding this process has focused on the benefit to the health care system. Despite some positive findings in these studies, major questions exist. Specifically, "what do the pharmacists that achieve board certification receive as a benefit from this activity?" also "what motivational factors can lead pharmacists to seek and maintain board certification?"

A research project is underway that seeks to answer these questions via a demonstrated survey instrument. This $\mathrm{Ph}$.D. dissertation project at the University of Tennessee Health Science Center in Memphis, Tennessee, is entitled "Why do qualified pharmacists choose to seek or not seek board certification in pharmacy practice?" Expectations are that motivational factors leading to pursuit of board certification may demonstrate a proclivity to seek board certification in pharmacy practice and that this group, compared to a similar group of pharmacists that have chosen not to pursue (or maintain) board certification in pharmacy will be different.

It is proposed that an index can be directly calculated from the responding values on the survey instrument. This "soore" will allow some direct measure and stratification within groups. These findings will be substantiated by way of statistical verification. Although the intent of the research is not to adjust pharmacy organization's methods to promote board certification that could be an ongoing project after the initial study.

We ask that your organization utilize the link to the survey, either as an e-mail attachment or an addition as a link on your website, to allow us to gather information on pharmacists that have not achieved board certification but that otherwise have all the qualifications. These will serve as a control group. The Board of Pharmaceutical Specialties has agreed to do likewise for those that are currently, or were formerly, so credentialed. Your endorsement of the research project and request for participation will be greatly appreciated. Our research effort should provide useful information about pharmacists practitioners related to board certification. 
Please see the attached survey instrument which as stated can be deployed as a link in an e-mail message and/or a website link. This link will go to a third party survey tool which will be used. to collect the data. Please advise as to your consideration and support of this important research endeavor.

We will gladly forward, upon your agreement to participate, the e-mail URL link and/or website code.

Sincerely,

$\frac{\text { /hark tan kersley }}{\text { Mark A. Tankersley, D.Ph. }}$

Ph.D. Candidate

Health Science Administration Graduate Program

College of Pharmacy

University of Tennessee Health Science Center, Memphis, Tennessee

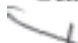

Dienterte

David K. Solomon, Pharm.D., FASHP

Research Committee Chair

Chief of Pharmacy, VA Medical Center-Memphis

Professor and Associate Dean

Director, Health System Pharmacy Management Graduate Program

College of Pharmacy

University of Tennessee Health Science Center, Memphis, Tennessee

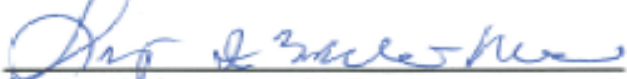

Shelley White-Means, Ph.D.

Department Chair, Health Science Administration Graduate Program

Professor and Vice-Chair, Department of Pharmaceutical Sciences

College of Pharmacy

University of Tennessee Health Science Center, Memphis, Tennessee

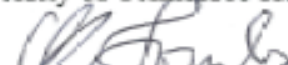

Dick R. Gourley, Pharm. D.

Professor and Dean

College of Pharmacy

University of Tennessee Health Science Center, Memphis, Tennessee

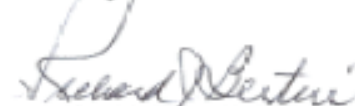

Richard J. Bertin, PhD, RPh

Executive Director, Boand of Pharmaceutical Specialties

Consultant to the Graduate Research Committee 


\section{Mark Tankersley}

$\begin{array}{ll}\text { From: } & \text { Lucinda Maine [lmaine@aacp.org] } \\ \text { Sent: } & \text { Friday, April 20, } 2007 \text { 1:13 PM } \\ \text { To: } & \text { Mark Tankersley }\end{array}$

Subject: Here's the homepage blurb on Pathways

AACP Encourages Members to Participate in Career Pathway Program Survey [3/27/07]
The Career Pathway Evaluation Proqram provides useful information about many career paths for student pharmacists and practicing pharmacists. Keeping the career profiles in the program current is dependent upon information provided by pharmacy faculty members. AACP and APhA are inviting members to participate in a web-based survey that asks about characteristics of pharmacy faculty work and activities.

Lucinda L. Maine, PhD, RPh

Executive Vice President

AACP

703-739-2330 Ext 1021

Imaineqaacporg 
Mark Tankersley

\author{
From: Bertin, Richard [RBertin@APHANET.ORG] \\ Sent: Thursday, July 05, 2007 12:27 PM \\ To: Mark Tankersley \\ Subject: Message to BPS is out
}

Finally, our e-mail push system is up and functioning, and we sent the message and survey link this morning to about 5500 persons. I heard back from a few that they were having trouble accessing the survey. The link was working fine before we sent and a little while ago, so maybe the large number of diligent BPS-certified specialists responding immediately bogged down the system. I told them to try again later.

Dick

Richard J. Bertin, $\mathrm{PhD}, \mathrm{RPh}$

Executive Director, Board of Pharmaceutical Specialties

1100 Fifteenth Street, NW Suite 400

Washington, DC 20005

202-223-7192 - FAX 202-429-6304

rbertin@aphanet.org

www.bpsweb.org

Please note new mailing address 
Appendix C 


\title{
Permission to Reprint Figure 1-1 from the Pharmaceutical Journal
}

\section{Mark Tankersley}

\author{
From: Pauline Heslop [pauline.heslop@pharmj.org.uk] \\ Sent: Monday, October 29, 2007 11:25 AM \\ To: Mark Tankersley \\ Subject: Re: permission to use \\ Dear Mark
}

Thank you for your request. The Editor is pleased to grant permission for you to use the article as stated in your dissertation, provided that the Journal and authors are acknowledged in full.

Regards

Pauline Heslop

Administrative Assistant

The Pharnascentical Jorran

1 Lambeth Hith Sirae.

Tol +44 (0) 2076722422

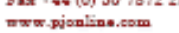

On 29/10/07 16:12, "Andrew Haynes" <andrew haynes@pharmj.org.uk> wrote:

-..-Original Message--....

From: Mark Tankersley [mailto:Mark.Tankersleyialaccredohealth.com]

Sent: Fri 10/19/2007 7:07 PM

To: Olivia Timbs; Andrew Haynes; Graeme Smith

Subject: permission to use

I would like to use information form an article publiahed in your

journal for my doctoral dissertation. It was published by Graham Calder and I do not know how to get in touch with him to obtain permission. Can you assist? The item I would like to use with permission is the chart in the article titled: "The VIE Model of Motivation".

http://www.pharmicom/Editorial/20000513/articlea/motivating.html

Mark Tankersley

Director

Medical Informatics and Outcomes Measurement

Accredo Therapeutica

Phone: 901.381 .7558 (Int 57558)

Cell: 901.383 .0803

mark.tankersley@accredotx.com 
Appendix D 


\section{University of Tennessee IRB Approval (Exemption)}

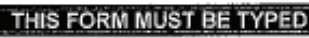

FORM 5

Date: $2 / 27 / 2007$

UTHSC IRB

REQUEST FOR EXEMPTION FORM

PROPOSAL TITLE: _ Why do qualified pharmacists choose to seek or not seek board œertification in pharmacy practice?

INVESTIGATOR:___Mark Tankersley, D.Ph., Graduate Student

DEPARTMENT \& SCHOOL: Health Sciences Administration__ TELEPHONE *_448-1060__ FAX * 448-4731

ADDRESS: 847 Monroe, COP

E-MAIL: mark.tarkersleyeacocredotx.oom

FUNDING SOURCE (SPONSOR): Șelf funded (Mark Tankersley)

STUDY SITE(S):__University of Tennessee College of Pharmacy/Health Sciences Administration - Home Office

(Answer all items, attach separate sheets as necessary)

1. PURPOSE OF THE STUDY:

The primary purpose of this study is to determine what values and instrumentalities motivate pharmacists to seek or not seek board certification in a pharmacy specialty. (Instrumentality is a perceived or known probability that a performance will lead to an outcome).

2. DESCRIPTION OF SUBJECT POPULATION AND METHOD(S) OF SUBJECT RECRUITMENT: (Include an explanation how recruitment of subjects is intended to satisfy NIH or FDA requirements for the inclusion of women, racial/athnic groups and children in human subjocts research).

The study will be conducted via the internet. The study group will include currently BPS board certified members from the five specialties and those that are not and have never been board certified. Former board certified pharmacists that have not renewed their certification will not be considered for the comparison but their information will be evaluated against the ones that have remained board certified.

Subjects will be recruited from cooperative efforts with the four major pharmacy organizations and the Board of Pharmaceutical Specialties. The four pharmacy organizations that will be asked to cooperate with recruiting efforts are the American Pharmacists Association (APhA), American Society of Health-System Pharmacists (ASHP), American Association of Colleges of Pharmacy (AACP) and the American College of Clinical Pharmacy (ACCP).

3. DESCRIPTION OF PROCEDURES: (Attach copies of aurveys, questionnaires, etc.)

The data for the survey will be collected and made available via an internet/web based survey tool. This research is designed as a prospective survey employing a cross-sectional exploratory descriptive design. Participants that agree to participate in the study will be asked to respond to a series of questions related to probability of occurrence of an event stated and the importance or value to them of that event/action. Additionally, the respondents will be asked a question regarding their anticipated success rate given that effort is put forth. The survey instrument is unique in design in that multiple levels of answers to the same statement are required. The investigator will obtain demographic information that is completed by the respondent. The demographic information will include age, gender and an additional 16 items summarized from the five separate board certification tests currently in use by the Board of Pharmaceutical Specialties for their Pharmacy Examination Demographic Survey, which accompanies the component of the Certification

Examination for Board Certification in any specialty area in pharmacy

Printed version of the survey form is attached. 

outlined in the instructions for Form 5.

The study qualifies under (b)(2) because it is an opinion survey and proposes no risk to patients.

EXEMPTION CATEGORY: Indicate the appropriate exemption category.

a. The study does not involve "research" as defined in the rogulations.

b. The study does not use "human subjects" as defined in the regulations.

(i) Al data or specimens are from deceased persons.

(ii) No data or specimens can be linked to identifiable individuals.

c. The study qualifies for exempt status under 45CFR46.101(b).

(Indicate category (b)(1) or (b)(2), etc.)

(b)(2)

6. INFORMED CONSENT: Informed consent is generally required for an exempt study unless it cannot practicably be carried cut without a walver of consent. Please check the appropriate box.

a. The study cannot practicably be carried out without a waiver of consent.

b. The study can be undertaken even If informed consent is required.

If ine (a) is checked, briafly explain below why the study cannot practicably be carried out without a waiver of consent. If the study involves the use of protected health information, also complete Form $B$ to request the use of protected health information without subjoct authorization.

If line (b) is checked, briefly descrbe below the plan to secure and document the informed consent of subjects. Attach the informed consent document to the application.

This information is in the header and instructions for the survey:

"This study has been approved by the University of Tennessee Institutional Review Board. There is no consequence for refusing to take the survey or any direct benefit to you other than professional value to Pharmacy in general. Your identity will not be disclosed and no relational information regarding your demographics information will be atternpted. The scope of this study is to characterize aggregate trends and not those of an individual. Summary data only will be made available to pharmacy organizations. The results of this survey may be presented at a professional meeting, become published or become part of a Ph.D. dissertation.

Consent for Participation:

This survey is voluntary. By proceeding with this survey I consent to participate."

Signature of Investigator _. Date: $13 / 8 / 07$

Typewrtten Name of Department or Program Chaimen She ILey White-Means

(The IRB reserves the right to request the Investigator to provide addisonal information concerning the proposel.)

Submission requires original and 2 copies.

SEE ATTACHED REVIENER COMMENTS 
Principal Investigator: Mark Tankersley

Brief Project Title:

Why do qualified pharmacists choose to seek or not seek board certification in pharmacy practice?

IRB ACTION:

Approved ________ Approved w/proviso(s)

Referred For Board Review

COMMENTS: This study qualifies for exempt status under 45CFR46.101(b)(2). In accord with

45CFR46.116(d), informed consent may be altered with the consent cover statement used in lieu of a consent interview. The requirement to secure a signed consent form is waived under 45CFR46.117(c)(2). 


\section{VITA}

Mark Tankersley was born in Jesup, Georgia in 1957. He grew up in the Atlantic coastal community of Brunswick, Georgia and the Golden Isles. Mark has practiced Pharmacy since graduating from the University of Georgia in 1980. He has worked directly with patients practicing in the realms of infectious disease, clinical nutrition, psychiatric Pharmacy, drug information and in general clinical practice in community, hospital, healthcare facility, nuclear Pharmacy and specialty Pharmacy settings. Mark also has held a variety of positions in local, regional and national managerial roles as well as that of a consultant providing support and assistance to healthcare organizations. He is an Authorized User of nuclear pharmaceuticals.

During his years in Pharmacy operations and clinical practice, Mark has participated in teaching clinical and administrative Pharmacy practice as and adjunct clinical instructor or faculty member for the University of Georgia, the University of South Carolina and The University of Tennessee Health Sciences Center.

While completing his graduate studies, Mark has kept current with the practice of Pharmacy by working continuously in patient care support roles and is currently Director of Medical Informatics and Outcomes at Accredo Health Group in Memphis, Tennessee. His interests in Pharmacy include infectious disease, clinical nutrition, applications of immune globulin for primary immune and neurological disorders, pulmonary arterial hypertension, biotechnology, health outcomes, medical informatics and clinical documentation systems. 